\title{
Estudo de Propriedades de Termoluminescência e Ressonância Paramagnética Eletrônica de Lapis Lazuli
}

\section{Betzabel Noemi Silva Carrera}

Orientador: Prof. Dr. Shigueo Watanabe

Dissertação de Mestrado apresentada ao Instituto de Física da Universidade de São Paulo.

Banca examinadora:

Prof. Dr. Shigueo Watanabe (IF-USP)

Profa. Dra. Ana Regina Blak (IF-USP)

Prof. Dr. Nilo F. Cano Mamani (UNIFESP - Santos)

São Paulo 
FICHA CATALOGRÁFICA

Preparada pelo Serviço de Biblioteca e Informação do Instituto de Física da Universidade de São Paulo

Silva Carrera, Betzabel Noemi

Estudo de propriedades de termoluminescência e ressonância paramagnética eletrônica de Lapis Lazuli. São Paulo, 2015

Dissertação (Mestrado) - Universidade de São Paulo. Instituto de Física. Depto de Física Nuclear.

Orientador: Prof. Dr. Shigueo Watanabe

Área de Concentração: Física.

Unitermos: 1. Termolunescência; 2. Ressonância paramagnética eletrônica; 3. Difração de raios X; 4. Silicatos Lapis Lazuli. 
A Deus

A meus pais María e Victor 


\section{Agradecimentos}

- Gostaria de agradecer, primeiramente, a meus pais Maria Carrera e Victor Silva pelo apoio e amor que sempre me dão.

- Ao Prof. Dr. Shigueo Watanabe, por ter me dado a oportunidade de fazer parte do laboratório LACIFID, pela orientação, e pelo apoio dado.

- Aos engenheiros do CTR-IPEN-SP, Elizabeth Sonessari Ribeiro e Carlos Gaia da Silveira pela colaboração nas irradiações das amostras.

- Ao Professor T.K. Gundu Rao por sua ajuda nas medidas de EPR.

- Ao professor Chubaci, pela colaboração nas medidas refletância.

- A Nilo, Rene e José Francisco pelas discussões e conselhos importantes para este trabalho.

- A Edna quem sempre me ajuda, em tudo o que preciso, pelos bons conselhos e palavras que só uma boa amiga pode dar.

- A minhas amigas do alojamento pela boa companhia nos primeiros meses no Brasil, por ter me feito sentir menos saudades do Perú. Fabíola, Yara, Danielli, Jéssica Silveira, Lara, Jéssica. 
Betzabel N. Silva C.

- A Diana, Denis, Fernando e Gustavo pela boa companhia, amizade e confiança que sempre me dedicaram, e de maneira especial a Tania por sua amizade incondicional.

- A meus grandes amigos Moisés, Katherine, Patty, Jean, Pocho, Susana Guerra por que sempre encontrarão a forma de estar presentes em meu dia a dia apesar da distancia.

- Aos companheiros de sala Lucas Carmo, Felipe, Lucas Bispo, Letícia, Karina pela boa convivência, e grande hospitalidade que sempre me dedicaram. 


\section{Resumo}

Lapis Lazuli é um mineral de silicato, que foi objeto do presente estudo. Trata-se de uma solução sólida complexa de outros quatro minerais de silicato, tais como: sodalita, noselita, huainita, e lazurita. Essa composição da solução sólida não permite estimar a porcentagem de cada mineral componente, na analise de fluorescência de raios X, onde se obteve que os principiais óxidos componentes do lapis lazuli são, (em \% mol) $\mathrm{SiO}_{2}(33,2), \mathrm{CaO}(16,3)$, $\mathrm{MgO}(12,1)$ e $\mathrm{Al}_{2} \mathrm{O}_{3}(10,1)$ e, em menor concentração , $\mathrm{Na}_{2} \mathrm{O}(6,10), \mathrm{SO}_{3}$ $(5,90), \mathrm{Fe}_{2} \mathrm{O}_{3}(2,05), \mathrm{K}_{2} \mathrm{O}(1,90)$ e outros óxidos em concentrações menores. Para a caracterização da amostra de lapis lazuli, foram utilizados termoluminescência (TL), ressonância paramagnética eletrônica (EPR) e técnicas de espectroscopia de refletância. Em TL, é claro, as curvas de emissão da amostra natural, irradiada ou com tratamento térmico têm sido utilizadas. Uma curva de emissão da amostra natural apresentou picos em $296^{\circ} \mathrm{C}$ e a $372^{\circ} \mathrm{C}$, mas as amostras irradiadas mostraram picos em $140^{\circ} \mathrm{C}, 250^{\circ} \mathrm{C}$ e $350^{\circ} \mathrm{C}$. Logo mostrou-se que o pico em $140^{\circ} \mathrm{C}$, é na verdade, uma sobreposição dos picos em $116^{\circ} \mathrm{C}$ e $160^{\circ} \mathrm{C}$. O segundo pico cresce linearmente com a dose até cerca de 7000-8000 Gy.

O lápis-lazúli apresenta um decaimento anômalo. O primeiro pico decaiu a partir de 3400(u.a) para 1700(u.a), em 45 horas, o segundo pico decaiu a partir de 8500(u.a) para 3000 (u.a), nas mesmas 45 horas. 
Betzabel N. Silva C.

Para a Avaliação da parâmetros $E$ e $s$, o método de forma de pico e TmTstop. O terceiro método com base em diversas taxas de aquecimento para a leitura TL, com a utilização direta do método resultou em valores de $E$ e $s$ irrealistas. Não se encontrou a explicação por que, mas ao fazer deconvolução das curvas de emissão para cada taxa de aquecimento encontramos resultados mais realistas. A deconvolução mostrou quatro picos em $110^{\circ} \mathrm{C}, 146^{\circ} \mathrm{C}, 191^{\circ} \mathrm{C}$ $245^{\circ} \mathrm{C}$, com valores $E$, respectivamente iguais a $1,229 \mathrm{eV} ; 1,23 \mathrm{eV} ; 1,24 \mathrm{eV}$ e $1,25 \mathrm{eV}$.

O espectro de EPR da amostra experimental apresentou seis sinais de $M n^{2+}$ e um sinal grande de $\mathrm{Fe}^{3+} \operatorname{com} \mathrm{g}=2,0$.

A irradiação da ordem de dezenas de kGy produzido um sinal em torno de $\mathrm{g}=2,003$ devido ao centro $\mathrm{F}$ induzido pela radiação.

O espectro de refletância mostra um vale em torno de 600 a $800 \mathrm{~nm}$, que corresponde a uma banda de absorção do mesmo comprimento de onda e é responsável pela coloração azul. 


\section{Abstract}

Lapis Lazuli is a natural silicate mineral investigated in the present work. It is a complex solid solution of four other silicate minerals, sodalite, Nosean, Hanyne and Lazurite. This compositon of solid solution does not allow the estimate of the percentage of each mineral component from the result of $\mathrm{X}$ ray fluorescence analysis, which has revealed as main oxide components of lapis lazuli as (in mol \% ) $\mathrm{SiO}_{2}(33,2), \mathrm{CaO}$ (16.3), $\mathrm{MgO}$ (12.1) and $\mathrm{Al}_{2} \mathrm{O}_{3}$ and in smaller concentrations $\mathrm{Na}_{2} \mathrm{O}(6,10), \mathrm{Na}_{2} \mathrm{O}(6,10), \mathrm{SO}_{3}(5,90), \mathrm{Fe}_{2} \mathrm{O}_{3}$ $(2,05), K_{2} O(1,90)$ plus others in even smaller concentration.

For the characterization of the lapis lazuli sample, we used thermoluminescence (TL), electronic paramagnetic resonance (EPR) and reflectance spectroscopy techniques. In TL, of course, glow curves of natural or irradiated or annealed samples have been used.

A typical glow curve presented peaks at $296^{\circ} \mathrm{C}$ and at $372^{\circ} \mathrm{C}$, but irradiated sample has shown peaks at $140^{\circ} \mathrm{C}, 250^{\circ} \mathrm{C}$ and $350^{\circ} \mathrm{C}$.

Later it was shown that $140{ }^{\circ} \mathrm{C}$ peak is actually a superposition of $116^{\circ} \mathrm{C}$ and $160^{\circ} \mathrm{C}$ peaks. The second peak is the prominent one and its height grows linearly with the dose up to about 7000 to 8000 Gy.

Lapis lazuli presents an anomalous fading. The first peak decays from 3400 (a.u.) to 1700 (a.u.) in 45 hours, the second peak decays from 8500 (a.u.) to 3000 (a.u.) in the same 45 hours. 
Betzabel N. Silva C.

For the evalution of parameters $E$ and $s$, peak shape method and Tm-Tstop methods have been used. The third method based on various heating rates for TL reading, with the direct use of method yielded unrealistic $E$ and $s$ values. We did not find explanation why, but doing the deconvolution of glow curves for each heating rate we found more realistic results. The deconvolution has shown four peaks at $110^{\circ} \mathrm{C}, 146^{\circ} \mathrm{C}, 191^{\circ} \mathrm{C}$ ands $245^{\circ} \mathrm{C}$ with E-values, respectively equal to $1.229 \mathrm{eV}, 1,23 \mathrm{eV}, 1.24 \mathrm{eV}$ and $1,25 \mathrm{eV}$.

The EPR spectrum of natural sample consisted of six signals of $\mathrm{Mn}^{2+}$ and strong $\mathrm{Fe}^{3+}$ signal at $\mathrm{g}=2,0$.

The irradiation of the order of tens of kGy produced a signal around $\mathrm{g}=2,003$ due to radiation induced $\mathrm{F}$-center.

The reflectance spectrum shows a deep around 600-800nm which corresponds to an absorption band of the same wavelength and is responsible for blue colour. 


\section{Conteúdo}

$\begin{array}{ll}\text { Agradecimentos } & \text { I }\end{array}$

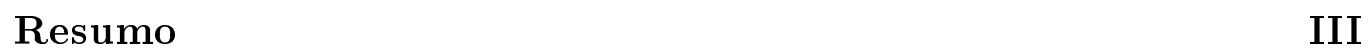

$\begin{array}{ll}\text { Abstract IV } & \text { IV }\end{array}$

Sumario

Îndice de Figuras $\quad$ X

Îndice de Tabelas $\quad$ XIV

1 Introdução 1

1.1 Considerações gerais sobre cristais de silicatos . . . . . . . . 3

1.1.1 Cristais iônicos .................. 3

1.1.2 Cristais de silicato . . . . . . . . . . 3

1.1.3 Ligação iônica e ligação de covalência . . . . . . . . . 6

1.1.4 Silício com coordenação $4 \ldots \ldots$. . . . . 7

1.2 Trabalhos de outros autores já publicados . . . . . . . 8

2 Revisão Teórica $\quad 9$

2.1 Cristais Ideais, Distribuição periódica dos átomos e teoria de bandas de energia . . . . . . . . . . . . . 9 
Betzabel N. Silva C.

2.1.1 Cristais Ideais e Distribuição periódica dos átomos . 9

2.2 Teoria de bandas de energia . . . . . . . . . . . 10

2.3 Cristais iônicos naturais e defeitos pontuais . . . . . . . 15

2.3.1 Cristais reais e defeitos . . . . . . . . 15

2.3.2 Criação de níveis de energia pelos defeitos pontuais na banda proibida .................. 18

2.3.3 Transições eletrônicas . . . . . . . . . . . . . . . 19

2.4 Fenômeno de termoluminescência . . . . . . . . . . . . 21

2.4.1 Termoluminescência (TL) . . . . . . . . . . 21

2.4.2 Equação que descreve a curva de emissão . . . . . . . . 22

2.5 Equações que descrevem as possíveis transições de cargas que ocorrem no processo da emissão da luz TL . . . . . . . . . . 24

2.6 Método para estimar os parâmetros de TL . . . . . . . 25

2.6.1 Método de forma do pico . . . . . . . . . 27

2.6.2 Taxas de aquecimento . . . . . . . . . . . 29

2.6.3 Método de subida inicial . . . . . . . . . . 30

2.6.4 Método $T_{m}-T_{\text {stop }} \ldots \ldots \ldots \ldots . \ldots . \ldots 31$

2.6.5 Decaimento anômalo (Anomalus Fading) . . . . . . . 32

2.7 Ressonância paramagnética eletrônica (EPR ou ESR de elétron spin resonance) . . . . . . . . . . . 33

2.7.1 Elétrons equivalentes a minúsculos imãs magnéticos . . 34

2.7.2 Eléctrons nos sólidos . . . . . . . . . . . 34

2.8 Absorção ótica e refletância . . . . . . . . . . . 38

2.8.1 Absorção Ótica . . . . . . . . . . . . . 40

2.8.2 Reflexão . . . . . . . . . . . . . . . 40

3 Materiais e métodos experimentais 41

3.1 Amostra natural . . . . . . . . . . . . . . . . 41 
Betzabel N. Silva C.

3.2 Irradiação e tratamento térmico . . . . . . . . . . . . . . 42

3.3 Equipamentos de medida . . . . . . . . . . . . . 43

3.3.1 Fluorescência de raios X . . . . . . . . . 43

3.3.2 Termoluminescência . . . . . . . . . . . 43

$3.3 .3 \quad \mathrm{EPR} \ldots \ldots \ldots \ldots \ldots \ldots . \ldots \ldots$

3.3.4 Refletância . . . . . . . . . . . 47

4 Resultados Experimentais $\quad 49$

4.1 Fluorescência de raios X . . . . . . . . . . . . . . 49

4.2 Medidas de termoluminescência . . . . . . . . . . . . . 49

4.2.1 Curva de TL da amostra natural ........ 50

4.2.2 Dependência de TL com a dose . . . . . . . . 50

4.2.3 Tratamento térmico $(\mathrm{TT}) \ldots \ldots \ldots 53$

4.2.4 Decaimento Anômalo da TL . . . . . . . . . . . 53

4.3 Análise das curvas de termoluminescência e determinação dos parâmetros $E$ e $s \ldots \ldots \ldots \ldots \ldots \ldots$

4.3.1 Determinação de $E$ e $s \ldots \ldots \ldots . \ldots . \ldots 57$

4.4 Medidas experimentais de Ressonância Paramagnética . . . . 64

4.4.1 Amostra natural ................ 65

4.5 Medidas de refletância . . . . . . . . . . 68

4.5.1 Refletância da amostra natural ......... . 68

5 Conclusões $\quad 70$ 


\section{Lista de Figuras}

1.1 Grupos tetraédricos na estrutura da sodalita, segundo Bragg and

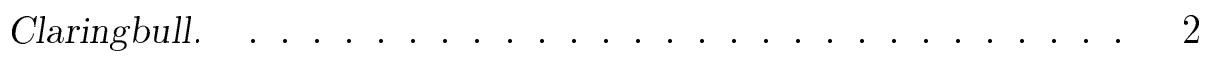

1.2 Tetraedro $\mathrm{SiO}_{4}$ (a), Octaedro $\mathrm{SiO}_{6}($ (b). . . . . . . . . . 5

1.3 Energia de ionização de Si e O. . . . . . . . . . . . . 6

1.4 Os orbitais $3 s$ de Si e $2 p$ de $O$ em superposição no hídrido $s p^{3}$ do tetraedro $\mathrm{SiO}_{4} \ldots \ldots \ldots \ldots \ldots \ldots \ldots$

2.1 Diagrama de kronig - Penney. . . . . . . . . . . . . . . . 11

2.2 Densidade de probabilidade. . . . . . . . . . . . . . 12

2.3 Curva de $E_{k}$ para o modelos de elétron livre e de elétrons no sólido. 13

2.4 Niveis $E_{k}$ para o modelos de elétrons livres . . . . . . . . . . 14

2.5 Banda de valência $(B V)$, banda proibida $(B P)$ e banda de condução (BC). Promoção do elétron de $B V$ à $B C$ e buraco na $B V$. . . . . 15

2.6 Cristal perfeito bidimensional . . . . . . . . . . . . 16

2.7 (a)Defeito de Frenkel, cations e anions intersticiais com suas vacâncias (b) Defeito de Schottky vacância de cation e anion. . . . . 17

2.8 Cation divalente. . . . . . . . . . . . . . . . . . . 18

2.9 Armadilhas de elétrons e de buracos separados pela chamada energia de Fermi. . . . . . . . . . . . . . . . . 19 
Betzabel N. Silva C.

2.10 Representação de transições elétricas comuns nos isolantes e semicondutores cristalinos . . . . . . . . . . . 20

2.11 Mecanismo de emissão TL no esquema de bandas de energia. 22

2.12 Modelo de Adirovitch. . . . . . . . . . . . . . 25

2.13 Pico de emisão TL, onde se pode observar a largura $\omega$ à meia altura. 26

2.14 Método $T_{m}-T_{\text {stop }}$. O cristal é aquecido à temperatura $T_{\text {stop }}$ na curva $A$, sendo esfriado. Para logo ser aquecido de novo até o final, registrando a curva de emissão restante - curva B. $T_{m}$ é registrado. 32

2.15 A representação da energia de um spin eletrônico desemparelhado na presença de um campo magnético (efeito Zeeman). (a) Os spins dos eletrons não pareados se orientam randomicamente, (b) no campo magnético externo os spins se orientam ao campo magnético (separação Zeeman) (c) mudança de orientação dos spins paralelamente orientados ao absorver uma energia de frequência $v_{r}$ de uma microonda aplicada. . . . . . . . . . . . 35

2.16 Banda do espectrômetro, comprimento de onda, frequência e campo

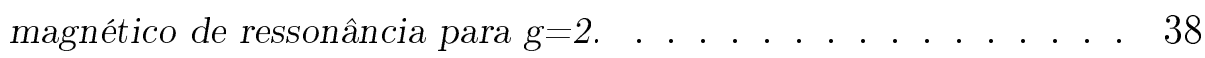

2.17 Sinal típico de EPR. . . . . . . . . . . . . . 39

3.1 Foto de Lapis Lazuli Natural a ser estudada . . . . . . . . . . . . 41

3.2 Harsaw, equipamento para fazer medidas de TL. . . . . . . . . . 44

3.3 Equipamento para fazer medidas de EPR. . . . . . . . . . . 45

3.4 Esquema do espectrômetro Bruker EMX. . . . . . . . . . . . 46

3.5 Esquema da esfera integradora do espectrômetro Variam Cary 500 para as medidas de refletância. . . . . . . . . . 47 
Betzabel N. Silva C.

4.1 Análise químico de Lapis Lazuli por fluorescência de raios X. Nos histogramas são apresentadas concentrações de óxidos da amostra natural em \% mol. Os compostos principais são: $\mathrm{SiO}_{2}$ (33.2), $\mathrm{CaO}$ (16.3), $\mathrm{MgO}$ (12.1), $\mathrm{Al}_{2} \mathrm{O}_{3}$ (10.1). Além dos componentes principais, há em quantidades consideráveis $\mathrm{Na}_{2} \mathrm{O}$ (6.10), $\mathrm{SO}_{3}$ (5.90), $\mathrm{Fe}_{2} \mathrm{O}_{3}$ (2.05), $\mathrm{K}_{2} \mathrm{O}$, (1.90) . . . . . . . . . . 50

4.2 Curva de emissão TL do Lapis Lazuli natural obtida com uma taxa de aquecimento $\left(\beta=4^{\circ} \mathrm{C} / \mathrm{s}\right)$. A curva apresentada é a média de 8 leituras. . . . . . . . . . . . . . . . 5 51

4.3 Curvas de emissão do Lapis Lazuli natural submetido a tratamento térmico de $600^{\circ} \mathrm{C}$ por meia hora e posteriormente irradiada com doses de 10 Gy até 20 kGy. . . . . . . . . . . . . . 51

4.4 Intensidade dos picos da figura 4.3 em função da dose de radiação. 52

4.5 Comportamento do segundo pico em função da dose. . . . . . . . 53

4.6 Curvas de emissão TL do lapis lazuli natural submetidas ao tratamento térmicos de $900^{\circ} \mathrm{C}, 1000^{\circ} \mathrm{C}, 1100^{\circ} \mathrm{C}$, e posteriormente irra-

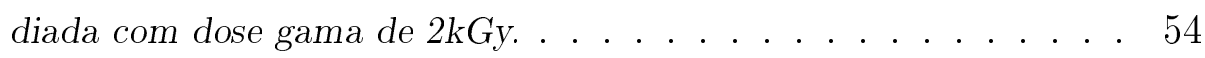

4.7 TL do lapiz lazuli iradiada con $2 \mathrm{k} G$ y em tempos diferentes, segundo o indicado no grafico. . . . . . . . . . . . . 55

4.8 Curva da intesidade de TL en função do tempo para o primeiro pico na temperatura ambiente. . . . . . . . . 56 56

4.9 Curva da intesidade de TL en função do tempo para o segundo pico. 56

4.10 Método de várias taxas de aquecimento. Neste método se utiliza a

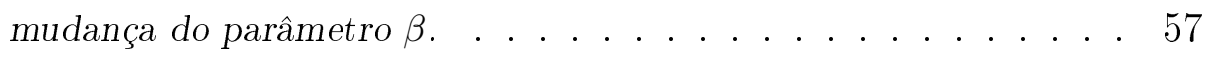

4.11 Logaritmo do primeiro membro da equação contra $\frac{1}{T_{m}}$ para o primeiro e segundo pico da figura 4.10. Cinética de $2^{\circ}$ ordem. . . . 58 
Betzabel N. Silva C.

4.12 Curva TL que foi utilizada para encontrar os valores da energia do primeiro e segundo pico pelo método da forma do pico, medida feita com taxa de aquecimento de $4^{\circ} \mathrm{C} / \mathrm{s}$. . . . . . . . . 59

4.13 Curvas TL submetida ao método $T_{m}-T_{\text {stop }}$, com saltos de tempera-

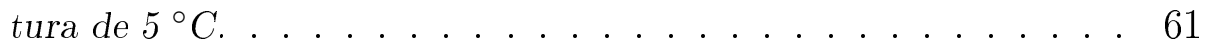

4.14 Curvas TL submetida ao método $T_{m}$ vs. $T_{\text {stop }}$, com saltos de tem-

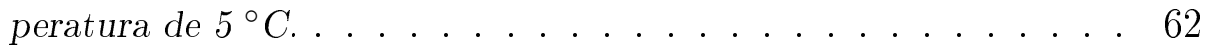

4.15 Deconvolução da curva de emissão de taxa $2^{\circ} \mathrm{C} / \mathrm{s}$. . . . . . . . 63

4.16 Deconvolução da curva de emissão de taxa $10^{\circ} \mathrm{C} / \mathrm{s}$. . . . . . . . . 64

4.17 Espectro EPR de lapis lazuli natural. Medida feita em temperatura ambiente com uma frequência de microonda de 9,761 GHz,banda X e uma potência de 1,011 $\mathrm{mW}$, para $250 \mathrm{mg}$ de amostra. . . . . 65

4.18 Espectro de EPR de lapis lazuli irradiada com radiação gama de $5 k G y, 10 k G y, 30 k G y \ldots \ldots \ldots 6 . \ldots \ldots$

4.19 Espectro de EPR de lapis lazuli irradiada com radiação gama de $5 k G y, 10 k G y, 30 k G y \ldots \ldots \ldots \ldots$. . . . . . . . . 67

4.20 Espectro de EPR de lapis lazuli com desfasagfem de 94 . . . . 67

4.21 Espetro de refletância de lapis lazuli natural. . . . . . . . . . . 68

4.22 Espectro de absorvância de lapis lazuli natural. . . . . . . . . . 69 


\section{Lista de Tabelas}

1.1 Abundancia de minerais de silicato na crosta terrestre. . . . . . . 4

1.2 Dimensões médias das ligações $\mathrm{Si}-\mathrm{O}$ e $\mathrm{O}-\mathrm{O} \ldots \ldots . . . . . .5$

2.1 Valores das constantes $c_{\gamma}$ e $b_{\gamma} \ldots \ldots \ldots$. . . . . . . . 29

2.2 Banda do espectrômetro, comprimento de onda, frequência e campo

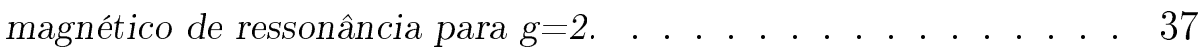

4.1 Energia $E$ do primeiro e segundo pico no método de varias taxas

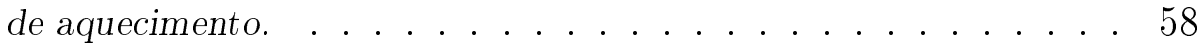

4.2 Valores obtidos para $\tau, \delta, \omega$. Pela relação das equações 2.6.1, obtemos os valores do fator geométrico $\mu_{g} \ldots \ldots . . . . . .660$

4.3 Valores de energia e fator de frequência pelo Método da forma do

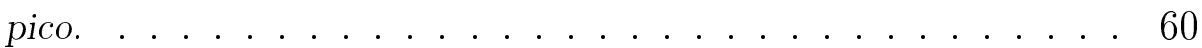

4.4 Posição dos picos 1,2,3 e 4 para taxa de aquecimento $\beta$ de $2{ }^{\circ} \mathrm{C} / \mathrm{s}$ e $10{ }^{\circ} \mathrm{C} / \mathrm{s} . \ldots \ldots \ldots \ldots \ldots \ldots \ldots$

4.5 Energia $\mathrm{eV}$ ) dos picos $1,2,3$ e $4 \beta=2{ }^{\circ} \mathrm{C} / \mathrm{s}$ e $\beta=10^{\circ} \mathrm{C} / \mathrm{s}$. . . . . 64 


\section{Introdução}

Há, na natureza, particularmente no Brasil, minerais naturais de silicatos, alguns deles muito conhecidos pelo seu valor gemológico, por isso têm sido estudados, principalmente, do ponto de vista de sua coloração. Há outros que, por não serem de interesse gemológico ou de aplicações práticas como na indústria, têm recebido pouca atenção quanto a suas propriedades físicas. Lapis Lazuli é uma das pedras preciosas mais antigas, que foi usada desde a antiguidade para fazer joias, amuletos, selos e pinturas que foram objeto de estudos em muitos trabalhos onde se estudaram a procedência do lapis lazuli utilizado nelas. Embora não compita com diamante, esmeralda, água marinha, topázio e outras pedras conhecidas, ainda assim tem valor gemológico pela sua coloração azul marinho cuja origem tem sido estudada. Porém, outras propriedades físicas não têm sido estudadas, motivo pelo qual o objetivo deste trabalho é investigar as propriedades físicas associadas aos defeitos pontuais com as técnicas de termoluminescência, ressonância paramagnética eletrônica, refletância e sua composição química através da análise por fluorescência de raios $\mathrm{X}$.

Lapis lazuli é um mineral de composição complexa, pois é uma solução só- 


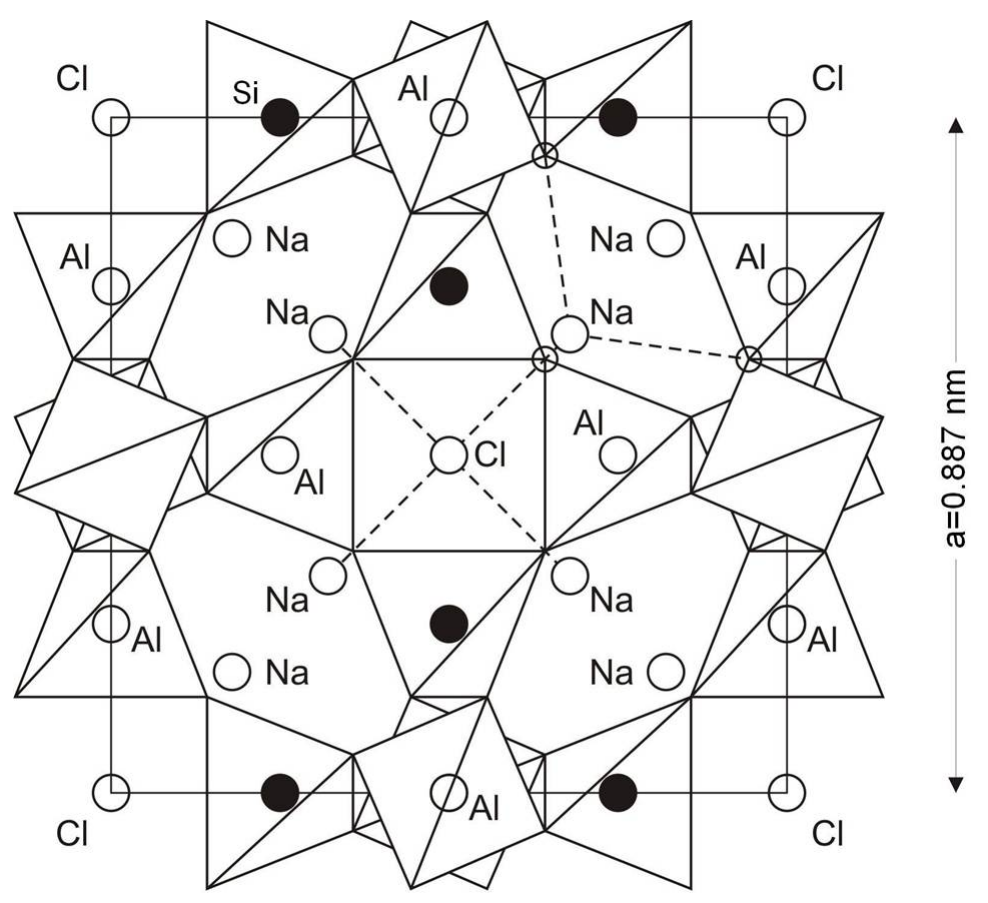

Figura 1.1: Grupos tetraédricos na estrutura da sodalita, segundo Bragg and Claringbull.

lida de quatro minerais: (1)Hauinita: $(\mathrm{Na}, \mathrm{Ca})_{4-8}\left(\mathrm{~S}_{3} \mathrm{SO}_{2}\right)_{1-2}\left(\mathrm{Al}_{2} \mathrm{Si}_{6} \mathrm{O}_{24}\right)$, a quem se deve a coloração azul, (2) Sodalita: $\mathrm{Na}_{8} \mathrm{Cl}_{12}\left(\left(\mathrm{Al}_{6} \mathrm{Si}_{6} \mathrm{O}_{24}\right)\right.$, (3) Noselita: $\mathrm{Na}_{8}\left(\mathrm{SO}_{2}\right)\left(\mathrm{Al}_{6} \mathrm{Si}_{6} \mathrm{O}_{24}\right)$ e (4) Lazurita, que é uma composição isomórfica de hauinita e sodalita, Esses quatros minerais pertencem ao grupo sodalita e se cristalizam no sistema cúbico. O índice de refração desses quatro minerais tem valor que gira em torno de 1,50. a variação, é claro, vem da composição da solução sólida. O mesmo vale para o peso específico, que varia de 2,7 a $2,9 \mathrm{~g} / \mathrm{cm}^{3}$.

A estrutura básica é formada por tetraedros de $\mathrm{SiO}_{4}$ e $\mathrm{AlO}_{4}$ alternados, ligados por vértices, formando dois anéis, um de doze tetraedros e outro de 
quatro, ambos no mesmo plano [1], como se vê na 1.1. Existem umas poucas fontes de Lapis Lazuli no mundo. As ocorrências são em Sar- e- Sang, no Afeganistão, conhecida há milênios, e era a principal fonte de lápis-lazúli na Europa e na Ásia por um longo tempo. Outras minas antigas estão no Tajiquistão (Lyadzhuar Dara, Pamir), no Paquistão (Chagai Hills), na Sibéria (Irkutsk, perto do lago Baikal)[2].

\subsection{Considerações gerais sobre cristais de sili- catos}

\subsubsection{Cristais iônicos}

Dos cristais sólidos, os cristais iônicos ocupam uma posição importante pela abundância e sua utilidade na prática. Basicamente, um cristal iônico é formado de íons positivos e negativos que, através da força coulombiana principalmente, garantem a formação do cristal. Em cristais simples, como haletos de alcalinos ou alcalinos terrosos, os íons positivos e negativos podem ser simples, mas em muitos cristais, principalmente os íons negativos, podem ser moléculas mais complexas. Em qualquer caso, nos chamados cristais iônicos ideais ou perfeitos, os dois grupos de íons se distribuem regularmente no espaço. Mas, como será visto no capitulo 2, nos cristais reais formam-se defeitos na rede cristalina com um papel muito importante.

\subsubsection{Cristais de silicato}

O silício é um dos elementos mais abundantes e espalhados na Terra, especificamente na crosta terrestre, na forma de cristais ou minerais de silicato. Para se ter ideia da abundância desses minerais inserimos a tabela 1.1 devido 
a Wedepohl [3]

A começar pelo quartzo, esses minerais de silicato têm uma aplicação indus-

\begin{tabular}{cc}
\hline \hline Mineral & Vol \% \\
\hline Plagioclase & 41 \\
Feldspato potássico & 22 \\
Anbíbola & 5 \\
Piroxênio & 4 \\
Magnetita, Imenita & 4 \\
Olivina & 1,5 \\
Apatatita & 0,5 \\
\hline
\end{tabular}

Tabela 1.1: Abundancia de minerais de silicato na crosta terrestre.

trial muito importante, por exemplo, na de cerâmicas, de vidros, de cimentos, etc., além de alguns deles serem gemologicamente importantes.

Uma grande variedade de minerais de silicatos é produzida pela mãe natureza, mas, no laboratório são, também, produzidos muitos deles, principalmente, para as pesquisas científicas. Os naturais, durante sua produção, incorporam vários elementos estranhos, as chamadas impurezas, e que são importantes porque muitas das propriedades dos minerais são dependentes delas. Nos materiais sintéticos, as impurezas são colocadas a critério do pesquisador para estudar seus efeitos.

A estrutura cristalina de um cristal de silicato tem como base o tetraedro $\left(\mathrm{SiO}_{4}\right)$ ou compostos deste. Raramente, acontece ter octaedro $\left(\mathrm{SiO}_{6}\right)$ como base, como se apresenta na figura 1.2.

A ligação Si-O é, portanto, de importância básica e tem sido motivo de muitos estudos. O cristal de silicato é, então, formado de tetraedro $\left(\mathrm{SiO}_{4}\right)$ e um, dois, três, ou mais cations. Os cations podem ser de valência um ,dois, 


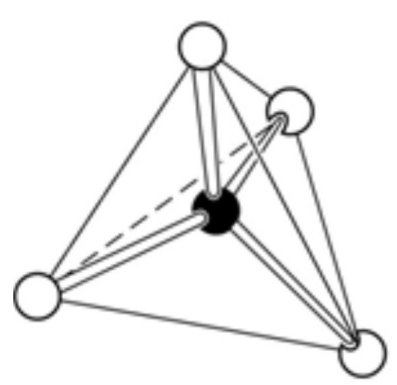

(a)

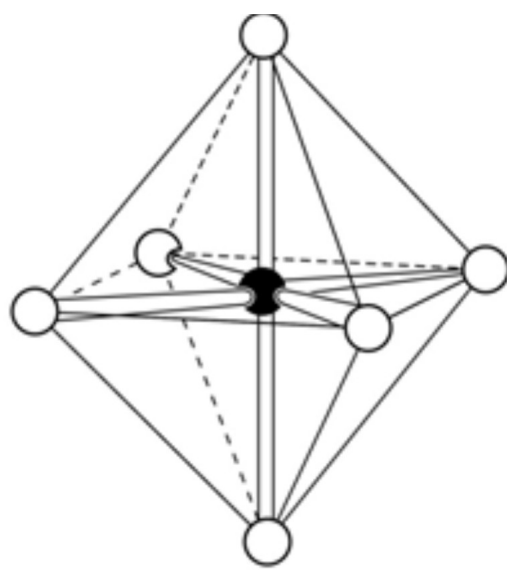

(b)

Figura 1.2: Tetraedro $\mathrm{SiO}_{4}$ (a), Octaedro $\mathrm{SiO}_{6}$ (b).

\begin{tabular}{ccc}
\hline \hline Tetraedro & & Octaedro \\
\hline $16,2 \mu$ & $\langle d(S i-O)\rangle$ & $17,7 \mu$ \\
$26,4 \mu$ & $\langle d(O-O)\rangle$ & $25,0 \mu$ \\
\hline
\end{tabular}

Tabela 1.2: Dimensões médias das ligações Si-O e O-O

três, etc., por isso indicamos esses com $M^{\prime}, M^{\prime \prime}, M^{\prime \prime \prime}$, etc. A fórmula química do cristal pode ser escrita como $M_{r^{\prime}}^{\prime} M_{r^{\prime \prime}}^{\prime \prime} \ldots S i_{s} O_{t}$, onde $r^{\prime}, r^{\prime \prime}, \ldots$ indicam as valências dos cations e a carga do anion $\mathrm{s}+\mathrm{t}$ deve compensar a carga dos cations.

Muitas vezes, é importante explicitar a quantidade de óxidos desses cations que compõem a fórmula química, assim escrevemos: $q^{\prime} M_{r^{\prime}}^{\prime} O \cdot q^{\prime \prime} M_{r^{\prime \prime}}^{\prime \prime} \mathrm{O} \ldots . . . s \mathrm{SiO}_{2}$. Em geral, os íons metálicos são maiores e tem valência menor do que o silício, de modo que as ligações M-O são mais fracas do que as ligações Si-O. Isso significa que o silício atrai os íons de oxigênio mais fortemente do que os íons de metais, formando o tetraedro $\left(\mathrm{SiO}_{4}\right)$ com uma distancia média de ligação 1.62. $\left\langle\left(d\left(S i^{(4)}-O\right)\right\rangle=1,62\right.$ angstrons ou $16,2 \mu \mathrm{m}$, conforme tabela 1.2. 


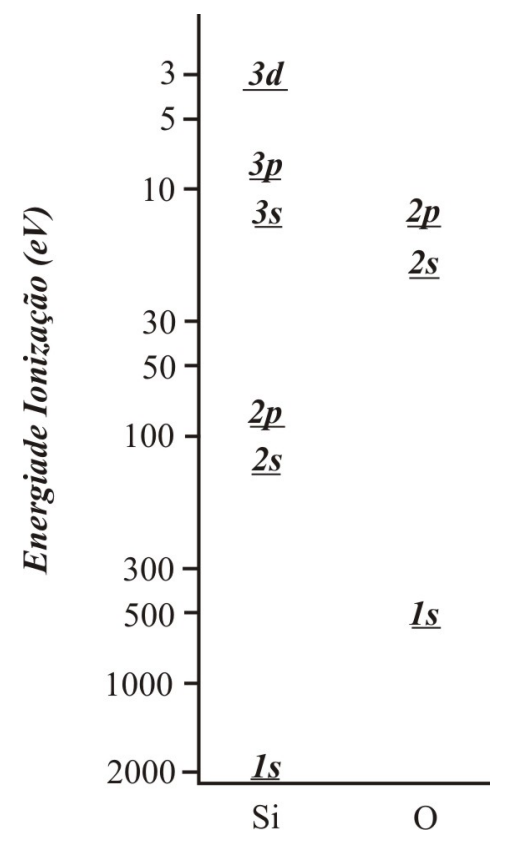

Figura 1.3: Energia de ionização de Si e O.

\subsubsection{Ligação iônica e ligação de covalência}

A ligação entre o silício e o oxigênio é, em geral, considerada ser em parte iônico e em parte covalente.

Se a ligação fosse puramente iônica, uma fórmula química $M_{r}^{q} S i_{s} O_{t}$ seria adequada. Como silício tem valência $(+4)$ e oxigênio $(-2)$, a valência $q$ positiva deve ser $q=2(t-2 s) / r$.

Vejamos agora a ligação covalente na ligação Si-O. A figura 1.3 dá as energias de ionização do átomo de Si e de $\mathrm{O}$.

A configuração eletrônica de um átomo de silício é dada por:

$$
1 s^{2} 2 s^{2} 2 p^{6} 3 s^{2} 3 p_{x}^{1} 3 p_{y}^{1} 3 p_{z}^{0} 3 d_{y z}^{0} 3 d_{x^{2}-y^{2}}^{0} 3 d_{z^{2}}^{0}
$$

Para levantar um elétron $3 s$ para o nível $3 p_{z}^{1}$ pela figura 1.3 é de apenas de 6 eV. Nesse estado, o Si está pronto para a ligação, como a diferença em energia 


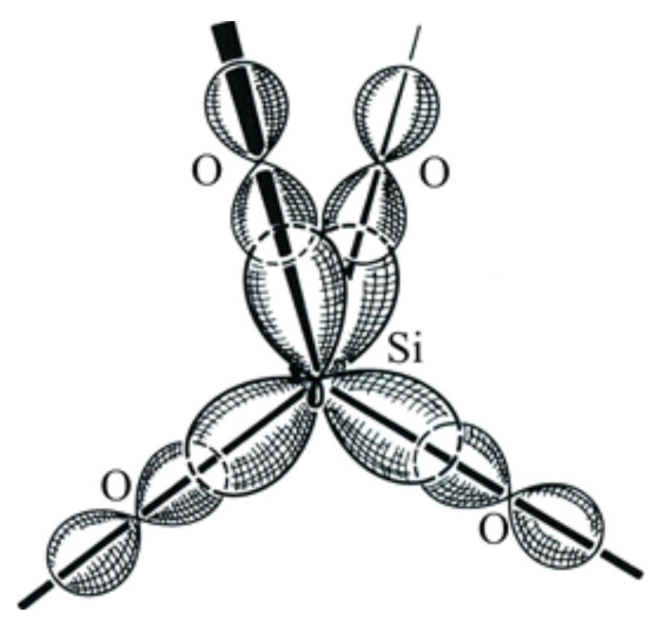

Figura 1.4: Os orbitais 3s de Si e $2 p$ de $O$ em superposição no hídrido $s p^{3}$ do tetraedro $\mathrm{SiO}_{4}$.

entre os níveis $3 s$ e $3 d$ no $S i$ é aproximadamente 11 eV que é da ordem da diferença em energia entre $S i 3 d$ e $O 3 p$. Todas as 9 orbitais da camada de valência de Si podem participar da ligação.

A participação dos vários orbitais Si3d nas ligações depende do tipo de ligantes (no caso oxigênio) e de sua electronegatividade.

\subsubsection{Silício com coordenação 4}

Aqui vamos considerar o silício no tetraedro $\left(\mathrm{SiO}_{4}\right)$ como no $\left(\mathrm{Fe}_{2} \mathrm{SiO}_{4}\right)$. Os orbitais $3 s$ e os três $3 p$ do silício formam um híbrido $s p^{3}$ com 4 orbitais híbridos equivalentes, cada orbital apontando para um dos oxigênios em um dos vértices do tetraedro. Cada lóbulo de um hibrido Sisp3 pode se superpor, frontalmente, com o orbital $O 2 p$ do oxigênio, formando a chamada ligação $\vartheta$, uma ligação em que o máximo da densidade de elétrons em superposição se acha ao longo da linha Si-O, figura 1.4.

A ligação covalente é importante na formação do tetraedro como um todo, que é um anion na estrutura de um cristal de silicato, os tetraedros podem se 
ligar um ao outro por um vértice, ou por uma aresta, ou por uma face, e constituírem cadeias, dando origem a variadas estruturas. Isto é de importância no estudo de propriedades dependentes da estrutura cristalina.

\subsection{Trabalhos de outros autores já publicados}

Jinyu, W, Liangbo F, [4], fizeram medidas de EPR para descobrir o mecanismo de coloração em amostras de mineral de lapis lazuli do Afeganistão, de pigmento de lapis e de uma amostra artificial.

Lo Gludice et al. [5] usaram catodoluminescência e ionoluminescência para descobrir (caracterizar) a origem da amostra de lapis lazuli, este mineral é encontrado em poucos lugares, examinaram lapis lazuli de Afeganistão, Tajikiotão, USA, Siberia e Chile, mas na amostra Siberiana, foi difícil distinguir a origem dos minerais.

Mauro Bacci [6], et al estudou o lapis lazuli de Afeganistão, encontrando a ocorrência de espécies $H S_{3}^{-}$o que ajudou a diferenciar à pedra preciosa de Afeganistão.

Schmidt et al. [7] usaram uma abordagem analítica multitécnica, encontrando um resultado que indica a presença de diopsídio no lapis lazuli, e que os metais de transição são responsáveis pelos resultados da espectroscopia Raman.

Bicchieri et al.[8], usaram as técnicas de espectroscopia Ramam e LIBS, para o análise de pigmentos de lazurite e lapiz lazuli que é de interesse na herança cultural. assim como Grassi et al. [9] fizeram analises para identificar pigmentos lapis lazuli, na pintura Madonna dei fusi de Leonardo. 


\section{Revisão Teórica}

\subsection{Cristais Ideais, Distribuição periódica dos átomos e teoria de bandas de energia}

\subsubsection{Cristais Ideais e Distribuição periódica dos áto- $\operatorname{mos}$}

Um cristal ideal é aquele em que os átomos ou moléculas constituintes se distribuem periodicamente no espaço. Um cristal metálico é formado de um só tipo de átomos ou íons, mas, num cristal iônico, os íons positivos e os íons negativos componentes podem ser moléculas; por exemplo no $\mathrm{CaCO}_{3}$ (calcita) temos cations divalentes $\mathrm{Ca}^{2+}$ e ânions divalentes moleculares. Aqui vamos nos concentrar nos cristais iônicos. A distribuição periódica dos cations e ânions formam uma rede cristalina, que pode ser descrita como um conjunto de pontos, cada um podendo ser representado por um vetor $\vec{r}$ como se vê na equação 2.1 :

$$
\vec{r}=n_{1} \vec{a}+n_{2} \vec{b}+n_{3} \vec{c}
$$


onde $n_{1}, n_{2}, n_{3}$ são inteiros e $\vec{a}, \vec{b}, \vec{c}$ são os vetores primitivos. Variando os valores de $n$, encontramos todos os pontos da rede, A periodicidade da rede em um cristal ideal permite realizar operações de simetria como a rotação, reflexão e translação, em três dimensões e os grupos de simetria pontuais compreendem 14 tipos de rede, um geral e 13 especiais. As 14 redes de bravais, cada uma com uma célula unitária característica, estão agrupadas em 7 grupos de simetria.

Chama-se célula unitária ou unidade menor aquela que, quando repetida, reproduz a rede cristalina. A forma da célula unitária deve ser escolhida, de tal modo que células idênticas possam ser arranjadas juntas para preencher o volume todo do cristal.

\subsection{Teoria de bandas de energia}

Muitas das propriedades de um sólido cristalino são devidas a elétrons de valência dos íons componentes do cristal. No metal, por exemplo, uma primeira aproximação é considerar esses elétrons livres exceto por estar limitado dentro do cristal. Nesse modelo de gás de elétrons livres se despreza a interação dos elétrons com os íons positivos da rede e para elétrons livres num poço de potencial infinito. No sistema tridimensional, a função de onda e a energia são dadas por:

$$
\begin{gathered}
\psi_{k(\vec{r})}=e^{i k \cdot \vec{r}} \\
E_{k}=\frac{\hbar^{2}}{2 m}\left(k_{x}^{2}+k_{y}^{2}+k_{z}^{2}\right)=\frac{\hbar^{2} k^{2}}{2 m}
\end{gathered}
$$

A função de onda 2.2 representa ondas progressivas de momento $p=h . k$. A energia $E_{k}$ em função de $k$ é dada pela equação 2.3. Mas, quando se quer estudar as diferenças entre metais, isolantes e semicondutores, o modelo de elétron livre falha, por isso é necessário considerar o efeito dos íons sobre os 


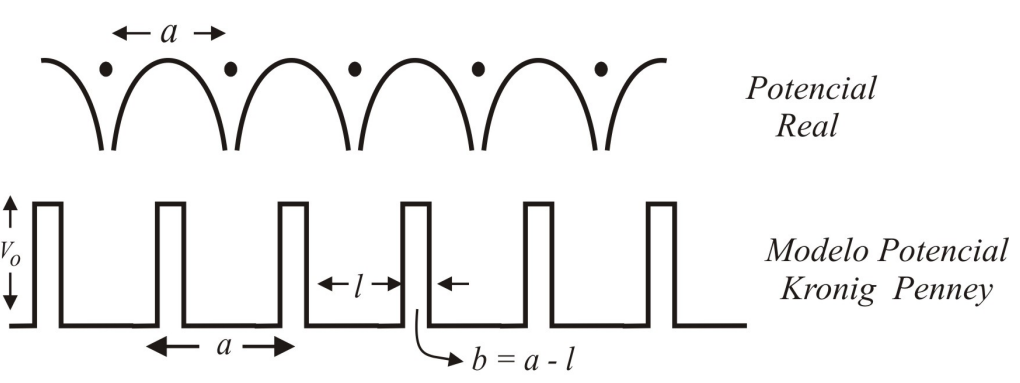

Figura 2.1: Diagrama de kronig - Penney.

elétrons, onde o potencial varia de forma periódica. Uma boa aproximação é o potencial de Kronig e Penney que é uma sucessão de poços e barreiras retangulares unidimensionais de periodicidade $a$.

A figura 2.1 mostra um potencial periódico unidimensional real e o potencial periódico Kronig - Penney, uma aproximação que consiste de poços retangulares finitos $\left(V_{0}\right)$, de largura $l$ de cada poço e periodicidade $a$.

Num potencial periódico como esses, as ondas ficam sujeitas à condição de reflexão de Bragg dada por:

$$
k^{\prime}-G=k
$$

Onde $G$ é o módulo do vetor da rede reciproca, no caso unidimensional:

$$
k= \pm \frac{1}{2} G= \pm n \frac{\pi}{a}
$$

Onde $n$ é um número inteiro, os valores de $k$ da equação 2.4 definem as zonas de Brillouin.

Para cada valor de k há uma reflexão. As soluções para a equação de Schrondinguer, que satisfazem a condição de Bragg, são dadas por ondas estacionárias:

$$
\begin{aligned}
& \psi_{+(x)}=\exp ^{\frac{i \pi x}{a}}+e x p^{\frac{-i \pi x}{a}}=2 \cos \left(\frac{\pi x}{a}\right) \\
& \psi_{-(x)}=e x p^{\frac{i \pi x}{a}}-e x p^{\frac{-i \pi x}{a}}=2 i \operatorname{sen}\left(\frac{\pi x}{a}\right)
\end{aligned}
$$


As ondas estacionárias são a combinação linear de ondas planas, e a densidade de probabilidade é proporcional aos quadrados da parte real que é representada na figura 2.2 .

A distribuição de energia em função de $k$, em referência ao modelo do elétron

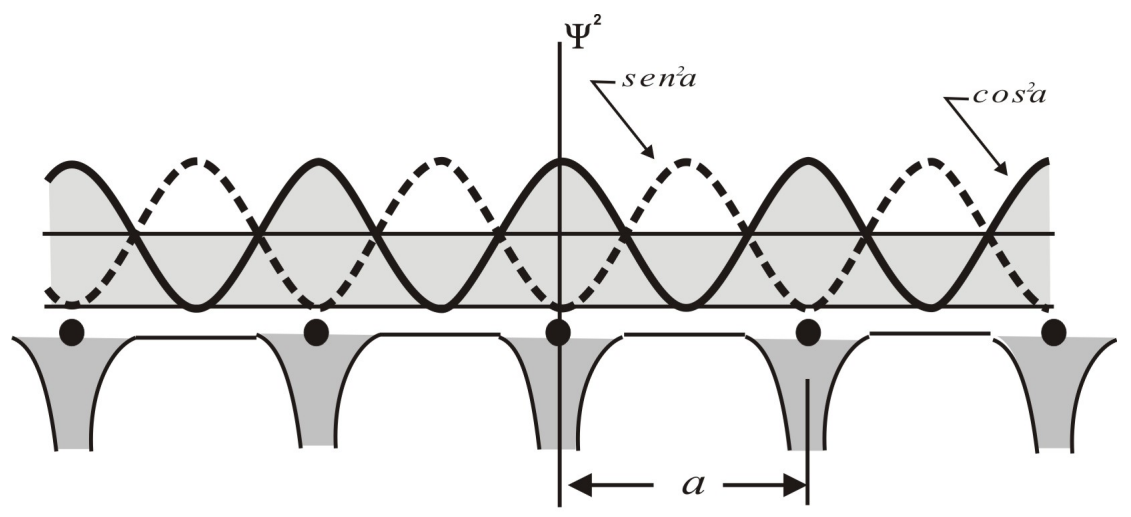

Figura 2.2: Densidade de probabilidade.

livre é afetada pelo potencial periódico, apresentando contínuos de energias permitidas e contínuos de energias proibidas. O modelo de Kronig e Penney é mais fácil de se tratar matematicamente, do que o caso real, mas ele é importante porque retem os aspectos importantes .

Ao resolver a equação de Shrodinguer para o potencial de Kronig e Penney, devemos impor as condições de continuidade da função de onda $\psi$ e de sua derivada $d \psi / d x$, como se faz no caso de um poço retangular. Isto restringe os valores de energia dando origem à bandas. As autofunções são amortecidas na forma de um exponencial decrescente das bandas proibidas. A expressão da energia $E_{k}$ para energias permitidas em termos de $k$ dos elétrons tornase mais complicada do que para os elétrons livres. As descontinuidades da energia ou gaps ocorrem para valores de $\mathrm{k}$ dados por:

$$
k= \pm \frac{\Pi}{a}, \pm \frac{2 \Pi}{a}, \pm \frac{3 \Pi}{a}
$$


Na figura 2.3 temos o gráfico de $E_{k}$ em bandas.

Uma maneira diferente de explicar a formação de bandas de energia, é

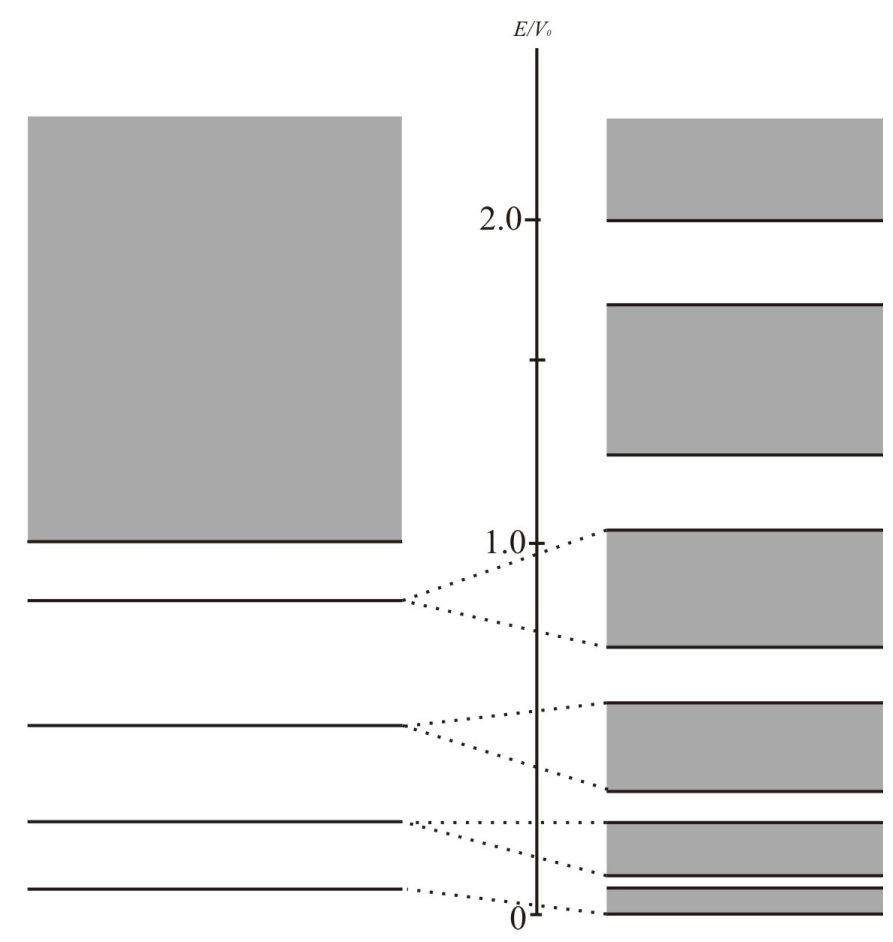

Figura 2.3: Curva de $E_{k}$ para o modelos de elétron livre e de elétrons no sólido.

considerando a é o principio de Pauli, para simplificar vamos considerar o sódio sólido. Um átomo de sódio no estado fundamental tem a seguinte configuração eletrônica: $1 s^{2} 2 s^{s}, 2 p^{6} 3 s^{1}$. Um $\mathrm{cm}^{3}$ de sódio sólido contém cerca de $10^{22}$ a $10^{23}$ átomos. Assim há cerca de $2 \times 10^{22}$ elétrons no estado $1 \mathrm{~s}$, outro tanto no estado $2 s$ e assim por diante. No caso de elétrons $1 s$, sendo $E_{1 s}$ a energia de cada átomo, enquanto eles estão suficientemente afastados um do outro, a energia de cada um nesse estado continua sendo $E_{1 s}$. Mas, se os átomos são aproximados para formar um sólido, os elétrons ficam sujeitos ao princípio de Pauli e as energias dos elétrons $1 s$ têm de diferir uma da outra por um valor, ainda que sejam muito pequenas. O estado considerado degenerado com energia igual ao número de átomos multiplicado por $E_{1 s}$ 


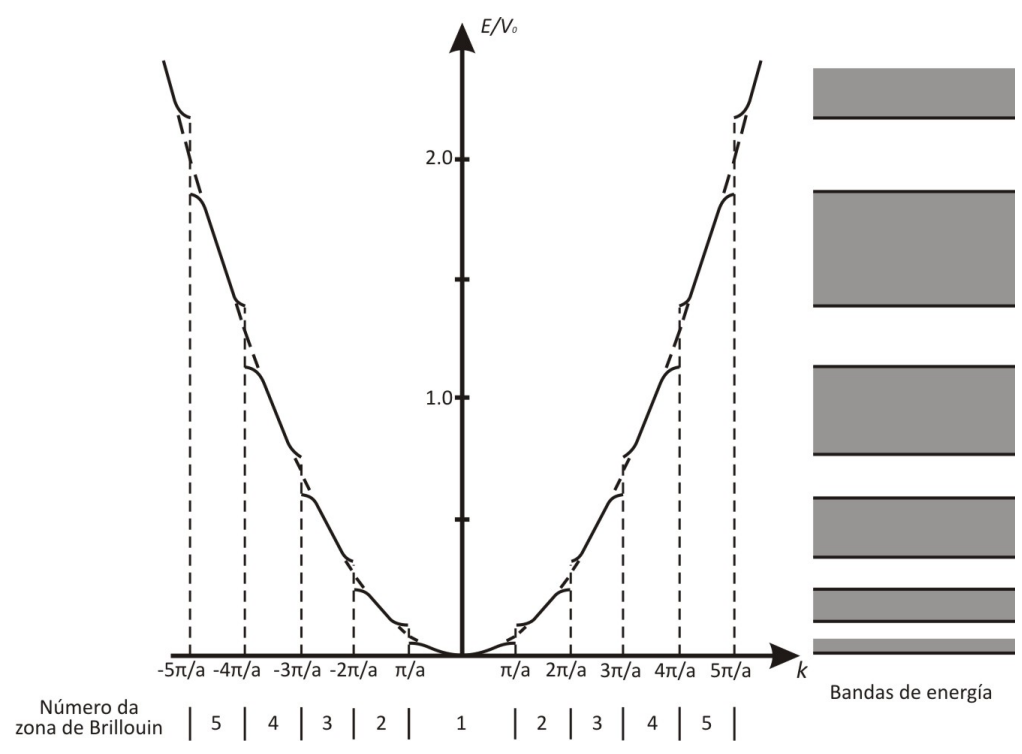

Figura 2.4: Níveis $E_{k}$ para o modelos de elétrons livres

agora passa a ter $2 x 10^{22}$ níveis separados formando uma banda $1 \mathrm{~s}$. Isso se aplica aos outros elétrons $2 s^{2} 2 p^{6}$, etc. e teremos uma formação de bandas de energia, mostrada na figura 2.4. No caso de cristais de isolantes de interesse neste Projeto, considerando, por exemplo, o caso de $\mathrm{NaCl}$, temos agora, cloro com uma configuração atômica $1 s^{2} 2 s^{s} 2 p^{6} 3 s^{2} 3 p^{5}$ e temos, que considerar as bandas de energia $1 s, 2 s$, etc. do cloro, também. Notemos que, quando um átomo de $\mathrm{Na}$ e um de $\mathrm{Cl}$ se aproximam para formar uma molécula de $\mathrm{NaCl}$, o elétron $3 s^{1}$ do sódio passa para o estado $3 p^{5}$ do cloro, completando $3 p^{6}$. É claro que, com isso, teremos íons positivos de Na e um íon negativo de $\mathrm{Cl}$, e que se atraem coulombicamente para formar a molécula ou o sólido se for o caso. Vê-se, então, que os elétrons $3 p^{6}$ do $\mathrm{NaCl}$ sólido são os de valência e devem preencher a última banda cheia, por isso chamada de banda de valência (BV), seguem a banda proibida (BP ou GAP) e a banda vazia que pode receber elétrons, chamada banda de condução (BC). Do ponto de 


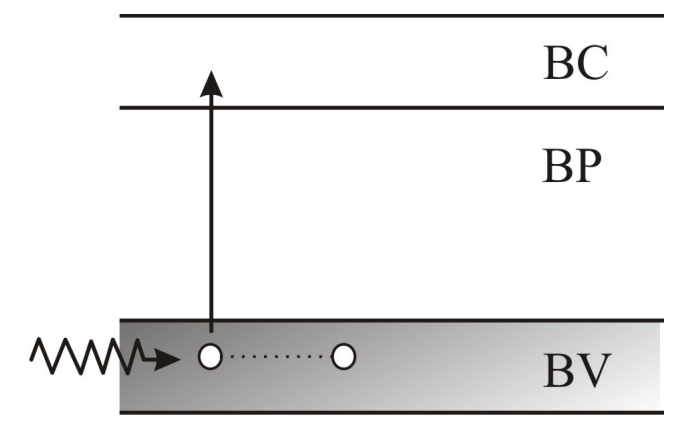

Figura 2.5: Banda de valência $(B V)$, banda proibida $(B P)$ e banda de condução (BC). Promoção do elétron de $B V$ à $B C$ e buraco na $B V$.

vista de estudar propriedades do cristal dependentes desses elétrons, basta considerar, portanto, BV, BP e BC como apresentado na figura 2.5. Irradiar um cristal isolante é uma prática muito frequente, por isso vamos considerar o que acontece com os elétrons da BV com a irradiação. Na figura 2.5 se vê o elétron sendo promovido à $\mathrm{BC}$ quando recebe uma parte da energia da radiação. $\mathrm{O}$ elétron na $\mathrm{BC}$ se move livremente e o buraco deixado na banda de valência passa a se comportar como uma partícula carregada com carga oposta do elétron, mas, tendo a mesma massa e spin do elétron, o buraco desempenha um papel importante no cristal.

\subsection{Cristais iônicos naturais e defeitos pontuais}

\subsubsection{Cristais reais e defeitos}

Os cristais naturais ou produzidos no laboratório contêm imperfeições ou defeitos na sua rede cristalina. Dependendo do critério usado, os defeitos podem ser classificados em:

a) pontuais (ou puntiformes) ou extensos,

b) intrínsecos ou extrínsecos. 


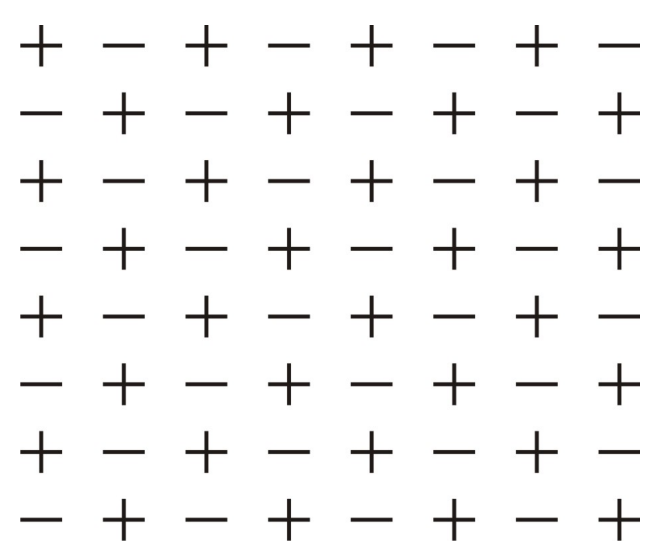

Figura 2.6: Cristal perfeito bidimensional

Os defeitos pontuais assim são chamados por envolverem poucos átomos ou íons, enquanto que os extensos são formados de vários íons. Aqui estamos interessados somente em defeitos pontuais.

Os defeitos intrínsecos ocorrem na própria rede cristalina; os extrínsecos são devido a elementos estranhos ao cristal. Os primeiros ocorrem por razão termodinâmica. Um cristal iônico é formado de íons positivos e negativos e, principalmente, os negativos podem ter composição química mais complexa. Para o propósito desta seção, podemos nos basear na estrutura de cristais simples como halogenetos (ou haletos) de alcalino, como $\mathrm{NaCl}$, LiF, etc., caso em que podemos representar a rede cristalina como dada pela figura 2.6.

O defeito pontual chamado de vacância é devido à ausência de um íon da sua posição normal. É claro que temos vacância catiônica e vacância aniônica. O íon que saiu de sua posição normal pode terminar na superfície, mas, frequentemente, se aloja na posição intersticial, nesse caso ele recebe o nome de defeito intersticial. As vacâncias e os intersticiais podem se associar formando novos defeitos. Assim uma vacância de anion (ou cation) e um intersticial de anion (ou cation) formam um defeito chamado defeito 


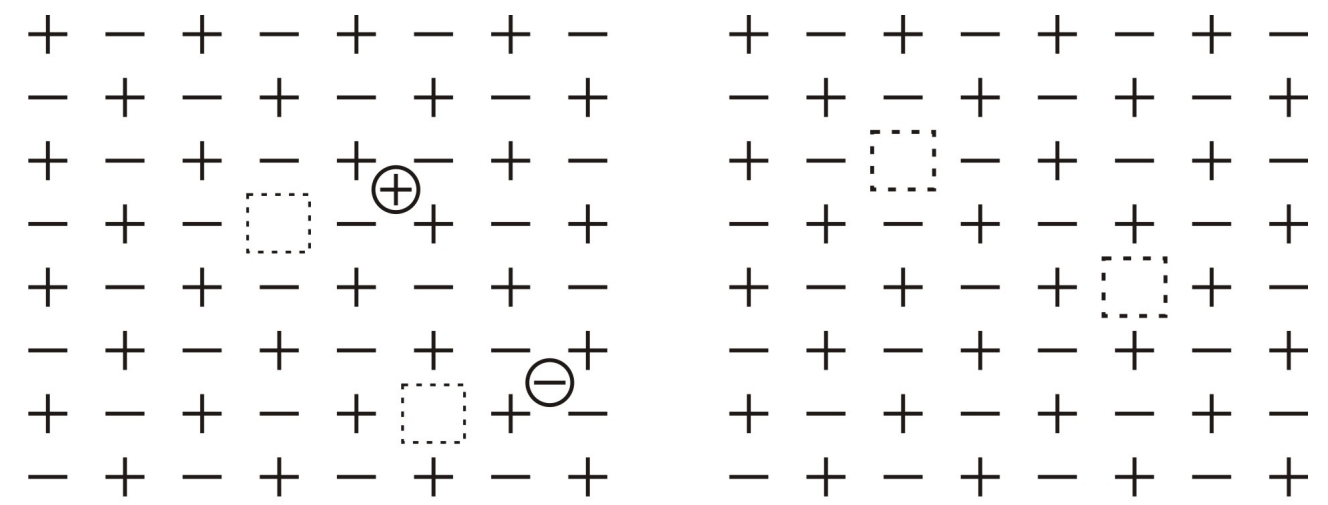

(a) (b)

Figura 2.7: (a)Defeito de Frenkel, cations e anions intersticiais com suas vacâncias (b) Defeito de Schottky vacância de cation e anion.

Frenkel (ver figura 2.7 (a)). Vacância catiônica e aniônica forma o defeito de Schottky (figura 2.7) (b). Não vamos falar sobre outros defeitos formados por associação de defeitos simples acima. Também não vamos a calcular o número de defeitos como vacâncias ou intersticiais, mas, usando a mecânica estatística, pode-se deduzir , por exemplo: $n_{i}=$ número de intersticiais na temperatura $\mathrm{T}$ :

$$
n_{i}=\sqrt{N N_{i}} \exp \left(-\frac{w_{i}}{k T}\right)
$$

Onde N é o número total de pontos da rede num cristal ideal; $N_{i}$ o número total de posições intersticiais possíveis; $\omega_{i}$ é a energia necessária para formar um defeito Frenkel; $k$ é a constante de Boltzmann.

Se os defeitos intrínsecos, particularmente as vacâncias, desempenham um papel importante, os defeitos extrínsecos são, também, fontes de muitas propriedades do cristal. Por exemplo, nos anos 1950, o LiF foi mostrado ser base de dosimetria da radiação, mas só depois de adicionar o magnésio e o titânio, principalmente o primeiro que é muito importante. Vejamos rapidamente o 


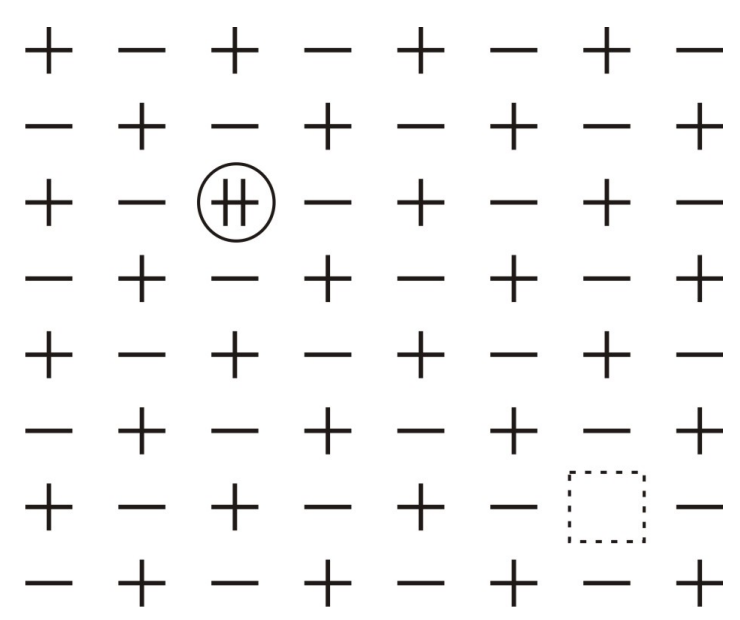

Figura 2.8: Cation divalente.

que acontece quando o cristal é "dopado"com uma impureza.

Na figura 2.8 temos o esquema da rede cristalina de LiF. ++ é um cation divalente, $\mathrm{Mg}$, que entra na rede substituindo um átomo de Li. Como Mg é divalente e Li monovalente, o desequilíbrio de carga força uma vacância de outro íon de Li. Como a vacância de Li tem carga (-) e o $\mathrm{Mg}$ na rede é $(2+)$, os dois formam o que chamamos de dímero e desempenha um papel importante na termoluminescência do LiF:Mg,Ti.

Os metais de transição (também chamados íons $3 d$ ) e as terras raras (íons $4 f)$ estão presentes em muitos minerais naturais e, é claro, em cristais sintéticos e ditam muitas das propriedades desses minerais. Por exemplo, o $\mathrm{Cr}^{3+}$ no berilo produz a esmeralda e $\mathrm{Fe}^{3+}$, a água-marinha.

\subsubsection{Criação de níveis de energia pelos defeitos pontu- ais na banda proibida}

Entre os vários fatos notáveis, que são observados nos cristais iônicos reais, a criação de níveis de energia na banda proibida BP, por defeitos, capazes 


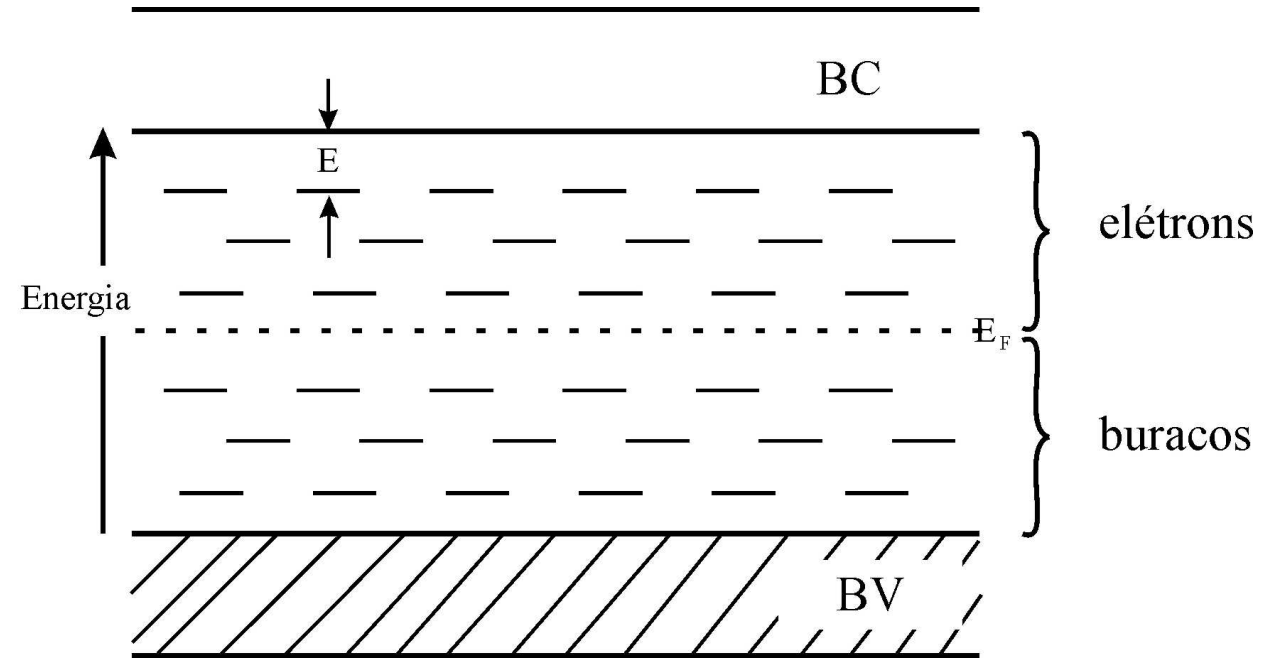

Figura 2.9: Armadilhas de elétrons e de buracos separados pela chamada energia de Fermi.

de capturar elétrons ou buracos é algo extraordinário. Como foi visto nos cristais ideais, na BP, não existe níveis de energia. Os níveis de energia que podem receber elétrons ou buracos são chamados de armadilhas. Na Figura 2.9, temos as armadilhas de elétrons e de buracos separados pela chamada energia de Fermi, $E_{F}$ que divide a BP em duas partes.

Pode haver um, dois ou mais grupos de armadilhas. Cada armadilha de um grupo é caracterizada pela energia $E$ que a separa do fundo da BC (no caso de buraco é calculada do topo da BV). E chama-se energia de ativação.

Existe outro parâmetro que caracteriza cada armadilha: é o fator de frequência $s$, que pode ser interpretado como número de vezes que o elétron oscila entre as paredes do poço de potencial, que representa a armadilha.

\subsubsection{Transições eletrônicas}

Quando um elétron da BV recebe parte da energia de uma radiação que incide sobre o cristal, ele passa da BV para a BC, deixando um buraco que se 


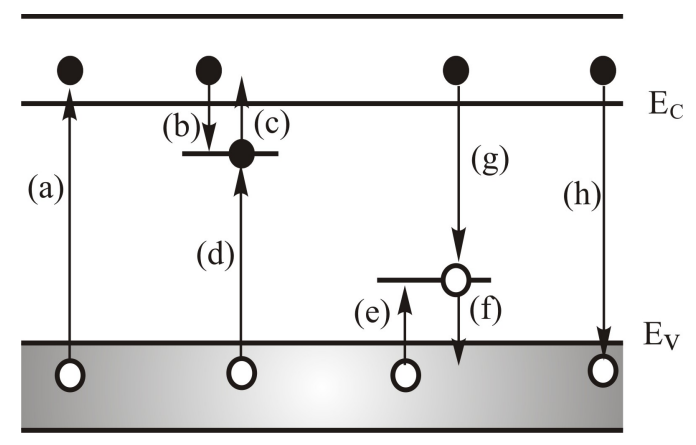

Figura 2.10: Representação de transições elétricas comuns nos isolantes e semicondutores cristalinos

move na BV. A criação de pares elétron - buraco em grande número é conhecida como ionização. Tanto o elétron como o buraco se movem livremente, o primeiro na $\mathrm{BC}$ e o buraco na $\mathrm{BV}$, até eles serem aprisionados nas respectivas armadilhas. Esses movimentos de carga são chamados de transições eletrônicas.

Por exemplo, a passagem da BV para BC é uma transição chamada direta, Na figura2.10, algumas das transições possíveis são mostradas. A transição (b) da BC para uma armadilha é uma transição importante, assim com a transcrição (e) de um buraco da BV para uma armadilha da BV. A parte da energia que a radiação incidente deposita no cristal ficam nessas armadilhas armazenadas e, dependendo do valor $E$ da energia de ativação, essas cargas podem lá permanecer por muito tempo. Na seção de termoluminescência, veremos que as transições (c),(d) ,(f) e (g), têm um papel importante para gerar a luz termoluminescente. 


\subsection{Fenômeno de termoluminescência}

\subsubsection{Termoluminescência (TL)}

Se um cristal iônico for irradiado com uma radiação ionizante, depois de algum tempo quando aquecido, emite luz visível. É o fenômeno de termoluminescência. A luz emitida é em geral fraca e só é visível se o cristal de alguns gramas de massa for irradiada intensamente e se for aquecido até cerca de $300^{\circ} \mathrm{C}$; tudo isto no escuro. Nos trabalhos de um laboratório de pesquisa, usa-se, em geral, uma massa muito pequena, inferior a um grama, por isso, para captar a luz fraca usa-se a chamada válvula fotomultiplicadora (PMT) a qual tem uma segunda função importante. Não se registra diretamente a luz, mas o PMT converte-a em corrente elétrica; sendo está registrável. A intensidade da corrente elétrica é, então, registrada em função da temperatura de aquecimento e resulta então uma curva muito importante chamada de curva de emissão (Glow Curve). Uma curva de emissão, exceto em poucos casos, contém picos com alturas diferentes. Cada pico provém de um grupo de armadilhas, isto é, o número de picos indica o número de grupos de armadilhas de diferentes $E$ e $s$. Se um pico aparece em uma temperatura acima de cerca de $200^{\circ} \mathrm{C}$, ele é estável na temperatura ambiente de cerca de $30^{\circ} \mathrm{C}$. Um pico que aparece acima de $250^{\circ} \mathrm{C}$ a $280^{\circ} \mathrm{C}$ é muito estável e pode ser usado em dosimetria da radiação e em datações arqueológicas e geológicas. O mecanismo de emissão pode, agora, ser explicado usando o esquema de bandas de energia. Vamos partir da condição de que o cristal já foi irradiado, portanto muitas armadilhas já se encontraram preenchidas.

Na figura 2.11 temos algumas armadilhas com energia $E$ preenchidas com elétrons; quando aquecemos o cristal, o elétron recebe suficiente energia e 


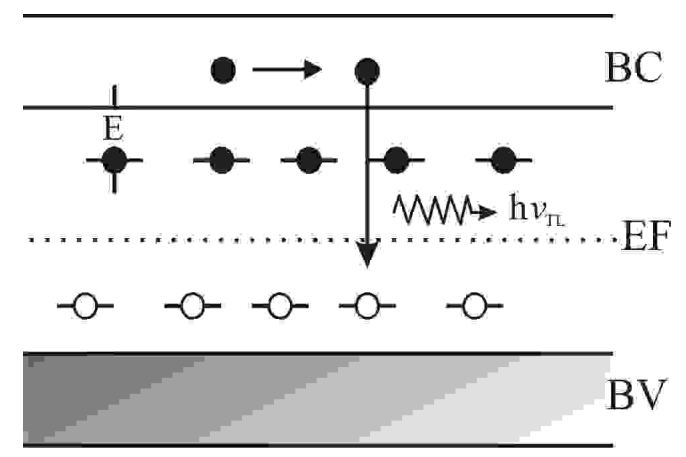

Figura 2.11: Mecanismo de emissão TL no esquema de bandas de energia.

faz transição para BC de lá para uma armadilha de buraco, onde há uma recombinação elétron - buraco e emite a luz TL. Armadilha de recombinação recebe o nome de centro de recombinação.

\subsubsection{Equação que descreve a curva de emissão}

Descrevemos acima, figura 2.11, o mecanismo de emissão TL no esquema de bandas de energia. Randall-Wilkins, consideraram o caso simples de haver somente um tipo de armadilhas de elétrons e um só de buracos (centro de recombinação) e admitiram, ainda, que sendo $n_{t}$ o número de armadilhas de elétrons no instante $t$, a sua variação com o tempo $t$ é proporcional a $n_{t} \mathrm{e}$ à probabilidade por unidade de tempo de liberar elétrons das armadilhas de energia $E$, na temperatura $T$, com fator de frequência $s$ e $k$ a constante de Boltzmann, eles escreveram:

$$
-\frac{d n_{t}}{d t}=n_{t} p=\eta n_{t} \operatorname{sexp}\left(\frac{-E}{k T}\right)
$$

O sinal (-) indica perda de elétrons com a hipótese adicional de que os elétrons liberados não voltam às armadilhas de onde saíram, a intensidade $I$ da luz emitida quando os elétrons liberados se recombinam com buracos nos 
centros de recombinação é dado por (usando $n$ no lugar de $n_{t}$ ):

$$
I_{(t)}=-\eta \frac{d n}{d t}=\eta n \operatorname{sexp}\left(\frac{-E}{k T}\right)
$$

$\eta$ é uma constante, que pode ser igualado a 1. Quando nas equações 2.10 e 2.11 o segundo membro é dependente de $n$, dizemos que temos processo de cinética de primeira ordem. O inverso de $p$, isto é, $\tau=s^{-1} \exp \left(\frac{E}{k T}\right)$ caracteriza o tempo de permanência de elétrons na armadilha. Por exemplo , se $E=1.5 \mathrm{eV}, s=10^{12} \mathrm{~s}^{-1}$, na temperatura ambiente de $T=298 \mathrm{~K}$, e $\tau=7.3 \times 10^{5}$ anos. A temperatura $T$ de aquecimento para a emissão da luz TL varia linearmente com $t$.

$$
T=T_{0}+\beta t
$$

Onde $\beta$ é constante e é a taxa de aquecimento. De 2.10 e 2.11 e usando 2.12, podemos mostrar que a intensidade da termoluminescência, no modelo de Randall - Wilkins, pode ser escrita: contendo $n_{0}$ elétrons no instante inicial, $t_{0}, E_{a}$ é a energia de ativação das armadilhas de elétrons. A célebre equação de Randall - Wilkins é:

$$
I(T)=n_{0} s e^{-E / k T}\left[-\frac{s}{\beta} \int_{T_{0}}^{T} \exp \left(\frac{-E}{k T}\right) \cdot d T\right]
$$

Garlik \& Gibson [10] consideraram a possibilidade de muitos elétrons liberados pelo aquecimento serem rearmadilhados por armadilhas de onde saíram. Isso consiste em substituir a equação 2.10 por:

$$
-\frac{d n}{d t}=n p^{2}=n^{2} \operatorname{sexp}\left(\frac{-E}{k T}\right)
$$

o processo é considerado como cinética de segunda ordem. Procedendo do mesmo modo para obter a equação de Randall - Wilkins, obtém-se agora a equação de Garlick \& Gibson.

$$
I(T)=\frac{n_{0}^{2}}{N} s e^{-E_{a} / k t}\left[1+\left(\frac{n_{0} s}{N}\right) \int_{T_{0}}^{T} \exp \left(\frac{-E_{a}}{k T^{\prime}} \cdot d T^{\prime}\right]^{-2}\right.
$$


$N$ é o número total de armadilhas ocupadas e não ocupadas. Em alguns casos reais, há picos que não obedecem nem à cinética de primeira ordem nem de segunda ordem. Por isso, May Partridge introduziu a equação de ordem geral escrevendo empiricamente:

$$
I_{t}=n^{b} s^{\prime} e^{-E_{a} / k T}
$$

onde $b$ é definido como a ordem da cinética diferente de 1 ou 2 , s'é novo fator de frequência. Eles mostraram que:

$$
\left.I(t)=n_{0}^{2} s^{\prime \prime} e^{-E / k t}\left\{1+(b-1) s^{\prime \prime} / \beta\right) \int_{T_{0}}^{T} e^{-E / k t} d T\right\}^{-b / b-1}
$$

\subsection{Equações que descrevem as possíveis tran- sições de cargas que ocorrem no processo da emissão da luz TL}

Levando em conta que, embora por um tempo curto, há durante o aquecimento, elétrons na BC com concentração $n_{c}$ e sendo a concentração de centros de recombinação $m_{t}$, Adirovitch [11], Haering \& Adams [12] e Halperin \& Braner [13] escreveram:

$$
\begin{gathered}
\frac{d n}{d t}=-n \operatorname{sexp}\left(-\frac{E}{k T}\right)+A_{n}(N-n) n_{c} \\
\frac{d n_{c}}{d t}=n \operatorname{sexp}\left(-\frac{E}{k T}\right)-A_{n}(N-n) n_{c}-A_{m} m n_{c}
\end{gathered}
$$

A intensidade TL é dada por:

$$
I=-A_{m} m n_{c}
$$

Onde $A$ é o coeficiente de transição entre dois estados. Por exemplo $A_{m}$ se refere à transição do elétron da BC para o centro de recombinação, por isso 


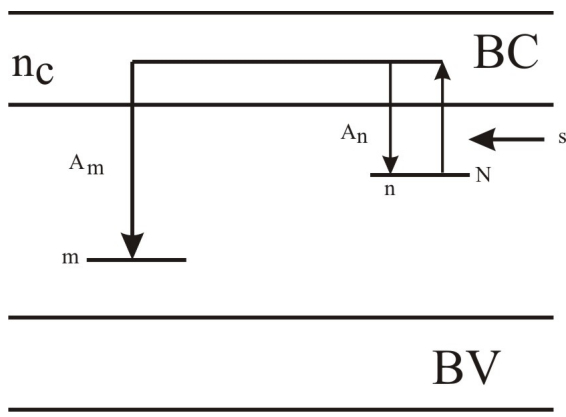

Figura 2.12: Modelo de Adirovitch.

a equação 2.20 representa a intensidade da luz TL emitida. Não vamos examinar essas equações, mas é importante lembrar a condição de neutralidade de carga, que é sempre exigida. No caso, num instante dado:

$$
n+n_{c}=n_{h}=m
$$

esta também pode ser escrita:

$$
\frac{d n}{d t}+\frac{d n_{c}}{d t}=\frac{d m}{d t}
$$

Contudo, vale lembrar que debaixo da condição: que diz que a recaptura do elétron liberado é desprezível, obtêm-se a equação de Randall- Wilkins de primeira ordem.

Não vamos discutir aqui as equações $(2.17),(2.18),(2.19),(2.20)$.

\subsection{Método para estimar os parâmetros de TL}

Analisar um fenômeno físico consiste em descreve lo, qualitativa e quantitativamente através de medidas de grandezas físicas que o caracterizam. No caso de curvas de emissão TL é necessário caracterizar cada pico que aparece na curva, quanto à ordem de cinética e aos parâmetros relacionados às 


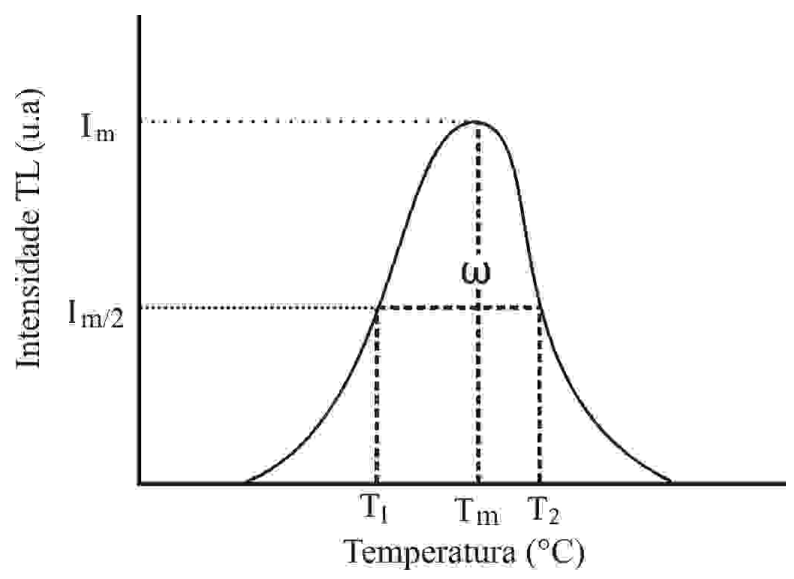

Figura 2.13: Pico de emisão TL, onde se pode observar a largura $\omega$ à meia altura.

armadilhas que dão origem aos picos.

A figura 2.13 mostra um pico, onde $T_{m}$ é a temperatura do pico (que é um dos parâmetros que depende da taxa de aquecimento da leitura TL no aparelho), $\omega$ é a largura do pico à meia altura, isto é, se $I_{T m}$ é a altura do pico, $\omega$ é medida onde a leitura TL é $I_{T m} / 2 ; T_{1}$ e $T_{2}$ são as temperaturas em que a intensidade TL é $I_{T m} / 2 ; \omega=T_{2}-T_{1}, \delta=T_{2}-T_{m}, \tau=T_{m}-T_{1}$. Experimentalmente, foi observado por Chen as diferenças que existem entre os picos de primeira, segunda e ordem geral. Chen utilizou o fator geométrico $\mu_{g}=\frac{\delta}{\omega}$, definido por Halperin e Braner. Então o pico é de primeira ordem se $\mu_{g} \approx 0.42$, e da segunda se $\mu_{g} \approx 0.52$.

Os picos de uma mesma curva de emissão podem ser de diferentes ordens de cinética. Como vimos, o grupo de armadilhas que dá origem a um pico é caracterizado pela energia $E$ de ativação, pelo fator de frequência $s$ e pelo número inicial $n_{0}$ de armadilhas preenchidas com elétrons.

No esquema de bandas de energias, $E$ é a distância em energia da armadilha ao fundo da banda de condução. Se uma armadilha pode ser pensada como um poço de potencial, o fator de frequência é a frequência com que o elétron 
se move dentro do poço, bate e se reflete nas paredes. A determinação de $E$ e $s$, a partir da curva experimental de emissão, pode ser feita usando os seguintes métodos : (1) Forma do pico, (2) Várias taxas de aquecimento, (3) Subida inicial e (4) Ajuste da curva experimental.

\subsubsection{Método de forma do pico}

O nome de método da forma do pico é restrito aos casos em que os parâmetros cinéticos são avaliados usando um número pequeno de pontos extraídos da curva de emissão. A temperatura do pico $T_{m}$ é, normalmente, usada neste método, juntamente com as temperaturas $T_{1}$ e $T_{2}$ da figura 2.13. Urbach [14] propôs uma fórmula empírica, que não é mais usada, e dá o valor da energia $E, E=\frac{T_{m}}{500}$, uma modificação foi introduzida, mas não vamos descrevê-la aqui.

Lushchik [15] propôs para a primeira ordem de cinética o que segue: considerese o triângulo,na figura 2.13, formado pela altura do pico, o lado que liga o pico e o ponto da curva no ponto $T_{2}$. Ao medir a área do triângulo da curva de emissão para $T>T_{m}$, encontrou valores muito próximos, assim ele escreveu:

$$
\delta I_{m}=\beta n_{m}
$$

$I_{m}=I_{T_{m}}, \beta=$ taxa de aquecimento, e $n_{m}$ é a concentração de elétrons em $T_{m}$, dada por:

$$
n_{m}=\int_{t_{0}}^{\infty} I \cdot d t
$$

Na formulação matemática de Randall \& Wilkins:

$$
I_{t}=\eta \frac{d n}{d t}=\eta n \operatorname{sexp}\left(\frac{-E}{k T}\right)
$$

onde $\eta$, na prática, é considerada igual a 1, então:

$$
I_{m}=n_{m} \operatorname{sexp}\left(\frac{-E}{k T_{m}}\right)
$$


Na equação de Randall \& Willkins, $\frac{d I}{d T}$ em $T_{m}$ é igual a zero, e daí se tem:

$$
\operatorname{sexp}\left(\frac{-E}{k T_{m}}\right)=\frac{\beta E}{k T_{m}^{2}}
$$

de 2.26 e 2.27 , tem-se:

$$
\frac{I_{m}}{n_{m}}=\frac{\beta E}{k T_{m}^{2}}
$$

De 2.23 e 2.28 :

$$
\frac{\beta}{\delta}=\frac{\beta E}{k T_{m}^{2}}
$$

i.e.

$$
E=\frac{k T_{m}^{2}}{\delta}
$$

Para a cinética de segunda ordem, foi obtido

$$
E=\frac{2 k T_{m}^{2}}{\delta}
$$

No caso de primeira ordem, uma vez determinada a energia $E$, através da equação 2.29, s se obtém da equação 2.27 .

Vários autores discutiram uma dependência similar de $E$ com $k T_{m}^{2}$ e $k T_{m}$, usando:

$$
\begin{gathered}
\tau=T_{m}-T_{1} \\
\omega=T_{2}-T_{1} \\
\delta=T_{2}-T_{m}
\end{gathered}
$$

E obtiveram a expressão para energia:

$$
E_{\gamma}=c_{\gamma}\left(\frac{k T_{m}^{2}}{\gamma}\right)-b_{\gamma}\left(2 k T_{m}\right)
$$

onde $\gamma$ pode ser $\delta, \tau$ ou $\omega$. Os coeficientes $c_{\gamma}$ e $b_{\gamma}$ tem valores indicados na tabela 2.1. 


\begin{tabular}{ccccccc}
\hline & \multicolumn{3}{c}{ Primeira ordem } & \multicolumn{3}{c}{ Segunda ordem } \\
\hline \hline & $\omega$ & $\tau$ & $\delta$ & $\omega$ & $\tau$ & $\delta$ \\
\hline$c_{\gamma}$ & 2,52 & 1,51 & 0,976 & 3,54 & 1,81 & 1,71 \\
$b_{\gamma}$ & 1,0 & 1,58 & 0 & 1,0 & 2 & 0 \\
\hline \hline
\end{tabular}

Tabela 2.1: Valores das constantes $c_{\gamma}$ e $b_{\gamma}$.

\subsubsection{Taxas de aquecimento}

Em trabalhos que envolvem a termoluminescência foi notado que variando a taxa de aquecimento na leitura TL, a curva de emissão sofre pequenas variações, principalmente, na posição e altura de cada pico. Por exemplo, a posição do pico que é dada pela temperatura $T_{m}$, onde ocorre o pico tende a se deslocar para temperaturas maiores com o aumento da taxa de aquecimento. De qualquer modo, sendo $I_{T}$ a curva que descreve a TL em torno de um pico em $T_{m}, I_{T}$ é máximo em $T_{m}$, de modo que a derivada primeira de $I_{T}$ em $T_{m}$ deve ser igual a zero.

No caso da equação de Randall-Wilkim de primeira ordem, da condição de $\left(\frac{d I}{d T}\right)_{T_{m}}=0$, obtém-se:

$$
\frac{\beta E}{k T_{m}^{2}}=\operatorname{sexp}\left(\frac{-E}{k T_{m}}\right)
$$

onde $\beta$ é a taxa de aquecimento da leitura TL, E a energia de ativação do pico em $T_{m}$, e $k$ a constante de Boltzmann. Tomando-se o logaritmo da equação tem-se:

$$
\ln \left(\frac{T_{m}^{2}}{\beta}\right)=\ln \left(\frac{s k}{E}\right)-\frac{E}{k}\left(\frac{1}{T_{m}}\right)
$$

O coeficiente angular da curva do primeiro membro em função de $\left(\frac{1}{T_{m}}\right)$ é igual a $\frac{E}{k}$, o que nos dá o valor de $E$.

Se a ordem de cinética é segunda ordem, procedendo-se como no caso de 
primeira ordem, obtém-se a condição:

$$
\ln \left(\frac{I_{m} T^{4}}{\beta^{2}}\right)=\operatorname{Ln}\left(\frac{n_{0} E^{2}}{4 s k}\right)+\frac{E}{k T_{m}}
$$

Do gráfico de $\operatorname{Ln}\left(\frac{I_{m} T_{m}^{4}}{\beta^{2}}\right)$ em função de $\frac{1}{T_{m}}$ obtém-se o valor da inclinação da reta igual a $\frac{E}{k}$.

Chen \& Winer [16] consideraram que no caso de cinética de ordem geral (b):

$$
\frac{\beta E}{k T_{m}^{2}}=s\left\{1+(b-1) V_{m}\right\} \exp \left(\frac{-E}{k T_{m}}\right)
$$

onde $V_{m}=\frac{2 k T_{m}}{E}$, e $(b-1) V_{m}$ podem ser considerados aproximadamente constantes, caso em que a expressão 2.37 se reduz a 2.27 .

Lwandososki \& Mckeever [17] demostraram que o método de várias taxas de aquecimento é preciso.

\subsubsection{Método de subida inicial}

Chen \& McKeever [18] afirmam que esse método é o mais simples e o mais geralmente aplicável na avaliação da energia $E$ de ativação. O método se baseia no fato de que as equações que dão a intensidade TL nas cinéticas de primeira ordem e ordem geral contêm um fator $C \exp \left(\frac{-E}{k T}\right)$. Foi, então, desenvolvido um método em que, começando com o pico de mais baixa temperatura (ou pico isolado mesmo de temperatura alta), fazem-se medidas em intervalos pequenos de $\mathrm{T}$ de modo que a subida da intensidade medida como uma função de T seja praticamente:

$$
I_{T}=C \exp \left(\frac{-E}{k T}\right)
$$

Onde $C$ é constante e mantém-se a mesma durante essas medidas. Então:

$$
\ln (I)=\ln C-\frac{E}{k T}
$$


Assim, o gráfico de $\ln (I)$ em função de $1 / T$ fornece $E / k$ que é a inclinação da curva.

Para entender a razão desse método, é só lembrar que nas equações (2.13), (2.14) e (2.16), o fator $C \exp \left(\frac{-E}{k T}\right)$ vem multiplicado por uma função da integral que, para $T_{0}=T_{i n}+\Delta T$ com $\Delta T \ll T_{i n}$, é praticamente igual a 1 . De fato na cinética de primeira ordem, por exemplo:

$$
I(t)=n_{0} \operatorname{sexp}\left(\frac{-E}{k T}\right) \exp \left[\frac{-s}{\beta} \int_{T_{0}}^{T} \exp \left(\frac{-E}{k T}\right) \cdot d T\right]
$$

e para $T \approx T_{0}$ a segunda exponencial é igual a 1 .

\subsubsection{Método $T_{m}-T_{\text {stop }}$}

McKeever [19], com um método alternativo de se encontrar os parâmetros de $E$ e $s$ do pico de termoluminescência, sugeriu que este fosse monitorado em função da temperatura na qual a amostra é aquecida $\left(T_{S T O P}\right)$.

Levy [20] mostrou que a temperatura do pico $T_{m}$, na cinética de primeira ordem, é independente da concentração inicial de elétrons armadilhados, enquanto na de segunda e ordem geral, $T_{m}$ depende da concentração inicial. Por outro lado, tem sido observado o fato de que a variação de $T_{m}$ só se torna grande quando há muita variação na população inicial. Assim mantendose uma pequena variação da concentração inicial, o método de $T_{m}-T_{\text {stop }}$ é aplicável em todas as ordens de cinética. Neste método, inicia-se aquecendo a amostra até $T_{\text {stop }}$, com uma taxa linear. $T_{\text {stop }}$ além de ser inferior à temperatura $T m$ do primeiro pico, deve ser próximo de $T_{0}$, ver figura 2.14 . Neste ponto, deixa a amostra esfriar, aquece-se novamente até o segundo $T_{\text {stop }}$ e registra a nova emissão B. Assim, prosseguindo até o fim da curva correspondente a cada pico. O processo experimental é explicado na pagina 61. 


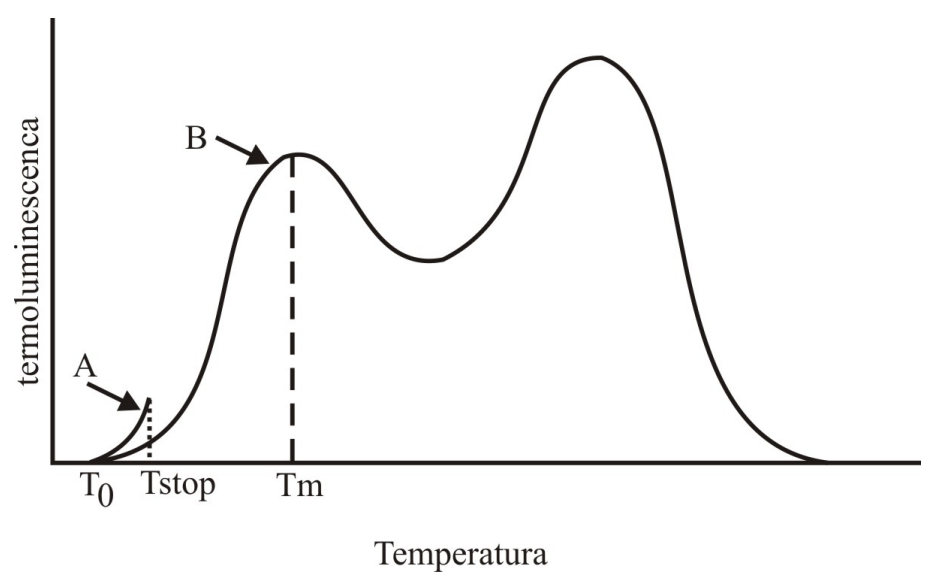

Figura 2.14: Método $T_{m}-T_{\text {stop }}$. $O$ cristal é aquecido à temperatura $T_{\text {stop }}$ na curva $A$, sendo esfriado. Para logo ser aquecido de novo até o final, registrando a curva de emissão restante - curva B. $T_{m}$ é registrado.

\subsubsection{Decaimento anômalo (Anomalus Fading)}

Vimos que um dado pico TL na curva de emissão, está associa-se a uma armadilha de elétrons (ou buracos) de energia $E$ de ativação e fator de frequência $s$, sendo sua estabilidade na temperatura ambiente $T_{a}$ expressa por:

$$
\tau=s^{-1} \exp \left(\frac{E}{k T_{a}}\right)
$$

Onde $\tau$ aumenta com $E$. Experimentalmente, foi encontrada para alguns materiais termoluminescentes, para $E$ relativamente elevado, para o qual se espera uma estabilidade na temperatura ambiente. encontra se o decaimento anômalo onde o fenômeno é prejudicial em dosimetria de radiação e em datação. Por exemplo, Wintle [21] ao datar uma lava vulcânica de idade conhecida, encontrou uma idade menor por um fator de dez. Este resultado foi considerado devido ao decaimento anômalo do pico usado na datação. Wintle cita os seguintes minerais, em que o decaimento anômalo foi observado: sanidina, flouroapatita, labradonita, andesina, zircão e bitonomita. Hoogenstraten [22] encontrou no cristal de $Z n S$ tal anormalidade 
e, se doparlo com $C u$ e $C o$, mesmo na temperatura de nitrogênio liquido, o decaimento anômalo ocorreu. Schulman et al. [23] observaram intenso decaimento anômalo no $\mathrm{CaF}_{2}$ (sintético) dopado com $\mathrm{Mn}$. Há outros exemplos que aqui não serão citados.

Um dos mecanismos mais estudados desse efeito é o de tunelamento, que foi primeiramente, sugerido por Hoogenstaater. Um estudo extensivo sobre esse assunto foi conduzido por Visocekas et al. [24] em calcita.

\subsection{Ressonância paramagnética eletrônica (EPR ou ESR de elétron spin resonance)}

Quando uma radiação ionizante incide sobre um sólido, deixa neste uma fração de sua energia, na forma de pares de elétrons e buracos ao longo de sua trajetória. Essa energia depositada no sólido, chamada dose absorvida, pode permanecer armazenanda, por certo tempo em defeitos pontuais.

Há várias formas de recuperar a energia armazenada acima mencionada. Aqui, vamos-nos restringir ao caso de cristais iônicos. Muitos dos elétrons produzidos na ionização vão se associar aos defeitos pontuais. No modelo de bandas de energia, esses defeitos criam níveis de energia para elétrons e buracos (armadilhas).

Vimos que, aquecendo o cristal, esses elétrons ou buracos por transições específicas, emitem a energia armazenada sob a forma de luz TL ou luz LOE. Os elétrons e os buracos aprisionados no defeitos podem ser observados na ressonância paramagnética eletrônica , isto é, outra forma de recuperar a energia armazenada. A seguir vamos ver como isso acontece. 


\subsubsection{Elétrons equivalentes a minúsculos imãs magnéti- $\cos$}

Classicamente, um elétron é considerado uma esfera minúscula carregada com a carga (-) e girando em torno de um eixo próprio. A lei de Biot Savart de electromagnetismo diz que uma esfera carregada em rotação produz, em sua volta, um campo magnético equivalente ao de um imã com o mesmo momento magnético.

Ikeya [25] relacionou os seguintes parâmetros para descrever as propriedades magnéticas de um elétron isolado.

- Momento angular de Spin: $S$ (em unidade $\frac{h}{2 \pi}$ )

- Número quântico do spin $S: S=\frac{1}{2}$

- Número quântico magnético $M: M= \pm \frac{1}{2}$

- Magneton de Bohr $\beta=\frac{e h}{2 m c}$

- Momento magnético $\mu_{e}=-g \beta S$

- Fator de separação espectroscópico g=2,0023 para um elétron livre.

\subsubsection{Eléctrons nos sólidos}

Em condições normais, num sólido, em geral, os elétrons estão emparelhados de modo que, cada par com momentos magnéticos opostos, tem momento magnético nulo. Existem casos especiais em que isso não acontece. Nos chamados metais de transição de primeira e segunda espécie, na camada $d$ no primeiro caso e na camada $f$ no segundo, é possível encontrar elétrons não emparelhados, de modo que os átomos podem ter spin $S$ igual a 1/2, 3/2, etc., dependendo se há 1, 3, 5 elétrons com seus spins alinhados. 
Num cristal iônico, que é do interesse neste trabalho, com a irradiação gamma, os pares de elétrons são desfeitos e os elétrons individuais vão se alojar nos defeitos pontuais.

Quando se aplica um campo magnético estático externo, os elétrons não emparelhados se alinham ao campo magnético, paralela ou antiparalelamente ao campo magnético. como mostra a figura 2.16. Este é o chamado efeito Zeeman.

Em (a) sem o campo magnético externo, o momento magnético do sólido

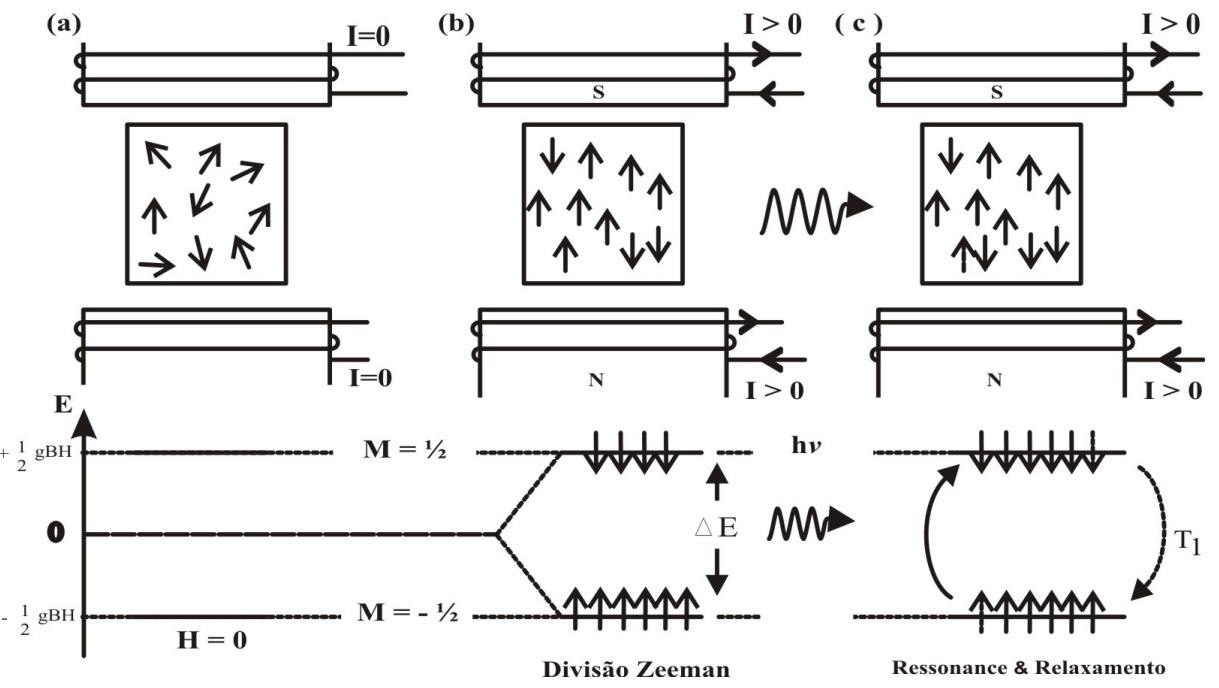

Figura 2.15: A representação da energia de um spin eletrônico desemparelhado na presença de um campo magnético (efeito Zeeman). (a) Os spins dos eletrons não pareados se orientam randomicamente, (b) no campo magnético externo os spins se orientam ao campo magnético (separação Zeeman) (c) mudança de orientação dos spins paralelamente orientados ao absorver uma energia de frequência $v_{r}$ de uma microonda aplicada.

é zero. Com o campo magnético, os spins se orientam ao campo de modo que aqueles com $M=-1 / 2$ têm energia mais baixa do que aqueles com $M=+1 / 2($ Figura 2.16(b)). 
Aplicando se microonda de frequência $v_{r}$, esta é absorvida de modo que muitos elétrons com $M=-1 / 2$ mudam de orientação e passam para o estado com $M=+1 / 2$ (Figura 2.16 (c)). Dizemos então que houve uma ressonância paramagnética eletrônica (EPR). Muitos preferem o termo ESR (Eletron Spin Resonance) ao invés de EPR.

A energia de interação entre um imã de momento magnético $\vec{\mu}$ e o campo magnético $\vec{H}$ (rigorosamente, deve se usar a indução magnética $\vec{B}$ ) é dada por $E_{z}=-\vec{\mu} \cdot \vec{H}=-g \beta \vec{S} \cdot \vec{H}$.

A energia Zeeman pode ser escrita como:

$$
E_{z}=g \beta H M
$$

A unidade de $H$ é $\operatorname{lm} T(T=$ tesla $)$, mas é frequente usar a unidade 1 Gauss $=0.1 m T$. A passagem do estado $M=+1 / 2$ para $M=-1 / 2$ requer, portanto, uma energia:

$$
h v_{r}=g \beta H_{r}
$$

Onde $H_{r}$ é o campo magnético de ressonância, e $v_{r}$ a frequência de microonda de ressonância. Na prática, a frequência é fixa e quem varia o campo magnético, isto é, os espectrômetros de EPR, que são encontrados comercialmente, têm a frequência fixa e é chamada de banda L, banda S, etc, conforme a frequência e o campo de ressonância para um elétron de $\mathrm{g}=2,0$ (veja a tabela 2.2 [25]) No campo magnético externo $\vec{H}$, os spins dos elétrons de um cristal se separam em níveis de energia com $M=\frac{1}{2}$ e $M=-\frac{1}{2}$. A separação sendo uma função de $\mathrm{H}$, e a ressonância ocorre quando esta separação por $g \beta H$ igual a $h v_{r}$.

Na parte inferior da figura 2.16, a potência $\mathrm{P}$ da microonda é representada em função de $H$ e, no ponto $H_{r}$ de ressonância à reta de $\mathrm{P}$, apresenta uma absorção na forma de uma banda. É claro que essa banda da energia da 


\begin{tabular}{cccc}
\hline \hline Banda & $\begin{array}{c}\text { Comp. onda } \\
(\mathrm{cm})\end{array}$ & $\begin{array}{c}\text { Frequência } \\
(\mathrm{GHz})\end{array}$ & $\begin{array}{c}\text { Campo Magnético } \\
(\mathrm{mT})\end{array}$ \\
\hline \hline$L$ & 20,0 & 1,5 & 53,5 \\
$S$ & 9,4 & 3,2 & 114 \\
$X$ & 3,2 & 9,5 & 339 \\
$K$ & 1,2 & 25 & 892 \\
$G$ & 0,86 & 35 & 1250 \\
\hline \hline
\end{tabular}

Tabela 2.2: Banda do espectrômetro, comprimento de onda, frequência e campo magnético de ressonância para $g=2$.

microonda é absorvida pelos elétrons de ressonância, e por isso, é que essa banda indica, por assim dizer, a intensidade da ressonância.

$\mathrm{Na}$ prática, o espectrômetro EPR registra a derivada primeira em $H$ da energia de absorção, assim a figura 2.17 mostra um sinal típico de EPR. O fator $g$ espectroscópico de separação, um sinal EPR, é um parâmetro importante. Os elétrons não emparelhados em diferentes ambientes têm fatores $g$ ligeiramente diferentes; em outras palavras, centros diferentes apresentam diferentes fatores $g$.

Como $g_{e}$ de um elétron livre é igual a 2,0023 e, como muitos das sinais de EPR são devidos a elétrons quase livres, o fator g de muitos dos sinais na prática, não se afasta muito de $\mathrm{g}=2,0$.

O fator g é na realidade um tensor, de modo que o tipo de cristal no qual os elétrons ou buracos se encontram faz com que os componentes do tensor $g$ sejam explicitados. É claro que a orientação do campo magnético em relação aos eixos do cristal, também afetam g. Numa simetria ortorrômbica, o tensor g é expresso com $g_{z z}, g_{x x}, g_{y y}$. Na simetria axial $g_{/ /}=g_{z z}$ e $g_{\perp}=g_{x x}=g_{y y}$. esse tema é importante, mas não vamos entrar em detalhes, também, não 


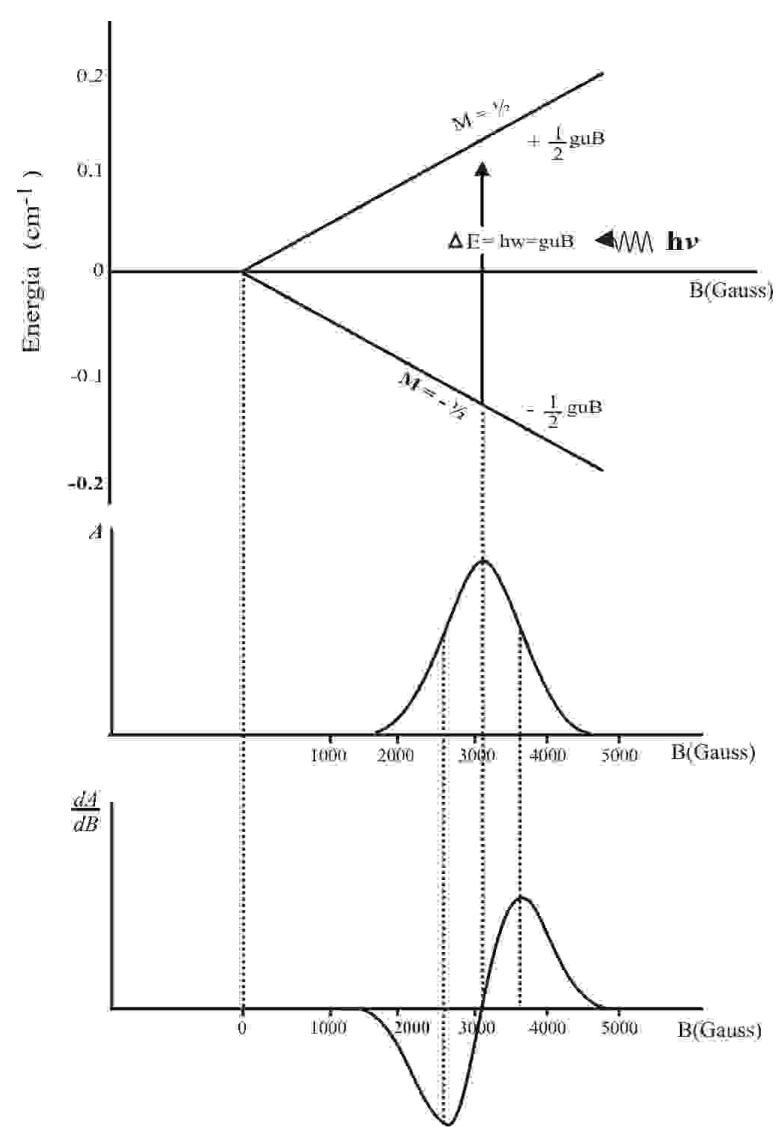

Figura 2.16: Banda do espectrômetro, comprimento de onda, frequência e campo magnético de ressonância para $g=2$.

trataremos da interação hiperfina.

\subsection{Absorção ótica e refletância}

Îndice de refração e permissividade

As propriedades óticas de um cristal estão baseadas na interação deste com ondas eletromagnéticas. Uma onda eletromagnética ao atravessar um material, interage com as cargas elétricas, causando seu movimento, isto é, seu deslocamento. Em consequência dessa interação, a velocidade e a intensidade 

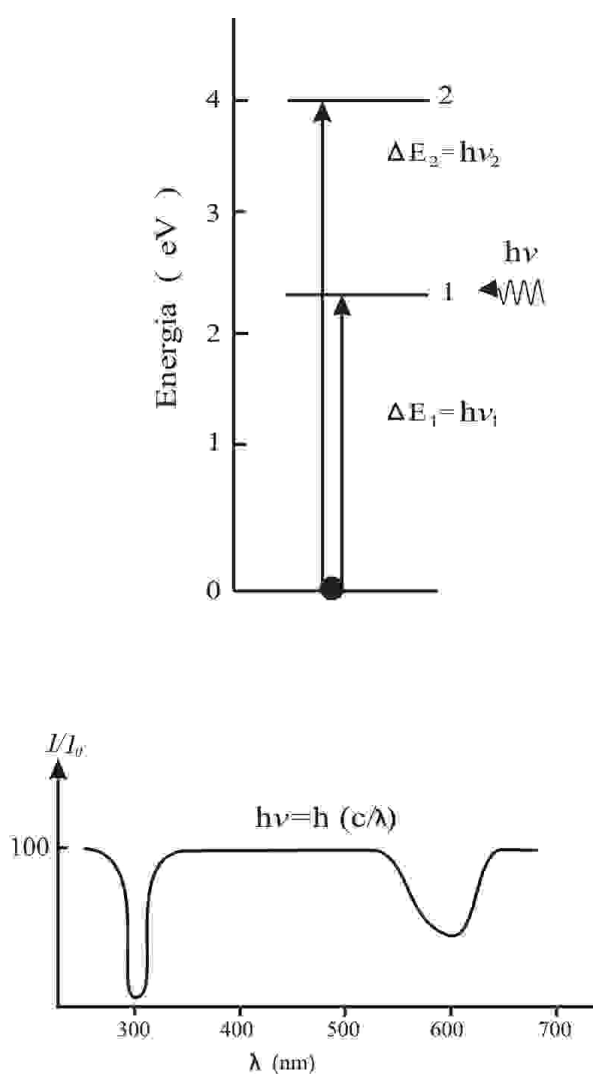

Figura 2.17: Sinal típico de EPR.

da onda se alteram, esses parâmetros estão contidos no índice de refração complexo $n *=n-i \kappa, n$ sendo o índice de refração real do meio, e $\kappa$ chamase índice de absorção. Se a permissividade do meio for também complexa $\kappa *=\kappa_{1}-i \kappa_{2}$, as seguintes relações podem ser demostradas:

$$
\begin{aligned}
\left(n^{*}\right)^{2} & =\kappa^{*} \\
n^{2}-\kappa^{2} & =\kappa_{1} \\
2 n \kappa & =\kappa_{2}
\end{aligned}
$$

$\chi=\kappa-1$ é a suscetibilidade eletrônica. 


\subsubsection{Absorção Ótica}

Para um meio homogêneo, a intensidade da luz ao atravessar uma espessura $d x$ deste meio sofre a variação $d I$ dada por:

$$
d I=-\alpha I d x
$$

Onde $\alpha$ é o coeficiente de absorção e pode ser mostrado que está relacionado ao índice de absorção $\kappa$ por:

$$
\alpha=4 \pi \frac{\kappa}{\lambda}
$$

onde $\lambda$ é o comprimento de onda da radiação incidente. Da relação entre $d I$ e $I$, a equação(2.45), tem-se

$$
I=I_{0} \exp (-\alpha x)
$$

$I_{0}$ sendo a intensidade da onda na superfície do material.

\subsubsection{Reflexão}

A fração $R$ da intensidade refletida, quando a luz incide normalmente à superfície do cristal, é dada pela fórmula de Fresnel de refletância $R$ :

$$
R=\frac{(n-1)^{2}+\kappa^{2}}{(n+1)^{2}+\kappa^{2}}
$$

$\operatorname{como} \kappa=\frac{\lambda}{4 \pi} \alpha, \mathrm{e}$

$$
\alpha^{2}=\left(\frac{4 \pi}{\lambda}\right)^{2} \cdot \frac{(n-1)^{2}-R(n+1)^{2}}{(R-1)}
$$

Dos valores de $R$ ou dos pontos da curva de refletância, podemos obter a curva de absorção ótica. 
3

\section{Materiais e métodos} experimentais

\subsection{Amostra natural}

A figura 3.1 mostra um fragmento de Lapis Lazuli, adquirido na loja de pedras e minerais LEGEP, em São Paulo. Pode-se observar que tem uma coloração azul forte com colorações brancas e douradas misturadas. O Lapis Lazuli utilizado neste trabalho é proveniente do Afeganistão.

Para o estudo, uma parte da amostra é pulverizada com um almofariz e um

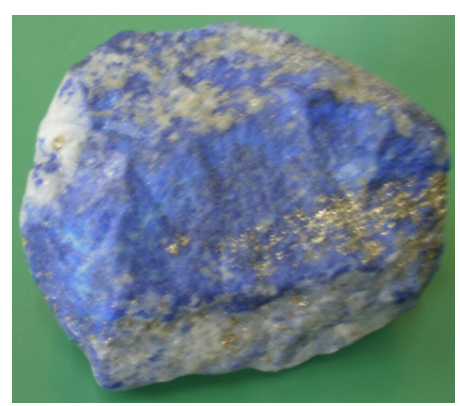

Figura 3.1: Foto de Lapis Lazuli Natural a ser estudada 
pistilo, ambos de cerâmica com uma grande dureza. A amostra é pulverizada e peneirada retendo grãos de $80 \mu \mathrm{m}$ a $180 \mu \mathrm{m}$ para medidas de TL, refletância e EPR, as menores que $80 \mu \mathrm{m}$ para difração de raios $\mathrm{X}$ e fluorescência de raios $\mathrm{X}$.

\subsection{Irradiação e tratamento térmico}

Os grãos entre $80 \mu \mathrm{m}$ e $180 \mu \mathrm{m}$ da amostra são protegidos com um envelope de papel vegetal e embrulhados com papel alumínio, para logo serem irradiados com radiação gama de ${ }^{60} \mathrm{Co}$, no laboratório do Centro de Tecnologia das Radiações do Instituto de Pesquisas Energéticas e Nucleares de São Paulo, Comissão Nacional de Energia Nuclear (CTR-IPEN-CNEN/SP), onde foram usadas duas fontes de ${ }^{60} \mathrm{Co}$, uma fonte Gamacell para altas doses com taxa de $2.04 \mathrm{kGy} / \mathrm{h}$, e outra fonte tipo panorâmica com taxa de $0,47 \mathrm{kGy} / \mathrm{h}$. Todas as irradiações foram feitas em temperatura ambiente.

No tratamento térmico, sabe-se que a energia térmica provoca modificações internas no material, através de dissoluções de alguns agregados e formação de outros, migração de defeitos ou de desarmadilhamento de portadores de carga, e a formação de mais vacâncias. Para estudar o comportamento da amostra, quando submetida a tratamentos térmicos por 30 minutos as temperaturas de $600^{\circ} \mathrm{C}, 900^{\circ} \mathrm{C}, 1000^{\circ} \mathrm{C}, 1100^{\circ} \mathrm{C}$. Os fornos empregados nos tratamentos térmicos foram montados no laboratório LACIFID. 


\subsection{Equipamentos de medida}

\subsubsection{Fluorescência de raios $\mathrm{X}$}

A fluorescência de raios $\mathrm{X}$ é uma técnica não destrutiva, que nos permite realizar análise quantitativa e qualitativa, e assim obter a informação dos elementos presentes na amostra quanto à natureza e suas concentrações.Uma fonte de raios $\mathrm{X}$ de elevada energia interage com a matéria (amostra) provocando a excitação dos átomos. Assim, parte da energia dos fótons emitidos pela fonte é utilizada para romper a energia de ligação do elétron interno do elemento da camada $\mathrm{K}$ e a energia restante acelera o elétron expulso, deixando o estado excitado. Os elétrons das camadas adjacentes passam a preencher os espaços vacantes dando origem às transições $L \rightarrow K, M \rightarrow K$, $M \rightarrow L$, tendo assim uma diferença de energia que é emitida em forma de raios $\mathrm{X}$, esse processo de emitir raios $\mathrm{X}$ é conhecido como fluorescência de raios $\mathrm{X}$.

\subsubsection{Termoluminescência}

Para realizar as medidas de Termoluminescência, foi utilizada a Harshaw TLD Model 4500 do Laboratorio LACIFID (figura 3.2). Este aparelho realiza a leitura da amostra por aquecimento para registrar a curva de emissão. A luz emitida é convertida em sinais através de uma válvula fotomultiplicadora e possui uma interface computacional que é controlada por um software denominado WINREMS (Windows Based Radiation Evaluation and Management System).

A leitora harshaw é composta por um sistema de aquecimento controlado, um sistema de detecção de luz e conversão em sinais elétricos. O sistema de 


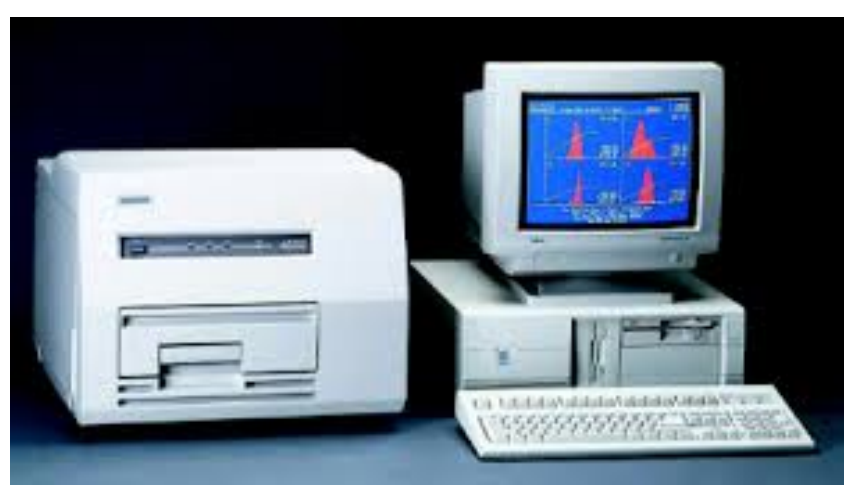

Figura 3.2: Harsaw, equipamento para fazer medidas de TL.

aquecimento tem uma prancheta metálica de alta resistência onde se coloca a amostra para ser aquecida. É monitorada por um termopar, a uma taxa de aquecimento constante.

O tubo fotomultiplicador faz a coleta da luminescência emanada transformandoa em sinal elétrica, cuja resposta é transmitida ao computador que realiza os controles da leitora e armazena os dados das respostas TL.

Para obter o sinal de TL devido, unicamente, à termoluminescência do material e evitar a irradiação do corpo negro, que ocorre quando um material é aquecido a certa temperatura (superior a $300^{\circ} \mathrm{C}$ ), são feitas duas leituras consecutivas da mesma amostra e assim, subtrai-se a segunda leitura ( ruído de fundo) para obter o sinal de TL limpo.

Os filtros têm como objetivo proteger a fotomultiplicadora, diminuindo a radiação do corpo negro produzido pela prancheta durante o aquecimento em altas temperaturas.

\subsubsection{EPR}

Os espectros de EPR foram obtidos com um espectrômetro EPR Bruker EMX que pertence ao Grupo de multi - usuários do Instituto de Física da 
USP. O espectrômetro opera na banda X, trabalha com frequência fixa de 9,7 GHz,e com frequência de modulação de 100 kHz.

O aparelho consta de controlador de campo magnético, fonte de microondas, cavidade ressonante e sistema de detecção de microondas.

A fonte de microondas é composta por uma fonte de microondas e um

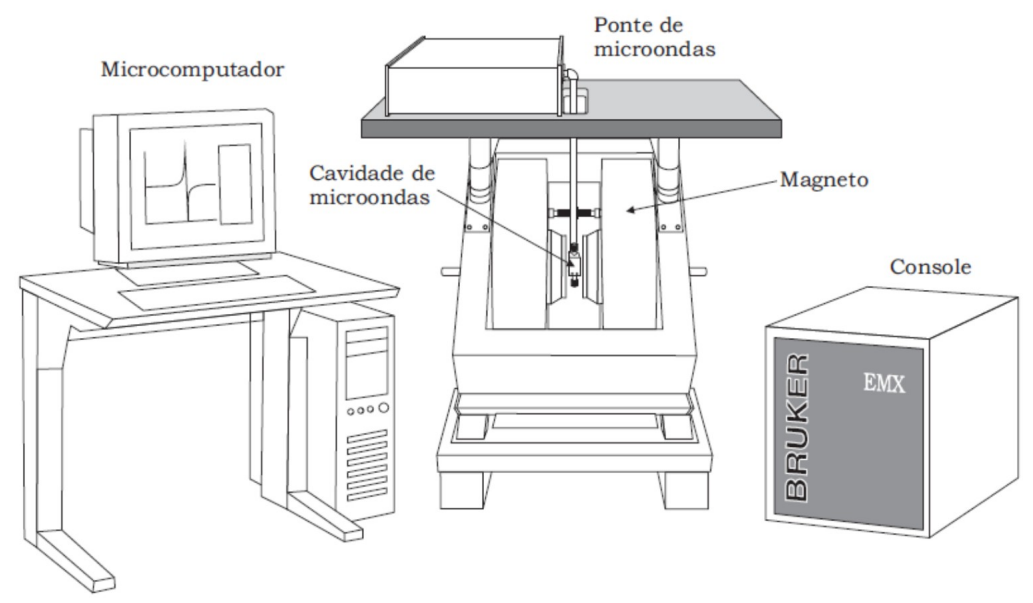

Figura 3.3: Equipamento para fazer medidas de EPR.

detector. A fonte de microondas emite radiação eletromagnética que é conduzida por uma guia de ondas até uma cavidade ressonante. O detetor é um diodo que capta o sinal absorvido pela amostra quando esta é atingida pela microondas, transformando a potência de corrente de microondas refletida em corrente elétrica.

O controlador de campo magnético tem duas partes, uma que ajusta os valores de campo e controla o tempo de varredura do campo e outra que regula a corrente das bobinas, permitindo, assim, obter um campo magnético estático, controlado e de boa precisão.

A cavidade de ressonância amplifica os sinais fracos das amostras paramagnéticas, armazenando energia de microondas, de tal modo que, para uma 


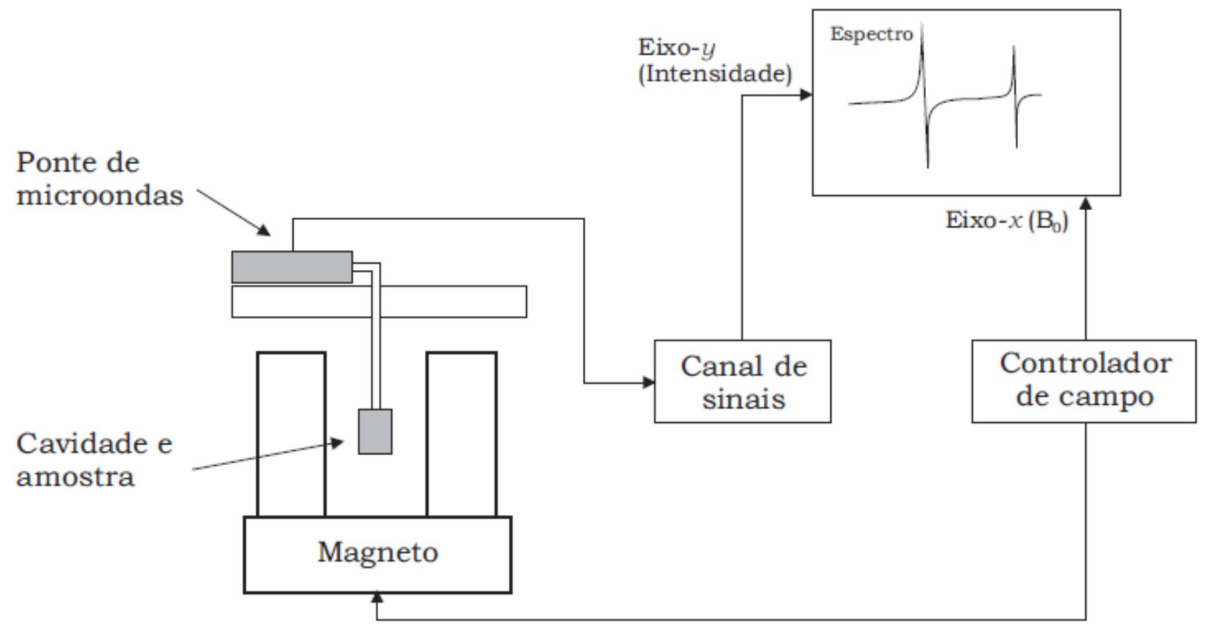

Figura 3.4: Esquema do espectrômetro Bruker EMX.

dada frequência de ressonância, nenhuma energia de microondas sejá refletida para o detector. Existe um parâmetro que caracteriza a cavidade que é o fator de qualidade Q que determina a eficiência da energia armazenada, que é dado por:

$$
Q=\frac{2 \pi \text { energia armazenada }}{\text { energia dissipada por ciclo }}
$$

Os espectrômetros EPR utilizam um conjunto de processos para obter um aumento na sensibilidade, que consiste em modular a intensidade do campo magnético externo e o sinal de absorção de ressonância inicialmente linear. O sinal resultante da modulação é uma onda sinusoidal com amplitude proporcional à derivada de absorção na região. Então, o sinal é comparado com outro sinal de referência, sendo que as que têm igual frequência e mesma fase de modulação do campo são detectadas. 


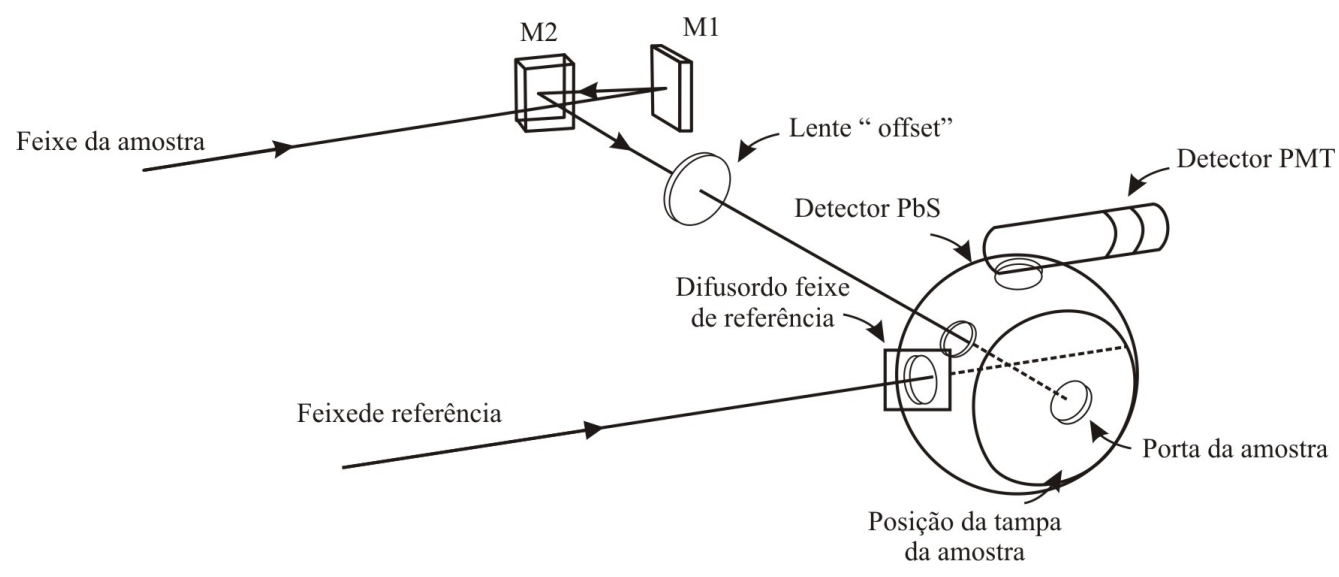

Figura 3.5: Esquema da esfera integradora do espectrômetro Variam Cary 500 para as medidas de refletância.

\subsubsection{Refletância}

Para as medidas de refletância, utilizamos um espectrômetro Varian Cary 500 UV -Vis-NIR que opera na faixa de 250 a $2500 \mathrm{~nm}$. O espetrofotômetro tem uma lampada de deutério que é empregada na região UV e uma lampada de quartzo - halogênio usada para a região visível e infravermelho próximo. O feixe de luz proveniente da fonte do espectrofotômetro passa por um monocromador antes de atingir a amostra. Para a refletância usa-se uma esfera integradora de $110 \mathrm{~mm}$ de diâmetro, um sistema de espelhos que direciona o feixe procedente da fonte e um sistema de detecção. A esfera integradora tem um orifício na parte lateral feito para colocar a amostra com um tamanho mínimo de $100 \mathrm{~mm}$ por $200 \mathrm{~mm}$. Toda a superfície interior da esfera está coberta de uma camada de politetrafluoretileno (PTFE). O sistema de detecção consiste de um tubo fotomultiplicador (PMT) e um diodo de sulfeto de chumbo $(\mathrm{PbS})$.

Para estabelecer a linha base foi utilizada PTFE. A Figura 4.5 mostra o funcionamento da Cary 500 no processo de refletância. As medidas foram 
efetuadas à temperatura ambiente. 


\section{Resultados Experimentais}

\subsection{Fluorescência de raios $\mathrm{X}$}

A análise, da amostra de Lapis Lazuli foi feita no Laboratório de Caracterização Tecnológica (LCT)do departamento de Engenharia de Minas e de Petróleo da Escola Politécnica da USP, num espectrômetro de fluorescência de raios X Axios Advanced, marca PANalytical, fornece elementos químicos de flúor a Urânio.

O resultado é apresentado em forma de histogramas na figura 4.1 pode se observar dois grupos de compostos, os que estão presentes em maior (em mol \%) e menor proporção (mol \%). Onde devido ao fato de lapis lazuli ser um silicato se obtêm em maior quantidade $\mathrm{SiO}_{2}$, seguido dos óxidos $\mathrm{CaO}$, $\mathrm{MgO}, \mathrm{Al}_{2} \mathrm{O}_{3}, \mathrm{Na}_{2} \mathrm{O}$. mas da fluorescência de raios X, não é possível definir a porcentagem dos silicatos, que fazem parte da solução sólida.

\subsection{Medidas de termoluminescência}

A medida de TL dá como resultado uma curva de emissão caracterizada por alguns picos; o número destes, como vimos, dá o número de grupos de 

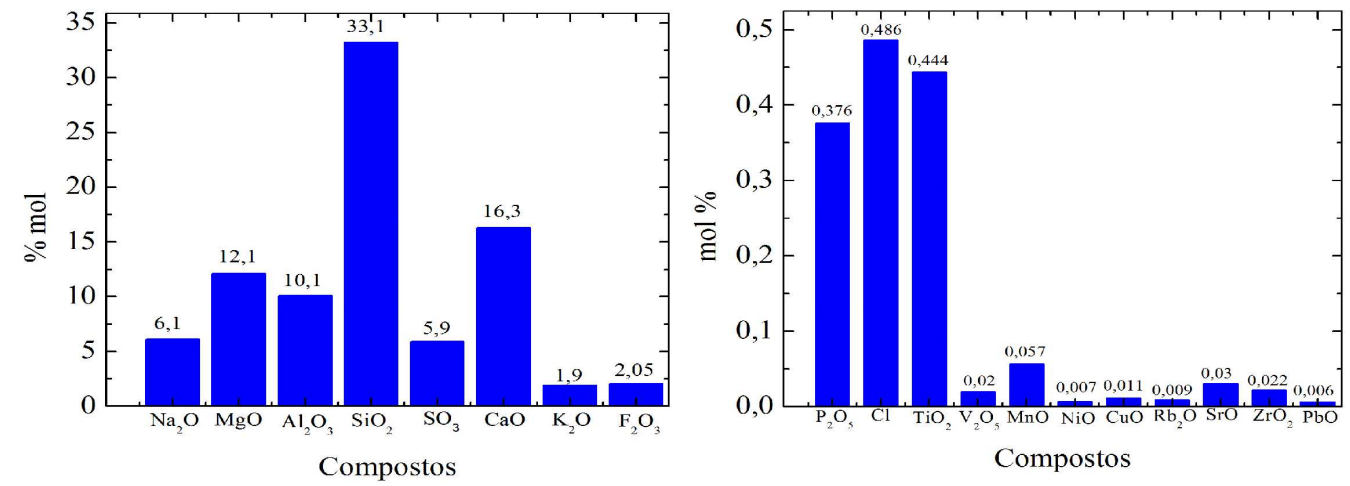

Figura 4.1: Análise químico de Lapis Lazuli por fluorescência de raios X. Nos histogramas são apresentadas concentrações de óxidos da amostra natural em \% mol. Os compostos principais são: $\mathrm{SiO}_{2}$ (33.2), $\mathrm{CaO}$ (16.3), $\mathrm{MgO}$ (12.1), $\mathrm{Al}_{2} \mathrm{O}_{3}$ (10.1). Além dos componentes principais, há em quantidades consideráveis $\mathrm{Na}_{2} \mathrm{O}$ (6.10), $\mathrm{SO}_{3}$ (5.90), $\mathrm{Fe}_{2} \mathrm{O}_{3}$ (2.05), $\mathrm{K}_{2} \mathrm{O}$, (1.90).

armadilhas responsáveis pelos picos.

\subsubsection{Curva de TL da amostra natural}

A primeira medida de TL foi feita para a amostra natural de Lapis Lazuli, sem tratamento térmico apenas com a radiação natural à qual foi exposta durante o tempo geológico. A figura 4.2 mostra a curva de emissão TL do Lapis Lazuli onde podemos observar dois picos bem definidos: um em torno de $296^{\circ} \mathrm{C}$, e outro em $372{ }^{\circ} \mathrm{C}$.

\subsubsection{Dependência de TL com a dose}

Além da importância para aplicações em dosimetria da radiação e datação, o comportamento da curva TL do material em função da dose está vinculado a processos de transferência de portadores de carga, tanto durante a irradiação quanto durante o aquecimento no processo de leitura TL, podendo revelar 


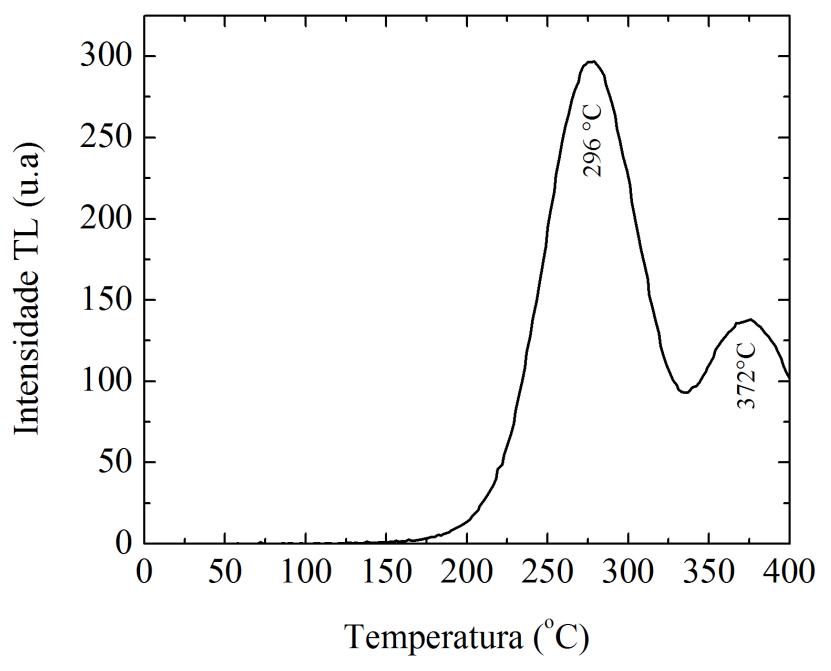

Figura 4.2: Curva de emissão TL do Lapis Lazuli natural obtida com uma taxa de aquecimento $\left(\beta=4^{\circ} \mathrm{C} / \mathrm{s}\right)$. A curva apresentada é a média de 8 leituras.

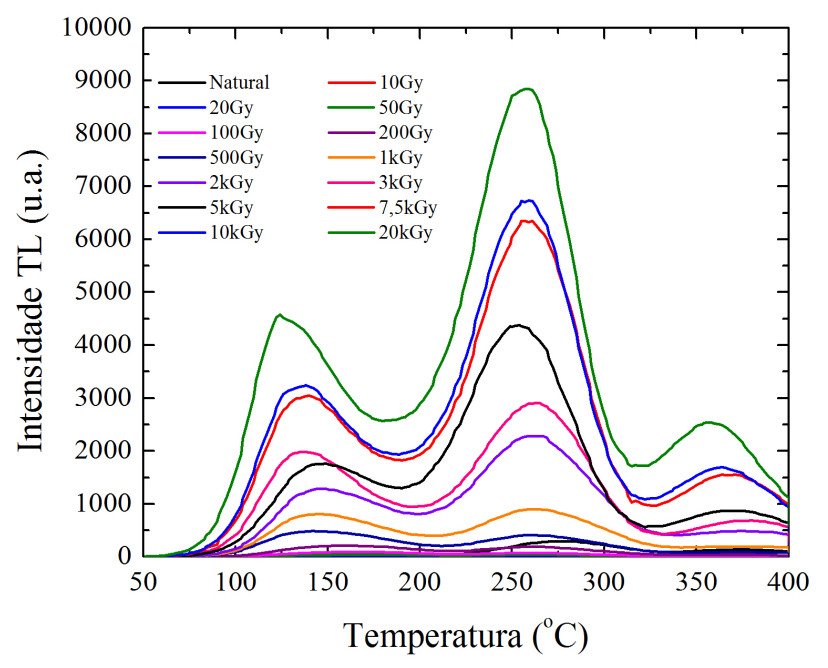

Figura 4.3: Curvas de emissão do Lapis Lazuli natural submetido a tratamento térmico de $600^{\circ} \mathrm{C}$ por meia hora e posteriormente irradiada com doses de 10 Gy até $20 \mathrm{kGy}$. 
a existência de processos de competição entre os defeitos pela captura de portadores de carga.

Após a medida de TL da amostra natural, separamos da amostra não usada em porções para serem irradiadas com doses crescentes de radiação gamma entre $10 \mathrm{~Gy}$ e $20 \mathrm{kGy}$, com tratamento térmico prévio de $600^{\circ} \mathrm{C}$ durante meia hora. Na figura 4.3, é possível observar dois picos: um pico em torno de $140^{\circ} \mathrm{C}$, o segundo em torno de $255^{\circ} \mathrm{C}$, que cresce linearmente até $3 \mathrm{kGy}$ e satura para doses acima de 7,5 kGy como se pode ver na figura 4.5. A partir de $3 \mathrm{kGy}$, apareceu um terceiro pico em $350^{\circ} \mathrm{C}$.

Esse resultado mostra que o pico de $255^{\circ} \mathrm{C}$ pode ser usado em dosimetria entre doses baixas e 10 kGy. Mesmo o primeiro pico pode ser usado em dosimetria até 5kGy. Em seguida, para ver o comportamento da intensidade TL em

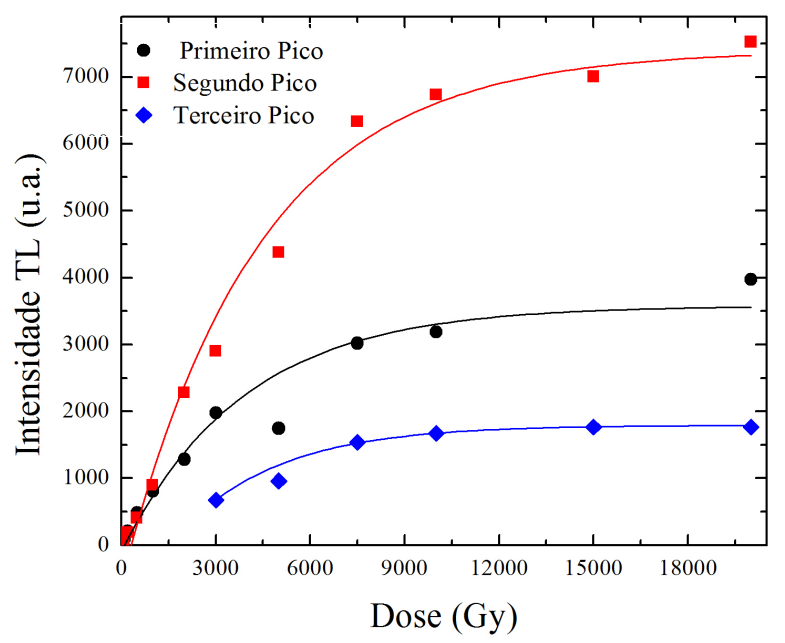

Figura 4.4: Intensidade dos picos da figura 4.3 em função da dose de radiação.

relação à dose para cada pico, foram obtidas as curvas da intensidade TL dos três picos, em função da dose. O resultado é mostrado na figura 4.4, para os três picos. Na Figura 4.5, a curva do segundo pico da figura 4.4 foi 


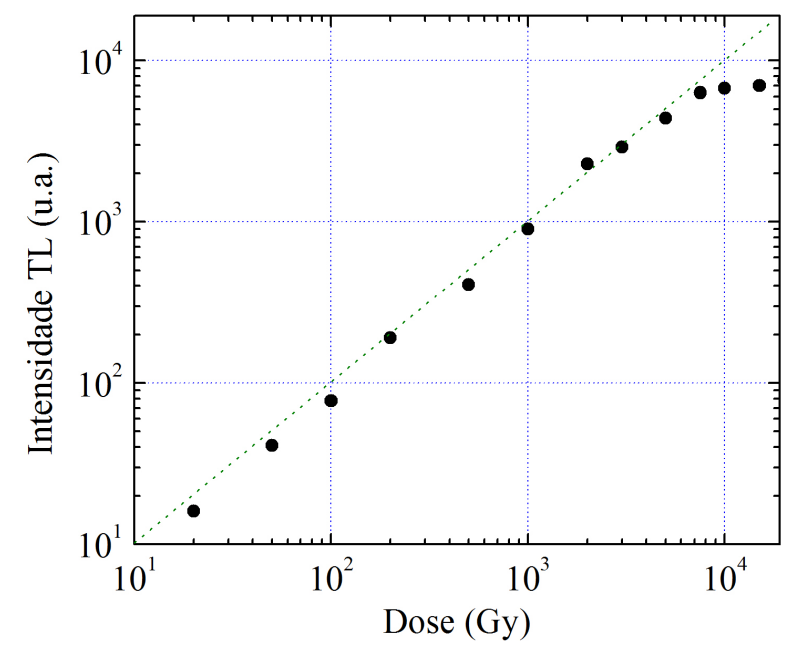

Figura 4.5: Comportamento do segundo pico em função da dose.

representada em escala log. Pode-se ver que ela é linear até cerca de 7-8 kGy.

\subsubsection{Tratamento térmico (TT)}

As amostras foram tratadas termicamente em $900^{\circ} \mathrm{C}, 1000^{\circ} \mathrm{C}, 1100^{\circ} \mathrm{C}$,seguido de um esfriamento rápido. Depois disso foram irradiadas com dose de radiação gamma de $2 \mathrm{kGy}$.

O comportamento das curvas de emissão TL para os diversos tratamentos térmicos efetuados é mostrado na figura 4.6, onde fazendo a comparação da curva de TL da amostra com TT de $900^{\circ} \mathrm{C}$ com aquela de $1100^{\circ} \mathrm{C}$, observou se que o primeiro pico cresceu quase 10 vezes e o segundo pico 4 vezes.

\subsubsection{Decaimento Anômalo da TL}

O desvanecimento na temperatura ambiente, mais conhecido pela denominação, em inglês, "Anomalous Fading ", como foi mencionado na secção 2.6.5, 


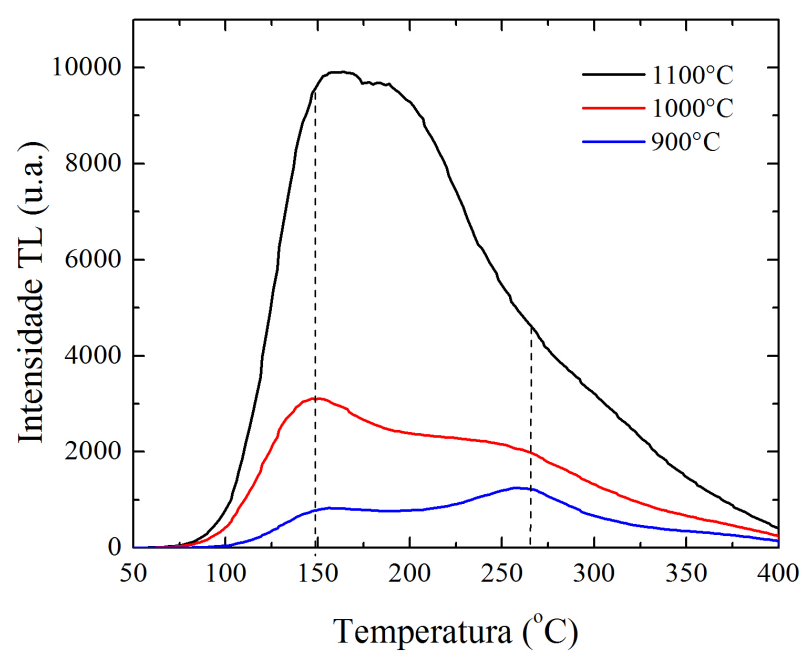

Figura 4.6: Curvas de emissão TL do lapis lazuli natural submetidas ao tratamento térmicos de $900^{\circ} \mathrm{C}, 1000^{\circ} \mathrm{C}, 1100^{\circ} \mathrm{C}$, e posteriormente irradiada com dose gama de $2 \mathrm{k} G y$.

consiste na liberação espontânea dos elétrons das armadilhas na temperatura ambiente. Portanto, um material TL irradiado nunca vai reter $100 \%$ das cargas armadilhadas. Isso é prejudicial na dosimetria da radiação e influi negativamente, também nas datações.

O grau desse efeito varia de cristal para cristal. Como veremos, em seguida, Lápis Lazuli apresenta forte decaimento anômalo. Para saber em que porcentagem o sinal de TL decai com o passar do tempo, fizemos várias medidas de uma porção da amostra com dose de $2 \mathrm{kGy}$, em função do tempo logo de ela ser irradiada, que são apresentadas na figura 4.7. A figura 4.8 e 4.9 apresentam as curvas de decaimento das intensidades TL do primeiro pico e do segundo, respectivamente em função do tempo, na temperatura ambiente. As amostras foram antes submetidas ao TT de $600^{\circ} \mathrm{C}$. Nas Figuras 4.8 


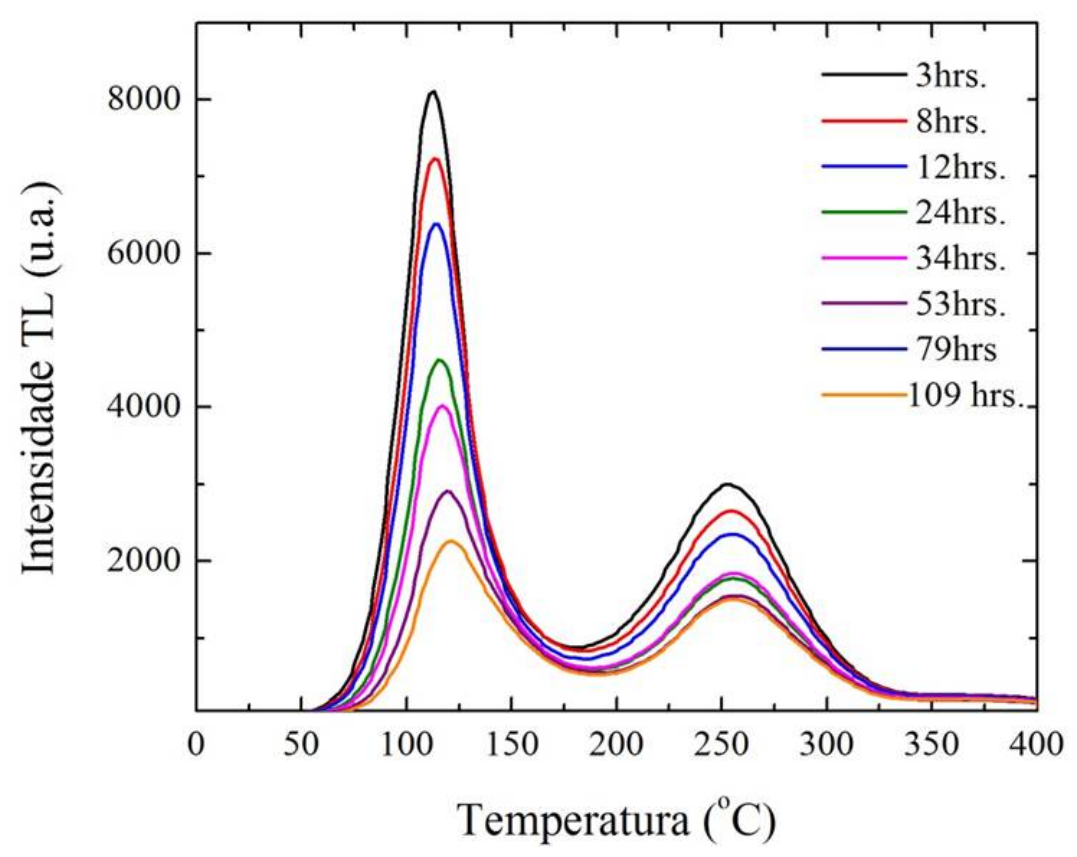

Figura 4.7: TL do lapiz lazuli iradiada con $2 k G y$ em tempos diferentes, segundo o indicado no grafico.

e 4.9 podemos ver que o decaimento anômalo é acentuado. O pico um decaiu quase o $50 \%$ em cerca de 20 horas; o pico 2, no mesmo intervalo de tempo, decaiu aproximadamente o $20 \%$.

\subsection{Análise das curvas de termoluminescência e determinação dos parâmetros $E$ e $s$}

Nesta parte, iremos analisar as curvas de TL, com os métodos explicados na secção 2.6, tentando encontrar, assim, o valor da energia de ativação $(E)$, a profundidade na qual se encontra cada armadilha, e o fator de frequência $(s)$. 


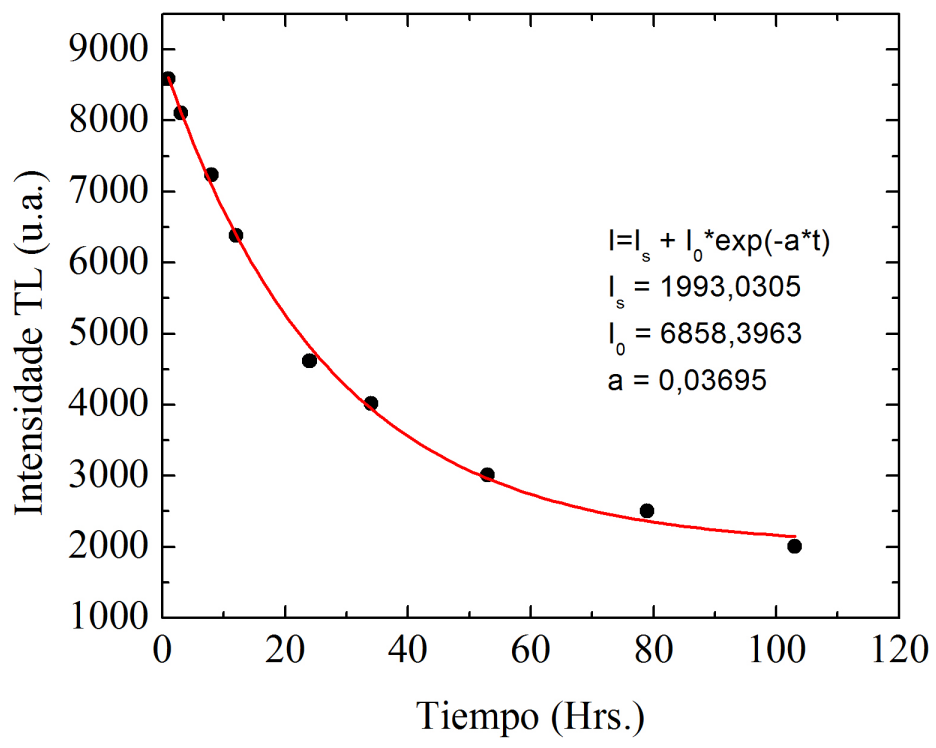

Figura 4.8: Curva da intesidade de TL en função do tempo para o primeiro pico na temperatura ambiente.

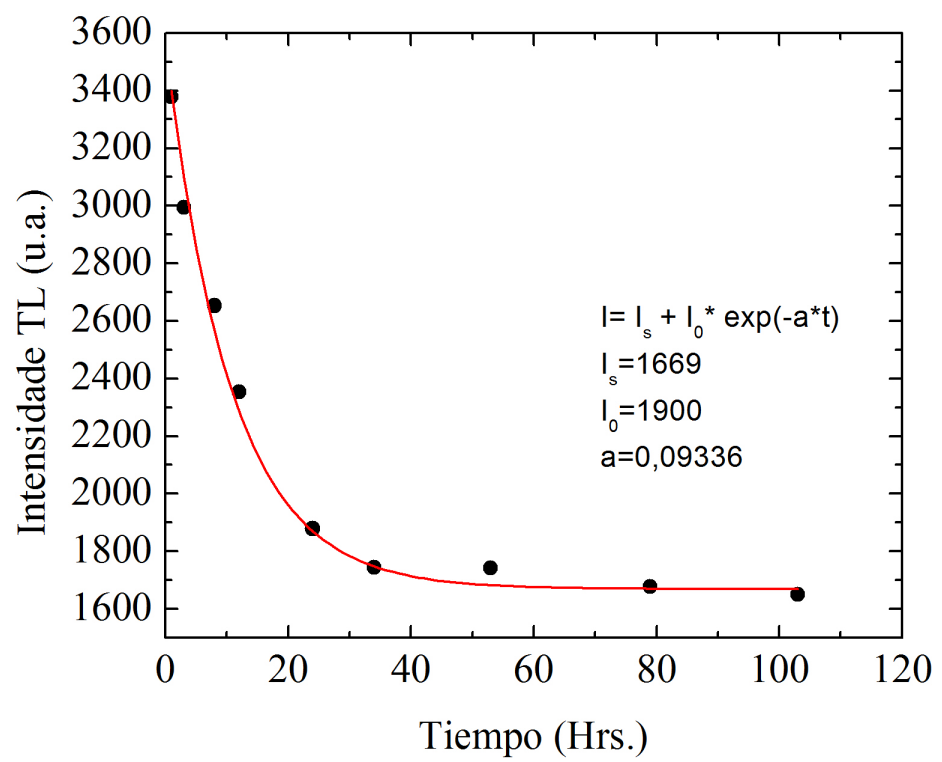

Figura 4.9: Curva da intesidade de TL en função do tempo para o segundo pico. 


\subsubsection{Determinação de $E$ e $s$}

\section{Método de varias taxas de aquecimento}

Na figura 4.10, apresentamos o efeito da mudança da taxa de aquecimento, $\beta$. Na leitura a variação da temperatura máxima $\left(T_{m}\right)$ e intensidade máxima $\left(I_{m}\right)$ da curva de TL é então, anotada. Usando a equação 2.35, com os valores de $I_{m}$ e $T_{m}$ das curvas da figura 4.10, foram obtidos os valores de $E$ dos dois picos, dados na tabela 4.1. Os valores obtidos foram bem acima do esperado.

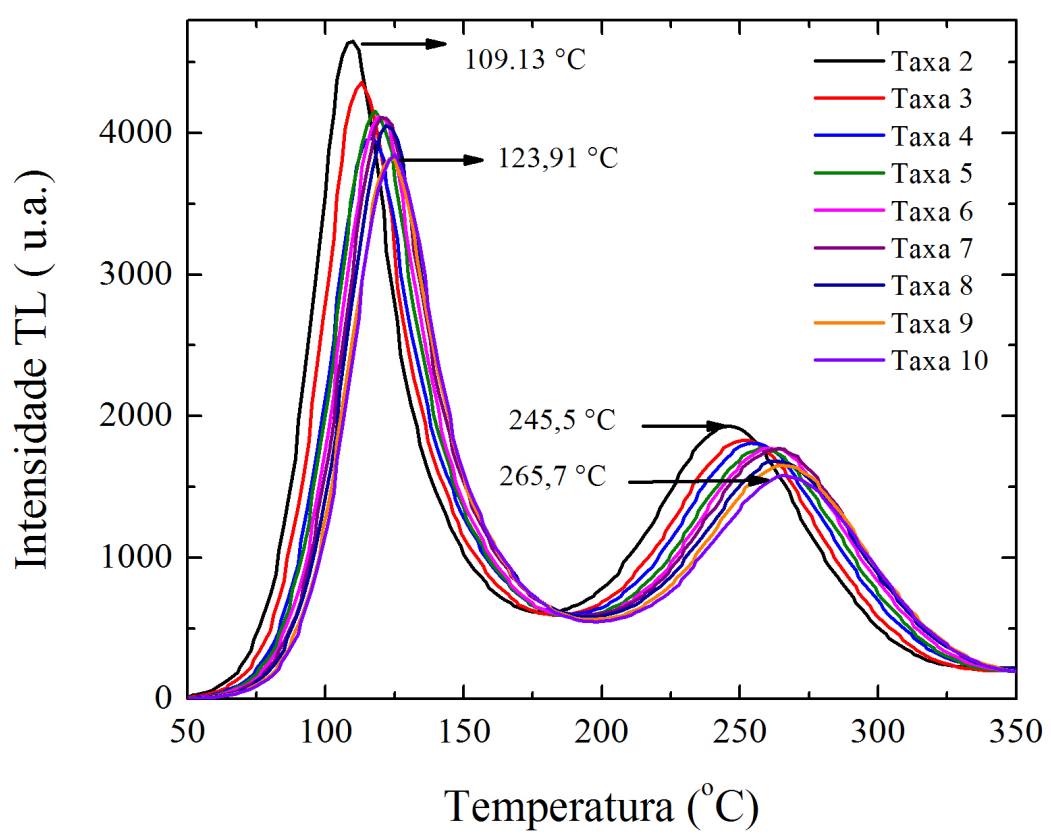

Figura 4.10: Método de várias taxas de aquecimento. Neste método se utiliza a mudança do parâmetro $\beta$. 


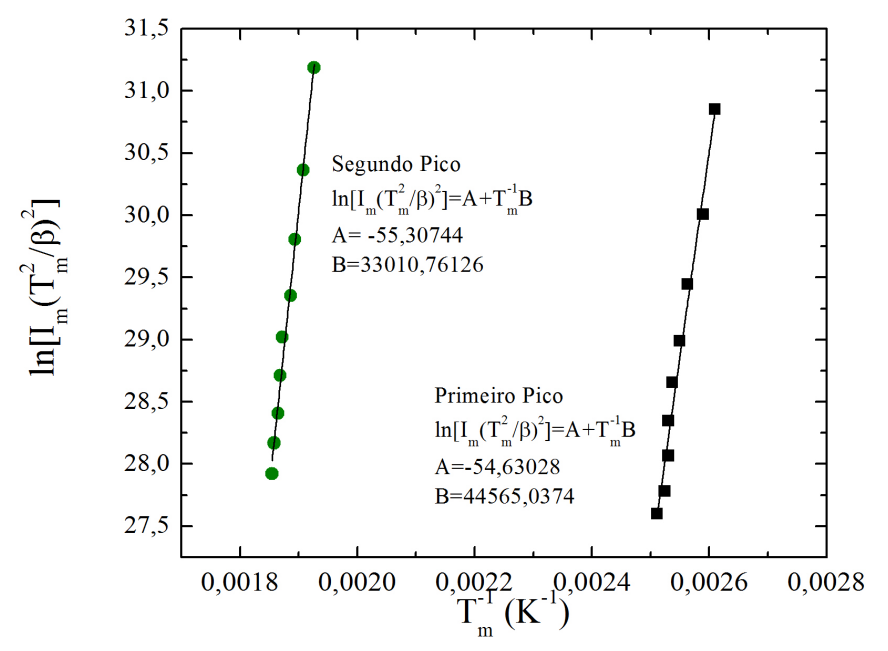

Figura 4.11: Logaritmo do primeiro membro da equação contra $\frac{1}{T_{m}}$ para o primeiro e segundo pico da figura 4.10. Cinética de $2^{\circ}$ ordem.

Tabela 4.1: Energia E do primeiro e segundo pico no método de varias taxas de aquecimento.

\begin{tabular}{lc}
\hline \hline & Energia $(\mathrm{eV})$ \\
\hline Primeiro Pico & 2,84 \\
\hline \hline Segundo Pico & 3,84 \\
\hline
\end{tabular}

\section{Método de Forma do Pico}

Apartir do método da forma do pico, com a fórmula mostrada na secção 2.6, analisamos uma amostra irradiada com 2 kGy.

Na tabela 4.2 usando a taxa de aquecimento de $4^{\circ} \mathrm{C} / \mathrm{s}$, temos as temperaturas $T_{1}, T_{m}, T_{2}$ e dai os valores de $\tau, \delta, \omega$, e obtemos também os valores do fator geométrico $\mu_{g}$, indicando que o pico é cinética de segunda ordem.

É interessante observar que, fazendo a leitura TL com diferente taxas de 
aquecimento como já é conhecido, obtém-se $T_{m}$ crescendo com a taxa de aquecimento, além da intensidade $I_{m}$ máxima em $T_{m}$ diminui ligeiramente com a taxa $\beta$; as larguras $\omega, \tau$ e $\delta$ também crescem com a taxa de aquecimento. Os valores de $T_{1}, T_{m}, T_{2}, \tau, \delta, \omega$ extraídos das curvas da figura 4.12, aparecem na tabela 4.2 para os dois picos, substituindo os valores da tabela 2.1 , pagina 27 , na equação 2.33 , foram obtidos os valores da tabela 4.3 .

Esses valores serão comparados com aqueles obtidos por outros métodos. O método da forma do pico é útil quando se trabalha com picos isolados, é devido a isso que a energia encontrada para o primeiro pico é maior do que para o segundo ( como se pode observar na tabela 4.3), nosso caso é útil para o primeiro pico, que é um valor muito mais próximo do valor realístico.

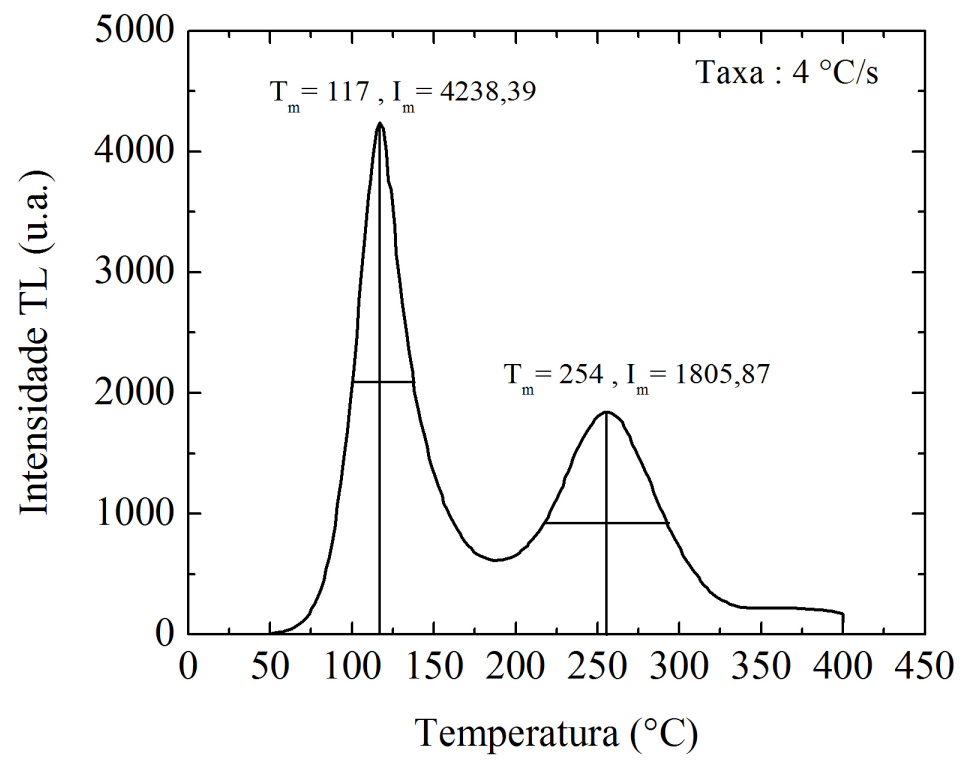

Figura 4.12: Curva TL que foi utilizada para encontrar os valores da energia do primeiro e segundo pico pelo método da forma do pico, medida feita com taxa de aquecimento de $4^{\circ} \mathrm{C} / \mathrm{s}$. 
Tabela 4.2: Valores obtidos para $\tau, \delta, \omega$. Pela relação das equações 2.6.1, obtemos os valores do fator geométrico $\mu_{g}$.

\begin{tabular}{cccccccc}
\hline \hline Pico & $T_{1}\left({ }^{\circ} \mathrm{C}\right)$ & $T_{m}\left({ }^{\circ} \mathrm{C}\right)$ & $T_{2}\left({ }^{\circ} \mathrm{C}\right)$ & $\tau$ & $\delta$ & $\omega$ & $\mu_{g}$ \\
\hline 1 & 98,87 & 117 & 137,66 & 18,13 & 20,66 & 38,79 & 0,53 \\
2 & 216,51 & 254 & 292,17 & 37,49 & 38,17 & 75,67 & 0,50 \\
\hline \hline
\end{tabular}

Tabela 4.3: Valores de energia e fator de frequência pelo Método da forma do pico.

\begin{tabular}{ccccccc}
\hline \hline Pico & $E_{\tau}$ & $E_{\delta}$ & $E_{\omega}$ & $s_{\tau}$ & $s_{\delta}$ & $s_{\omega}$ \\
\hline 1 & 1,199 & 1,142 & 1,241 & $1,06 \mathrm{E}+15$ & $1,84 \mathrm{E}+14$ & $4,76 \mathrm{E}+15$ \\
2 & 0,951 & 1 & 1.07 & $7,14 \mathrm{E}+07$ & $5,47 \mathrm{E}+08$ & $2,82 \mathrm{E}+09$ \\
\hline \hline
\end{tabular}

Método $T_{m}-T_{\text {stop }}$

Para utilizar o método de $T_{m}-T_{\text {stop }}$ com uma amostra submetida ao TT em $600^{\circ} \mathrm{C}$ por media hora e irradiada com $2 \mathrm{kGy}$, adotamos o seguinte procedimento:

- Partindo da temperatura ambiente $T_{0}$, a amostra é aquecida com taxa constante até uma temperatura $T_{\text {stop }}$, que aumenta de $5^{\circ} \mathrm{C}$ em $5^{\circ} \mathrm{C}$, isto é, $T_{\text {stop }}=55^{\circ} \mathrm{C}$;

- Atingida a primeira temperatura $T_{\text {stop }}$, registramos TL e paramos o aquecimento e resfriamos a amostra até a temperatura ambiente;

- em seguida, a amostra é aquecida novamente, com a mesma taxa de aquecimento até o segundo $T_{\text {stop }}$ e, assim por diante, até uma temperatura que contenha todos os picos TL. 


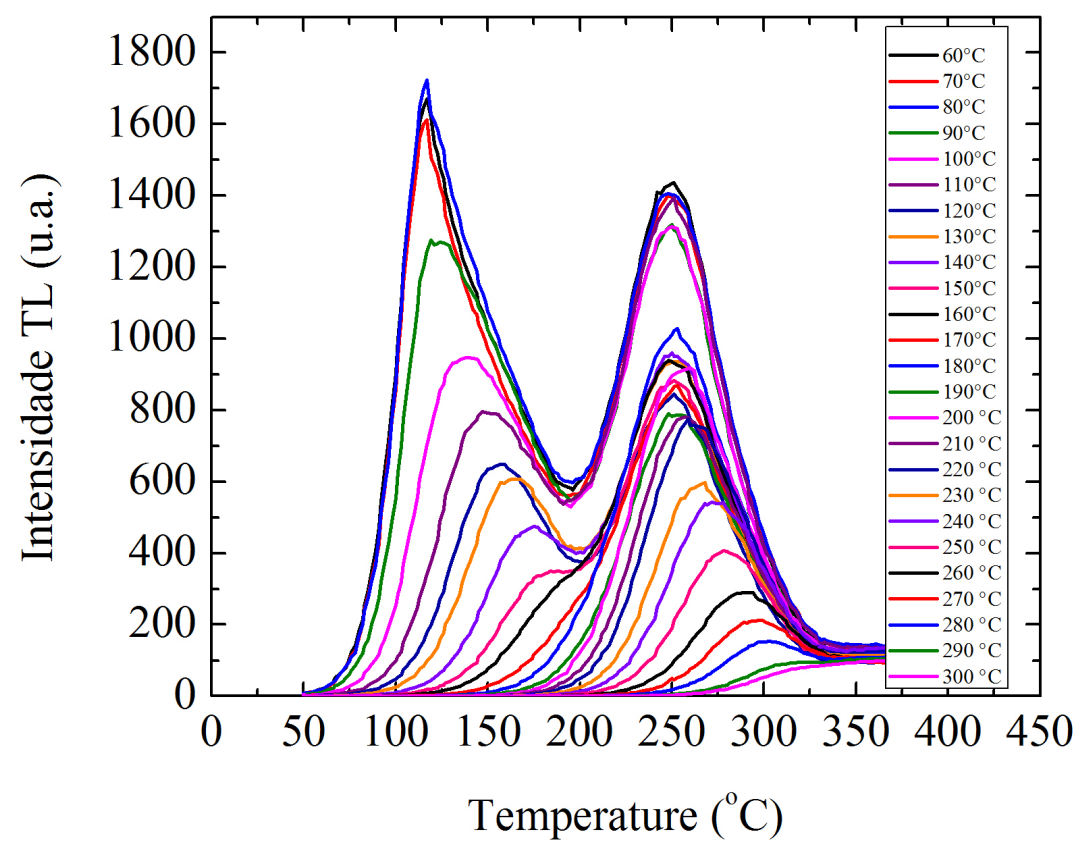

Figura 4.13: Curvas TL submetida ao método $T_{m}-T_{\text {stop }}$, com saltos de temperatura de $5{ }^{\circ} \mathrm{C}$.

- Anotamos a temperatura $T_{m}$ que é a temperatura máxima do pico mais próximo à $T_{\text {stop }}$.

- Os valores obtidos são colocados em um gráfico $T_{m}-T_{\text {stop }}$.

Foram analisadas 48 curvas TL. Na figura 4.13 são apresentadas apenas 24 para uma melhor visualização. O gráfico da curva $T_{m}-T_{\text {stop }}$ é apresentada na figura 4.14 .

Onde em torno de $115^{\circ} \mathrm{C}$ aparece um primeiro pico, o segundo em $160^{\circ} \mathrm{C}$, o terceiro em $250^{\circ} \mathrm{C}$ e quarto em $299^{\circ} \mathrm{C}$. Comparando esse resultado com a curva de emissão da figura 4.3 , nota-se que os picos em $115^{\circ} \mathrm{C}$ e em $160^{\circ} \mathrm{C}$ obtidos pelo método $T_{m}-T_{\text {stop }}$ aparecem superpostos na curva experimental, dando a impressão de que só há um pico em torno de $120-140^{\circ} \mathrm{C}$. Se bem 


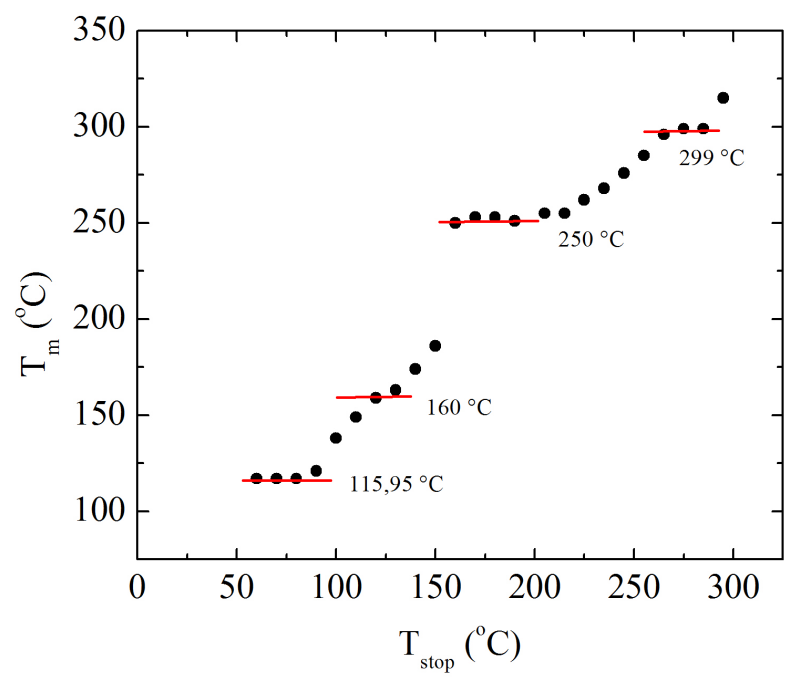

Figura 4.14: Curvas TL submetida ao método $T_{m}$ vs. $T_{\text {stop }}$, com saltos de temperatura de $5^{\circ} \mathrm{C}$.

que, com a irradiação, o pico de temperatura mais baixa parece crescer mais rapidamente com a dose e, com a dose em torno de $10 \mathrm{kGy}$, o pico em $115^{\circ} \mathrm{C}$ torna-se predominante.

\section{Deconvolução das curvas}

A deconvolução das curvas de emissão foram obtidas dos dados obtidos nos métodos anteriores, para as curvas obtidas do método de diferentes taxas de aquecimento na leitura TL. Vimos que, aplicando o método de várias taxas de aquecimento aos dois picos da amostra de lapis lazuli e considerando que elas são de segunda ordem, foram obtidos valores de E bem acima do esperado. Não foi encontrado o porquê desse resultado; é possível que o decaimento anômalo esteja interferindo, mas é difícil de visualizar como isso pode afetar. Passamos, então, a efetuar a deconvolução das curvas de emissão obtidas para as diferentes taxas de aquecimento. Aqui, foram reproduzidas, somente, as 
Tabela 4.4: Posição dos picos 1,2,3 e 4 para taxa de aquecimento $\beta$ de $2{ }^{\circ} \mathrm{C} / \mathrm{s}$ e $10{ }^{\circ} \mathrm{C} / \mathrm{s}$.

\begin{tabular}{ccccc}
\hline$\beta\left({ }^{\circ} \mathrm{C} / \mathrm{s}\right)$ & $T_{1}\left({ }^{\circ} \mathrm{C}\right)$ & $T_{2}\left({ }^{\circ} \mathrm{C}\right)$ & $T_{3}\left({ }^{\circ} \mathrm{C}\right)$ & $T_{4}\left({ }^{\circ} \mathrm{C}\right)$ \\
\hline \hline 2 & 109,84 & 115,9 & 191 & 245 \\
\hline 10 & 123 & 163 & 214,5 & 266 \\
\hline
\end{tabular}

curvas de emissão para taxa de aquecimento de $2{ }^{\circ} \mathrm{C} / \mathrm{s}$ ( figura 4.15) e de 10 ${ }^{\circ} \mathrm{C} / \mathrm{s}$ ( figura 4.16). A deconvolução indica quatro picos cujas $T_{m}$ aparecem na tabela 4.4 .

Embora os valores da E não sejam altos demais, a pequena variação, indo de pico 1 ao pico 4, não parece realístico. Veremos os valores obtidos com outros métodos.

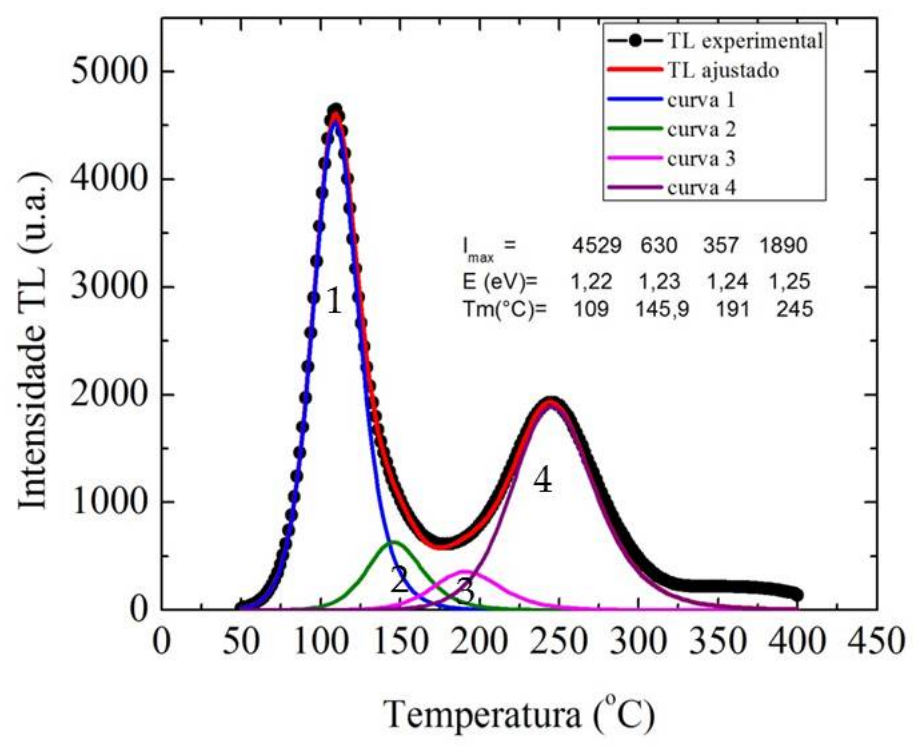

Figura 4.15: Deconvolução da curva de emissão de taxa $2^{\circ} \mathrm{C} / \mathrm{s}$. 


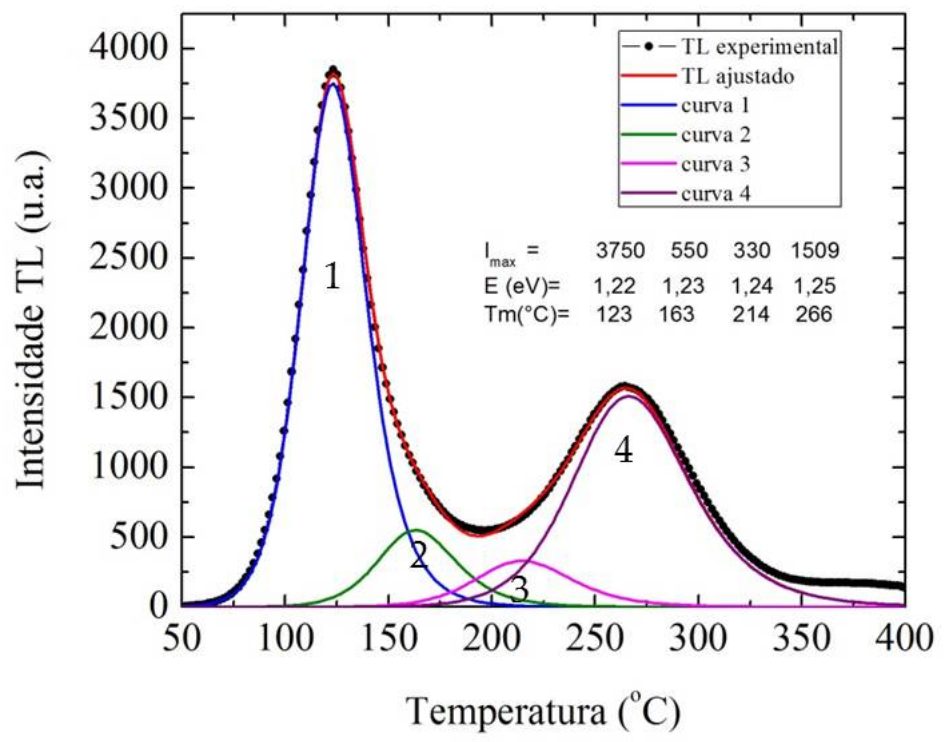

Figura 4.16: Deconvolução da curva de emissão de taxa $10^{\circ} \mathrm{C} / \mathrm{s}$.

Tabela 4.5: Energia eV) dos picos $1,2,3$ e $4 \beta=2{ }^{\circ} \mathrm{C} / \mathrm{s}$ e $\beta=10^{\circ} \mathrm{C} / \mathrm{s}$.

\begin{tabular}{ccccc}
\hline$\beta\left({ }^{\circ} \mathrm{C} / \mathrm{s}\right)$ & $E_{1}(\mathrm{eV})$ & $E_{2}(\mathrm{eV})$ & $E_{3}(\mathrm{eV})$ & $E_{4}(\mathrm{eV})$ \\
\hline \hline 2 & 1,22 & 1,23 & 1,24 & 1,25 \\
\hline 10 & 1,22 & 1,23 & 1,24 & 1,25 \\
\hline
\end{tabular}

\subsection{Medidas experimentais de Ressonância Pa- ramagnética}

Como foi dito em 2.7, o fenômeno de ressonância paramagnética eletrônica é um fenômeno de absorção de fótons de microondas por um material submetido a um campo magnético estático externo. Em uma medida de EPR, na prática, o comprimento de onda, ou frequência da radiação $(\nu)$, é mantido constante e através de um aumento de intensidade do campo magnético aplicado à amostra, verifica-se a absorção do fóton que dá o sinal de EPR. 


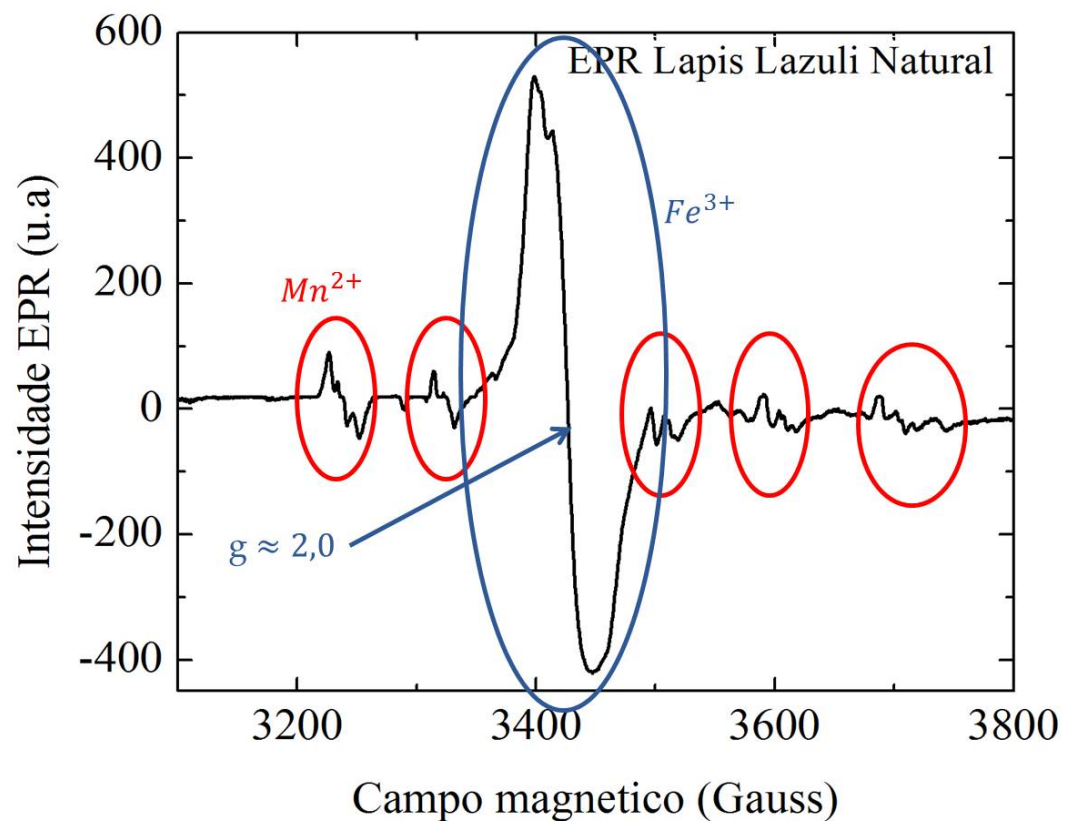

Figura 4.17: Espectro EPR de lapis lazuli natural. Medida feita em temperatura ambiente com uma frequência de microonda de 9,761 GHz,banda X e uma potência de 1,011 $\mathrm{mW}$, para $250 \mathrm{mg}$ de amostra.

Um espectro de EPR pode ter uma só ou um grande número de linhas de absorção, dependendo de centros paramagnéticos na amostra.

\subsubsection{Amostra natural}

As medidas de EPR da amostra natural, foram feitas utilizando uma potência de microonda de 1,011 mW, e frequência de 9,765 GHz. Na figura 4.17 é apresentado o espectro de EPR de amostra de Lapis Lazuli natural em um intervalo de campo magnético de 3100 até 3800 Gauss. Dois sinais podem ser vistos, um devido ao $\mathrm{Fe}^{3+}$ com $\mathrm{g} \simeq 2,0$ e outro composto de seis linhas devido a $M n^{2+}$. O sinal em $g \simeq 2,0$ tem na realidade, um segundo sinal, possivelmente, devido a $\mathrm{Fe}^{3+}$ em diferente lugar. 


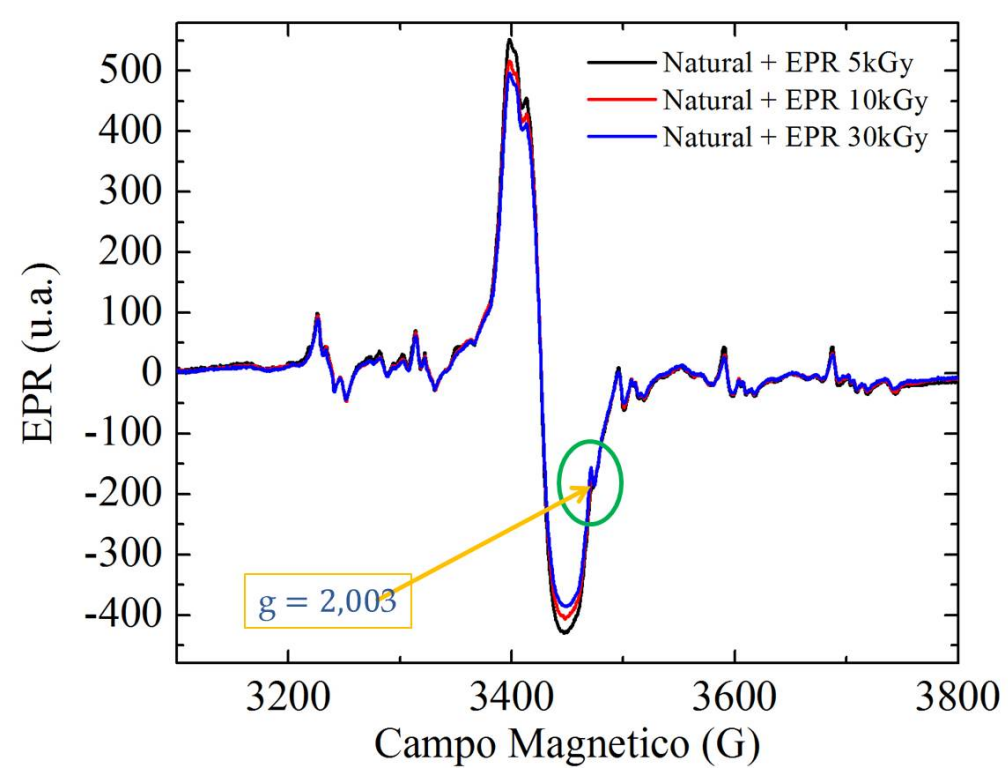

Figura 4.18: Espectro de EPR de lapis lazuli irradiada com radiação gama de $5 \mathrm{k} G y, 10 \mathrm{k} G y, 30 \mathrm{kGy}$.

Com objetivo de provocar mudanças nos sinais EPR da amostra natural, a amostra de lapis lazuli foi irradiada com doses gama de 5kGy, 10kGy e 30kGy. Como resultado adicional aos sinais de $\mathrm{Fe}^{3+}$ e $\mathrm{Mn}^{2+}$, agora aparece um sinal em $\mathrm{g}=2.003$, que é bem evidenciado quando se faz a medida com uma desfasagem de $94^{\circ}$ em relação à normal (fase $0^{\circ}$ ). Isso se vê na figura 4.20. O sinal em 3465 gauss é bem visível porque, com a medida de $94^{\circ}$ de defasagem, o sinal grande de $\mathrm{Fe}^{3+}$ fica bem reduzido. Presume-se que o sinal que apareceu devido à irradiação intensa é um centro F. Para provocar mudanças nas sinais de EPR da amostra natural, ela foi irradiada com doses gama de 5kGy, 10kGy, 30kGy, podemos observar nas figura 4.18 esses espectros. 


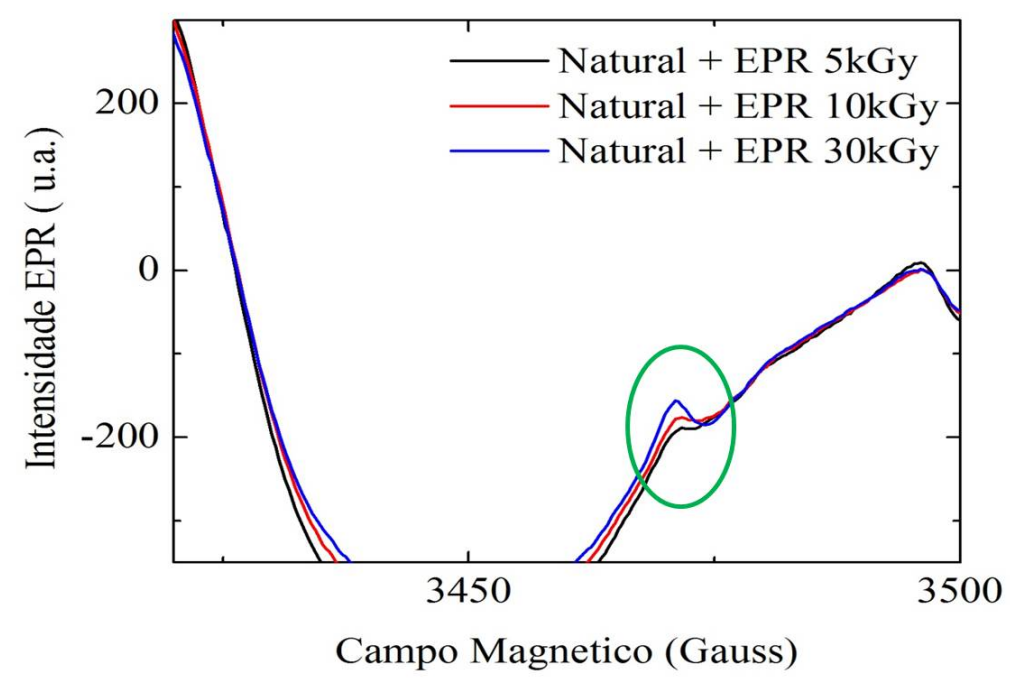

Figura 4.19: Espectro de EPR de lapis lazuli irradiada com radiação gama de $5 \mathrm{k} G y, 10 \mathrm{k} G y, 30 \mathrm{k} G y$.

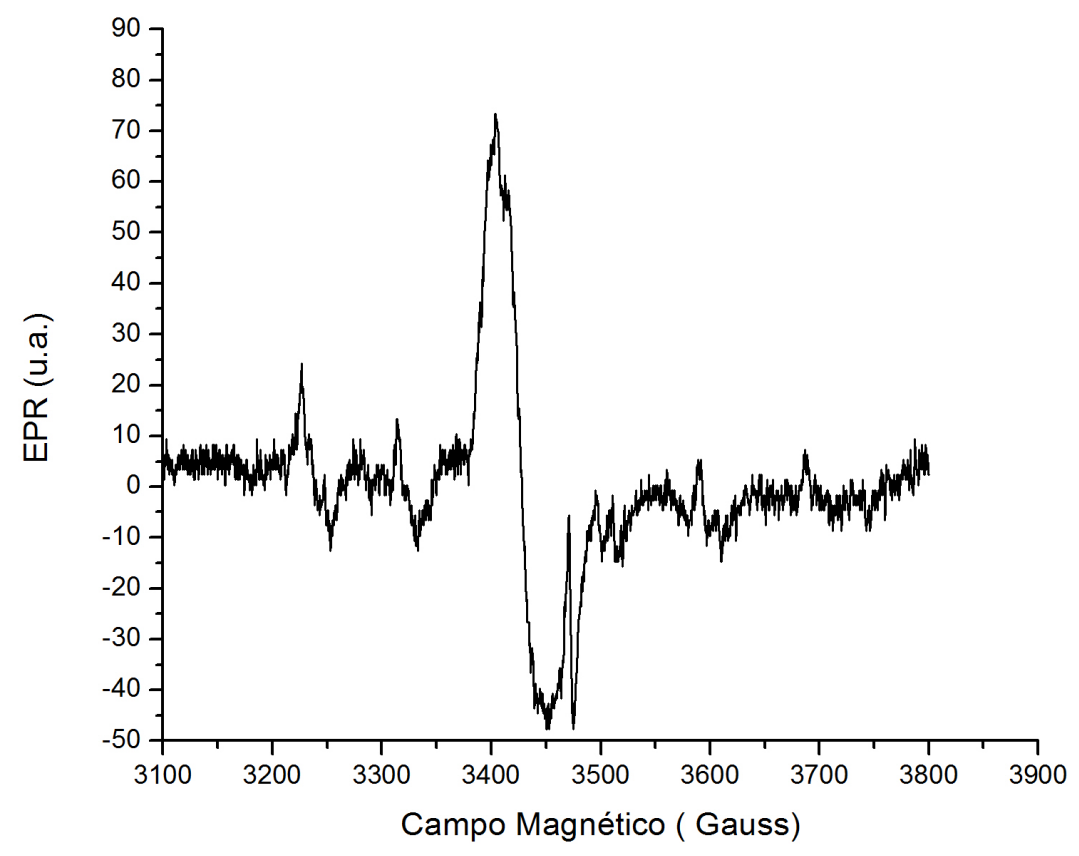

Figura 4.20: Espectro de EPR de lapis lazuli com desfasagfem de $94^{\circ}$. 


\subsection{Medidas de refletância}

Não foi possível obter lâminas de Lapis Lazuli para a medida de absorção ótica, motivo pelo qual medimos a sua refletância.

\subsubsection{Refletância da amostra natural}

A figura 4.21 mostra o espectro de refletância da amostra natural, onde podem ser observadas várias bandas no infravermelho próximo. A relação

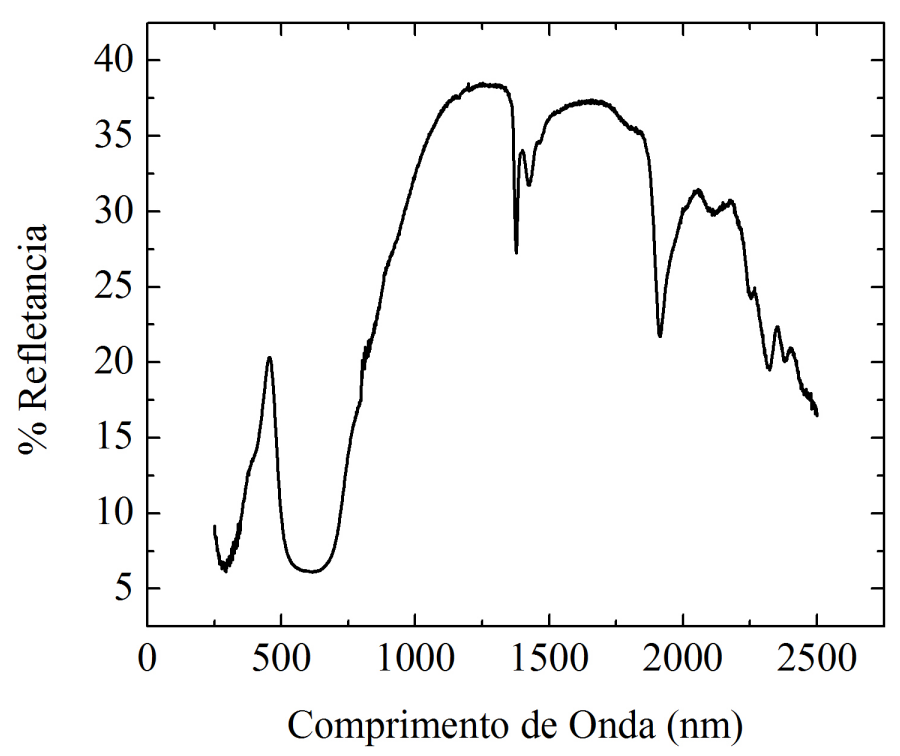

Figura 4.21: Espetro de refletância de lapis lazuli natural.

entre a refletância e a absorbância é dada pela fórmula [6]:

$$
A=\log (1 / R)
$$

A figura 4.22 dá a curva de absorbância ótica obtida usando a fórmula 4.1. Uma banda intensa de absorção é observada para valores menores a $400 \mathrm{~nm}$ 
e maiores a $520 \mathrm{~nm}$ deixando um vale entre $400 \mathrm{~nm}$ e $520 \mathrm{~nm}$; este vale é o que dá a cor característico de lapis Lazuli.

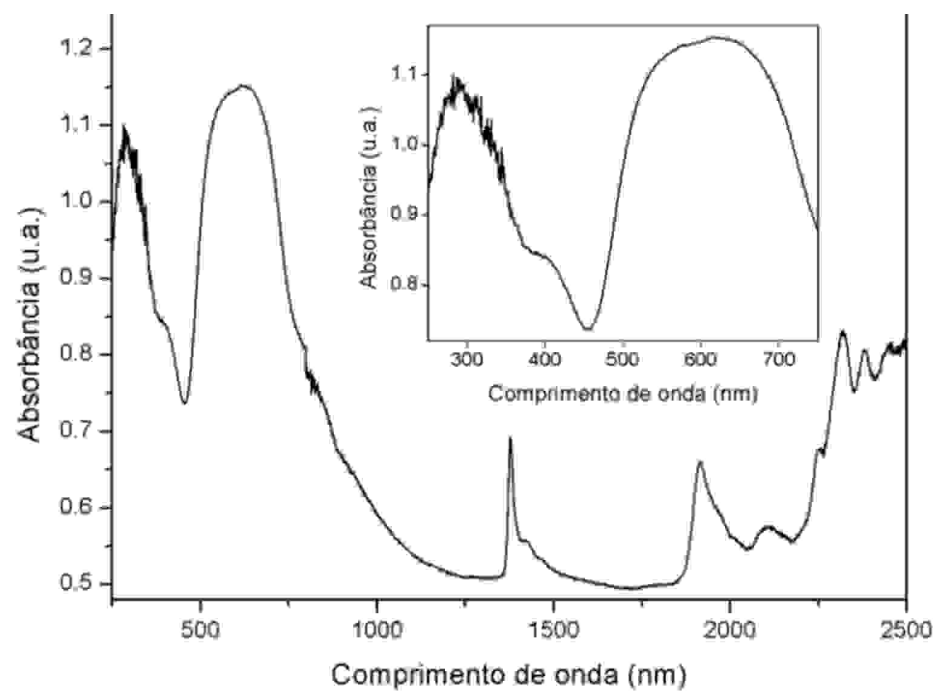

Figura 4.22: Espectro de absorvância de lapis lazuli natural. 


\section{Conclusões}

1. A solução sólida é muito complexa e, do resultado de medidas de fluorescência de RX, não foi possível determinar a porcentagem de cada componente.

2. Enquanto a amostra recozida em $600^{\circ} \mathrm{C} / 30 \mathrm{~min}$. e irradiada com várias doses apresenta três picos em $120^{\circ} \mathrm{C}-140^{\circ} \mathrm{C}, 250^{\circ} \mathrm{C}$ e $350^{\circ} \mathrm{C}$, a amostra natural apresentou só dois, um em $290^{\circ} \mathrm{C}$ e outro em $370^{\circ} \mathrm{C}$, porque a amostra natural ficou no subsolo por um tempo muito longo, quanto não sabemos e, deve ter sofrido, principalmente,o efeito de temperatura e pressão.

3. O Lapiz Lazuli apresentou um decaimento anômalo acentuado. O primeiro e segundo pico decaíram quase $50 \%$ em 20 horas.

4. Na irradiação com diferentes doses, o pico 2 cresceu mais rapidamente que o primeiro, e o terceiro cresceu bem mais lentamente. O segundo pico cresceu linearmente com a dose, saturando-se em torno de 7 - 8 kGy, o que indicaria que o lapis lazuli poderia ser usado na dosimetria da radiação até esta dose, mas pela presença do decaimento anômalo 
ele não seria um bom dosímetro.

5. O tratamento térmico (TT) em temperaturas acima de $900^{\circ} \mathrm{C}$ tornou a TL de lapis lazuli mais sensivel. Em $1100^{\circ} \mathrm{C}$, o primeiro pico cresceu mais 10 vezes em relação ao pico da curva de TL com TT de $900^{\circ} \mathrm{C}$ e o segundo pico 4 vezes mais.

6. Na determinação experimental dos parâmetros $E$ e $s$.

- Usando o método de varias taxas de aquecimento para uma cinética de segunda ordem, foram obtidos valores altos demais de energia $1^{\circ}$ pico $2,81 \mathrm{eV}$. e $2^{\circ}$ pico $3.84 \mathrm{eV}$; não foi encontrada a causa.

- Nesse método de várias taxas de aquecimento, usando a deconvolução das curvas de emissão, foram revelados 4 picos, cujas energias são de valores aceitáveis de 1,22; 1,23; 1,24 e 1,25 eV; embora era esperado para o primeiro pico um valor em torno de $1,0 \mathrm{eV}$.

- $\mathrm{O}$ método de forma do pico produziu para o primeiro pico $\mathrm{E} \approx$ $1,99 \mathrm{eV}$. E do segundo pico $\mathrm{E} \approx 1,07 \mathrm{eV}$, já que o método é útil para picos isolados.

7. O método de $T_{m}-T_{\text {stop }}$ mostrou que há quatro picos em $116^{\circ} \mathrm{C}, 160^{\circ} \mathrm{C}$, $250^{\circ} \mathrm{C}$ e $299^{\circ} \mathrm{C}$, sugerindo que o pico experimental em $120-140^{\circ} \mathrm{C}$ é uma superposição dos picos em $116^{\circ} \mathrm{C}$ e $160^{\circ} \mathrm{C}$.

8. O espectro EPR de uma amostra natural consistiu de 6 sinais de $M n^{2+}$ e um sinal grande típico de $F e^{3+}$ em $\mathrm{g}=2,0$.

9. A amostra irradiada com doses de alguns kGy apresentou um sinal pequeno em $\mathrm{g}=0,003$, devido ao centro $\mathrm{F}$ induzido pela radiação; uma 
medida feita com uma defasagem de $94^{\circ}$ reduz drasticamente o sinal grande em $\mathrm{g}=2.0$, tornando mais evidente o sinal em $\mathrm{g}=2.003$. 


\section{Bibliografia}

[1] W. A. Deer, R. A. Howie, J. Zussman, et al., An introduction to the rock-forming minerals, vol. 696. Longman London, 1992.

[2] S. Calusi, Set-up and applications of microanalysis techniques on materials of technological and cultual heritage interest by using external microbeamsof few MeV energy ions. PhD thesis, universita degli studi di Torino, 2010.

[3] K. . Wedepohl Geochemistry. New York: Holt, Rinehart 8 Winston., 1971 .

[4] W. Jinyu and F. Liangbo, "A study on the electron paramagnetic resonance of coloration mechanism of ultramarine pigment," Chinese Journal of Analytieal Chemistry, vol. 10, p. 009, 1994.

[5] A. L. Giudice, A. Re, S. Calusi, L. Giuntini, M. Massi, P. Olivero, G. Pratesi, M. Albonico, and E. Conz, "Multitechnique characterization of lapis lazuli for provenance study," Analytical and bioanalytical chemistry, vol. 395, no. 7, pp. 2211-2217, 2009.

[6] M. Bacci, C. Cucci, E. Del Federico, A. Ienco, A. Jerschow, J. M. Newman, and M. Picollo, "An integrated spectroscopic approach for the 
identification of what distinguishes afghan lapis lazuli from others," $V i$ brational Spectroscopy, vol. 49, no. 1, pp. 80-83, 2009.

[7] C. M. Schmidt, M. S. Walton, and K. Trentelman, "Characterization of lapis lazuli pigments using a multitechnique analytical approach: implications for identification and geological provenancing," Analytical chemistry, vol. 81, no. 20, pp. 8513-8518, 2009.

[8] M. Bicchieri, M. Nardone, P. Russo, A. Sodo, M. Corsi, G. Cristoforetti, V. Palleschi, A. Salvetti, and E. Tognoni, "Characterization of azurite and lazurite based pigments by laser induced breakdown spectroscopy and micro-raman spectroscopy," Spectrochimica Acta Part B: Atomic Spectroscopy, vol. 56, no. 6, pp. 915-922, 2001.

[9] N. Grassi, A. Migliori, P. Mando, and H. C. Del Castillo, "Identification of lapis-lazuli pigments in paint layers by pige measurements," Nuclear Instruments and Methods in Physics Research Section B: Beam Interactions with Materials and Atoms, vol. 219, pp. 48-52, 2004.

[10] G. Garlick and A. Gibson, "The electron trap mechanism of luminescence in sulphide and silicate phosphors," Proceedings of the physical society, vol. 60, no. 6, p. 574, 1948.

[11] E. Adirovitch, "La formule de becquerel et la loi élémentaire du déclin de la luminescence des phosphores cristallins," J. Phys. Radium, vol. 17, no. 8-9, pp. 705-707, 1956.

[12] R. R. Haering and E. N. Adams, "Theory and application of thermally stimulated currents in photoconductors," Physical Review, vol. 117, no. 2, p. 451, 1960. 
[13] A. Halperin and A. Braner, "Evaluation of thermal activation energies from glow curves," Physical Review, vol. 117, no. 2, p. 408, 1960.

[14] W. B. Urbach, F Vorbemerkung und orientierende Beobachtungen, p. 363,1930 .

[15] C. Lushchik, "The investigation of trapping centres in crystals by the method of thermal bleaching," Sovietic Physics JETP, vol. 3, p. 390, 1956.

[16] R. Chen and S. Winer, "Effects of various heating rates on glow curves," Journal of Applied Physics, vol. 41, no. 13, pp. 5227-5232, 1970.

[17] A. Lewandowski and S. McKeever, "Generalized description of thermally stimulated processes without the quasiequilibrium approximation," Physical Review B, vol. 43, no. 10, p. 8163, 1991.

[18] R. Chen and S. W. McKeever, Theory of thermoluminescence and related phenomena, vol. 200. World Scientific, 1997.

[19] S. McKeever, thermoluminescence of solids. 1985.

[20] L. PW, "Thermoluminescence studies having applications to geology and archaeometry cations to geology and archaeometry," PACT, vol. 3, p. $466,1979$.

[21] A. Wintle, "Anomalous fading of thermo-luminescence in mineral samples," 1973.

[22] W. Hoogenstraten, "Luminescence phenomenon in zns-type phosphors," Philips Res. Report, vol. 13, pp. 515-520, 1958. 
[23] J. Schulman, R. Ginther, S. Gorbics, A. Nash, E. West, and F. Attix, "Anomalous fading of caf 2: Mn thermoluminescent dosimeters," The International Journal of Applied Radiation and Isotopes, vol. 20, no. 7, pp. 523-529, 1969.

[24] R. Visocekas, T. Ceva, C. Martin, F. Lefaucheux, and M. Robert, "C.(1976) tunnelling process in after glow of calcite," Phys. Stat. Solidi, vol. 35, pp. 315-327.

[25] M. Ikeya, New applications of electron spin resonance: dating, dosimetry and microscopy. World Scientific, 1993. 